\title{
Advances in Thermally Sprayed WC-Based Wear-Resistant Coatings: Co-free Binders, Processing Routes and Tribological Behavior
}

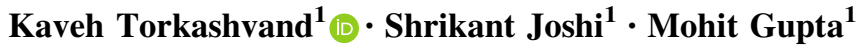

Submitted: 18 August 2020/in revised form: 2 January 2022 / Accepted: 6 January 2022 / Published online: 2 March 2022

(C) The Author(s) 2022

\begin{abstract}
A growing understanding of wear behavior of various thermally sprayed ceramic-metallic matrix coatings has occurred over recent years. This has resulted from the continuous evolution in spraying methods as well as material feedstock, and the corresponding new aspects of the field that have been thoroughly explored. This paper aims to review recent developments in thermally sprayed tungsten carbide-based coatings, with specific emphasis on evaluating alternative binders, processing routes and tribological behavior of the coatings. A comprehensive evaluation of various compositions as binders for WCbased coatings, considering environmental concerns and market requirements has been carried out. The properties and performance of various potential alternatives for cobalt as a conventional binder for these coatings have been assessed. Moreover, different thermal spray methods have been reviewed, particularly highlighting the role of processing parameters, phase change and feedstock characteristics in the high-velocity oxy-fuel (HVOF) and highvelocity air fuel (HVAF) techniques. A comparison is made between HVAF and HVOF coatings in terms of their performance under different wear environments. Finally, various scenarios of material removal in $\mathrm{HVAF}$ and $\mathrm{HVOF}$ coatings, under various wear conditions, have also been reviewed.
\end{abstract}

Keywords Co-free binders - HVAF · HVOF · tribology · WC-based coatings $\cdot$ wear mechanisms

\footnotetext{
Kaveh Torkashvand

kaveh.torkashvand@hv.se

University West, 46186 Trollhättan, Sweden
}

\section{Introduction}

Tungsten carbide (WC)-based metal matrix composite coatings are the most popular materials used as a thermally sprayed wear-resistant layer (Ref 1,2$)$, thanks to their excellent performance in severe wear environments (Ref $1,3,4)$. These coatings consist of two main phases: first, WC grains as a hard phase to resist against wear and, second, a metal matrix that acts as a ductile binder phase to hold the carbide grains together and provide them physical support (Ref 5). Embedded WC grains in a tough binder offer a hard composite system that has a high overall toughness (Ref 3 ). Cobalt is the most commonly used binder in the cemented carbide coatings (Ref 6, 7). However, apart from supply risk and economic reasons, this element is also not desired as it is known to be a carcinogenic material (Ref 8, 9). Consequently, during recent years, there has been extensive research to find a suitable substitute for $\mathrm{Co}$ as a binder in WC-based wear-resistant coatings. A comprehensive review is performed on hardmetal compositions for thermal spray coatings in (Ref 7) discussing various binder chemistries used in their systems. In another review by Wood et al. (Ref 10), mechanical properties (i.e., hardness and fracture toughness) of $\mathrm{Co}$ and $\mathrm{Ni}$ as binder with various fraction ratios are compared. Mechanical properties of WC-based hardmetals with iron-based alloys as binder were reviewed by OjoKupoluyi et al. (Ref 11). However, an update on existing potential candidates considering the processing route, mechanical properties and how they perform when comparing to the reference Co binder seems essential.

Thermal spray technique is the most frequently used processing route to deposit a WC-based coating on a substrate. Thermal spray techniques can be categorized based on the amount of thermal and kinetic energy transferred 
from the high-temperature, high-velocity gas stream to the feedstock particles. These transport processes control the particle temperature and velocity, having a huge effect on the resulting coating microstructure and its performance. In a thermal spray system, once the feedstock material (in its powder form) is injected into the plasma flame (in case of plasma spraying) or the combustion flame (in case of highvelocity techniques), heat transfer takes place from the gas stream to the surface of the feedstock particles through convection and the inside of the particles heats up through conduction. The final temperature of the particle at impact depends on the temperature and heat transfer coefficient of the flame, feedstock chemistry and morphology (which determines particle's thermal conductivity), and size distribution of the used feedstock particles. On the other hand, depending on the flame stream velocity, the amount of kinetic energy transferred to the particles can be different, which can determine the impact velocity of the particle. For a given feedstock composition, this velocity also depends on the size distribution of feedstock particles which governs mass of the particles. Atmospheric plasma spray (APS), high-velocity oxy-fuel (HVOF) and highvelocity air fuel (HVAF) are some of the most commonly used process routes for applying WC-based coatings. According to several reports, it is very well known that APS-sprayed WC-based coatings suffer from severe degradation (i.e., oxidation, decarburization, etc.) of the feedstock material during the spraying process (Ref 12-14). Among all thermal spray methods, high-velocity routes (i.e., HVAF and HVOF) provide a suitable combination of very high kinetic energy and adequate thermal energy to deposit dense, well-adherent coatings ideal for wear and corrosion applications. Due to velocity being high, the resulting coating is highly dense, and the porosity is minimized (Ref 15, 16). However, utilizing these techniques to build up a composite coating system demands a thorough understanding of the influence of process parameters on microstructure characteristics and, as a result, wear performance of the resultant coating. A typical microstructure image of HVOF- and APS-sprayed WC-Co coating is shown in Fig. 1(a) and (b), respectively. The mean carbide grain size of the feedstock powder used in APS coating was $17.5 \pm 7 \mu \mathrm{m}$, and carbide grains of fine size $(\sim 2 \mu \mathrm{m})$ were used in the HVOF coating. It can be seen that, in the HVOF coatings, even the small carbide grains were retained while in plasma spray coatings they were not, because of the considerably higher temperature encountered. Also, there are a large number of visible pores in the plasma spray coating, whereas the coating deposited by HVOF method exhibits a denser microstructure. Review studies can be found in literature discussing how the selected spraying route can influence in-flight state of feedstock powders and consequently microstructure characteristics as well as degradation in phase composition of WC-based coatings (Ref $1,14,17,18$ ), by mainly focusing on HVOF and APS as processing technique. Given the high potential of HVAF technique in retaining phase constitution of feedstock powders, due to its practical lower flame temperature, it seems vital to perform a review on its capability, challenges and competitiveness in processing this class of materials. Moreover, a detailed review is crucial to evaluate effective factors during spraying process by focusing on limitations and possibilities of HVOF and HVAF as the two processing routes for spraying WC-based materials.

WC-based coatings are usually exposed to a variety of wear environments, including two- and three-body abrasion, sliding, erosion and impact conditions. Sliding and abrasion are the most frequently encountered wear modes, with abrasion being reported to be the most common wear mode accounting for more than $50 \%$ of wear problems in the industry (Ref 21). Erosion and impact also can be problematic wear phenomena for a variety of applications such as turbine blades, pipelines, propulsors, etc. (Ref $22,23)$. Generally, in a wear process, more than one wear mode prevails, amplifying the complication of the phenomenon. Besides, having WC-based composite coatings comprising hard carbide grains with irregular shapes dispersed randomly throughout the coating as a wear counterpart makes the wear process even more complicated (as
Fig. 1 Typical cross section SEM image of (a) WC-17Co HVOF (Ref 19) and (b) WC18Co APS coatings (Ref 20)

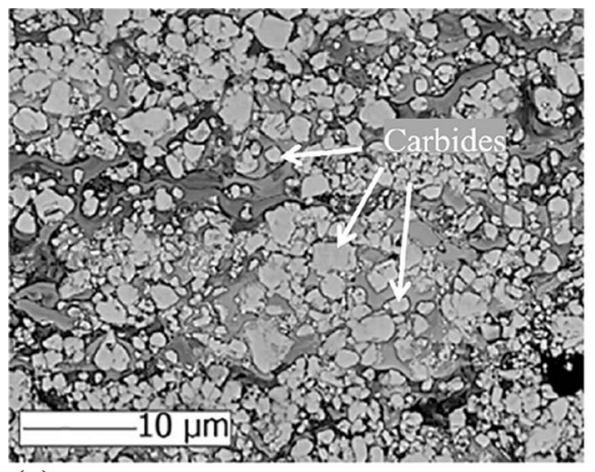

(a)

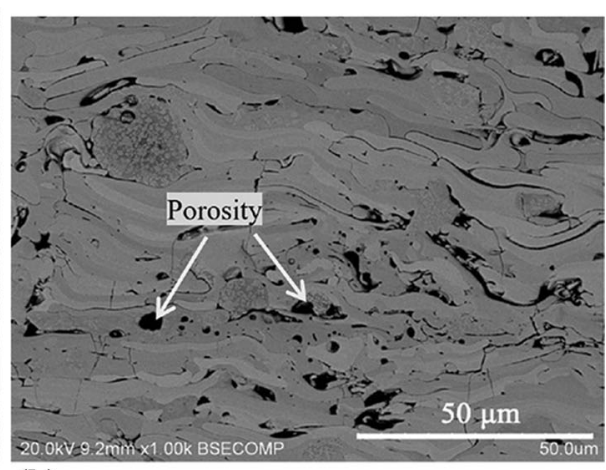

(b) 
compared to homogeneous material). There have been several investigations conducted to evaluate tribological behavior of WC-based coatings under various wear conditions. Ahmed et al. (Ref 6) reviewed sliding wear performance of thermal spray WC-12Co coatings with the focus on coating microstructure, carbide and binder characteristics, post-treatment and test environment. Also, reviews have been performed to evaluate effect of feedstock characteristics (Ref 24, 25) on wear behavior of WCCo coatings as well as tribocorrosion performance of thermal spray WC-based coatings (Ref 10). However, a comprehensive assessment of wear performance of WCbased coatings, taking processing route and wear conditions into account, seems essential. Besides, a fundamental understanding of different mechanisms of material removal in each of the three wear conditions seems crucial to design and develop an improved coating microstructure suitable for the desired application.

The emerging market pull for an alternative that meets environmental concerns and supply challenges has also contributed to the growing challenges to be addressed. In response to the above, a large variety of different feedstock materials have been introduced to act as a "green" binder for WC coatings. However, the wear performance of the proposed alternatives in comparison to the benchmark Co is not fully reviewed yet. Also, since there have been successive efforts in progress of deposition techniques, reviewing the success of the recent processing routes such as HVOF and HVAF, which are increasingly acknowledged as being most promising for depositing cermet coatings, seems meaningful at the moment. Moreover, considering several contradicting reports regarding the comparability of the performance of HVOF and HVAF methods, conducting a review on the latest comparative investigations seems vital. Finally, conducting a review on wear mechanisms of thermally sprayed WC-based coatings can provide a comprehensive understanding of the material removal of WC-based coatings under different wear environments. As discussed, it is acknowledged that there have been several reviews performed (Ref $1,6,7,10,11,14,17,18,24,25)$ on the subject. However, no comprehensive review exists to provide an overview of these different factors (binder chemistry, spray process and tribological behavior) in a single article. Considering these different aspects together is often necessary to select and achieve an optimal coating. In this paper, a comprehensive review is done to identify the most recent investigations in the field and to highlight the necessity of further attention to the ground. In the next section, a review is provided on binder selection and concerns in this regard. In "Processing Routes" section, the deposition techniques and parameters are provided with an emphasis on HVOF and HVAF methods. In "Tribological Behavior" section, a comparison on the performance of HVOF versus HVAF coatings is provided. Additionally, a discussion on different wear mechanisms under sliding, abrasive and erosive wear environments is reviewed, followed by "Summary and Conclusions" section.

\section{Binder Selection}

Binder, in WC-based composite coatings, acts as "cement" by firmly holding the hard carbide grains together. The desired cemented carbide composite coatings should have a combination of properties such as high strength, toughness and hardness which are crucial for wear applications. These performance parameters are necessary conditions but not sufficient. There are other determining factors such as supply risk, price and most important among them is environmental considerations ( $\operatorname{Ref} 9$ ). So, the selection of binder can critically influence the performance, sustainability and environmental aspects of the WC-based coating. In this section, different compositions as candidate binders will be presented and discussed.

\section{Cobalt as a Conventional Binder}

Co is the most common element used as a binder in cemented carbide coatings, deposited by different thermal spray methods such as plasma spray and high-velocity techniques, over the past decades (Ref 14, 26, 27). It shows excellent wetting during the sintering process, and good adhesion properties, leading to a strong carbide-binder bonding in both hardmetals as well as coatings (Ref 28, 29). Its ability to impart excellent wear performance when blended together with WC and outstanding mechanical properties such as ductility, malleability and strength makes Co the desirable choice as a matrix material to derive the best performance from cemented carbide coatings (Ref 30, 31). WC-Co feedstock deposited using HVOF technique can result in a hard coating with Vickers hardness number in the range of $1100 \mathrm{HV}$ to $1600 \mathrm{HV}$ and fracture toughness of $4 \mathrm{MPam}^{0.5}$ to $6 \mathrm{MPam}^{0.5}$ which is a desired combination for tribological applications (Ref $32,33)$. HVOF-sprayed WC-Co coatings exhibit a very low specific wear rate, typically in the order of $10^{-6} \mathrm{~mm}^{3}$ $\mathrm{N}^{-1} \mathrm{~m}^{-1}$ (Ref 34, 35) and in some cases even lower in the range of $10^{-7}$ to $10^{-8} \mathrm{~mm}^{3} \mathrm{~N}^{-1} \mathrm{~m}^{-1}$ (Ref 36, 37), when exposed to sliding wear testing. The sliding wear tests were conducted at room temperature using ball-on-disk rigs with alumina and tungsten-based balls as counter bodies, under various loads ranging from 10 to $100 \mathrm{~N}$, and for sliding distances up to $5000 \mathrm{~m}$. Also, it has been reported to show promising performance under abrasion and erosion wear (Ref 38, 39). Performance of WC-Co will be discussed in 
more detail in the following sections, and it is selected as the reference coating for deliberations on alternate binder chemistries in this paper.

$\mathrm{Cr}$ is typically added to $\mathrm{Co}$ in the binder when high requirements for corrosion and oxidation resistance are present, because of the relatively poor corrosion resistance of the latter (Ref 6, 40). The two compositions of WC$10 \mathrm{Co} 4 \mathrm{Cr}$ and $\mathrm{WC}-6 \mathrm{Co} 8 \mathrm{Cr}$ are commercially available for thermal spray (Ref 41, 42). WC-10Co4Cr, in particular, is nowadays extensively used in thermal spray coatings for combined wear and corrosion resistance purposes (Ref 7, 43). However, there have been some environmental, supply and economic concerns around Co for it to be frequently labeled as a "critical raw material" or "conflict element" by the European Commission (EC) and National Environmental Research Council (NERC) (Ref 9, 44).

Environmental risk: Cobalt is classified as carcinogenic and genotoxic by the International Agency for Research on Cancer (IARC) (Ref 45) and by the Department of Health and Human Services (Ref 46). It can lead to higher toxicity when combined with WC (Ref 46, 47). It can also promote some immune reactions such as inflammation in exposed tissues (Ref 48). There is a particularly higher risk with Co used in wear applications, because it potentially produces particles in the nanosize dimension in the form of wear debris, which can be disseminated systematically through the lymph and vascular system (Ref 48-50).

Supply risk: Co is generally mined as a by-product of other elements (Ref 9, 51). Most of the Co reserves are in the seafloor, and not economically efficient to mine (Ref 52). According to Fig. 2, around $70 \%$ of Co produced worldwide in 2018 was from Congo. Moreover, this country accounts for more than $50 \%$ of the Co reserves
(Ref 53). This makes the role of other countries limited in terms of planning against supply risk of this element.

Price: Although efficient recycling of the metal by industries as well as using Co-free alternatives are two strategies to reduce raw Co dependency and to keep Co price relatively stable in the long run, there has been a dramatic recent increase in its price. For example, the price has risen by 36 and 54\% during 2017 and 2018, respectively (Ref 54).

It should be mentioned that the latter two considerations, i.e., supply risk and price, are true for Tungsten too. This motivates the assessment of other carbides as a suitable alternative (Ref 52, 53), although this particular review only focuses on substituting $\mathrm{Co}$ in WC-based coatings.

\section{Substitution of Cobalt}

Several reports can be found in the literature trying to find a binder composition that is comparable to $\mathrm{Co}$, in terms of mechanical properties and tribological performance. In this section, some of the recent investigations in this area are provided.

\section{Alternatives Produced by Powder Metallurgy Techniques}

Although the material compositions discussed in this section were prepared using conventional powder metallurgy methods, the results can provide useful insight into the performance of these compositions since they are all possible to be thermally sprayed. One short-term solution for moving toward Co-free binders is to reduce Co content in WC-Co cermets by partially replacing Co with other
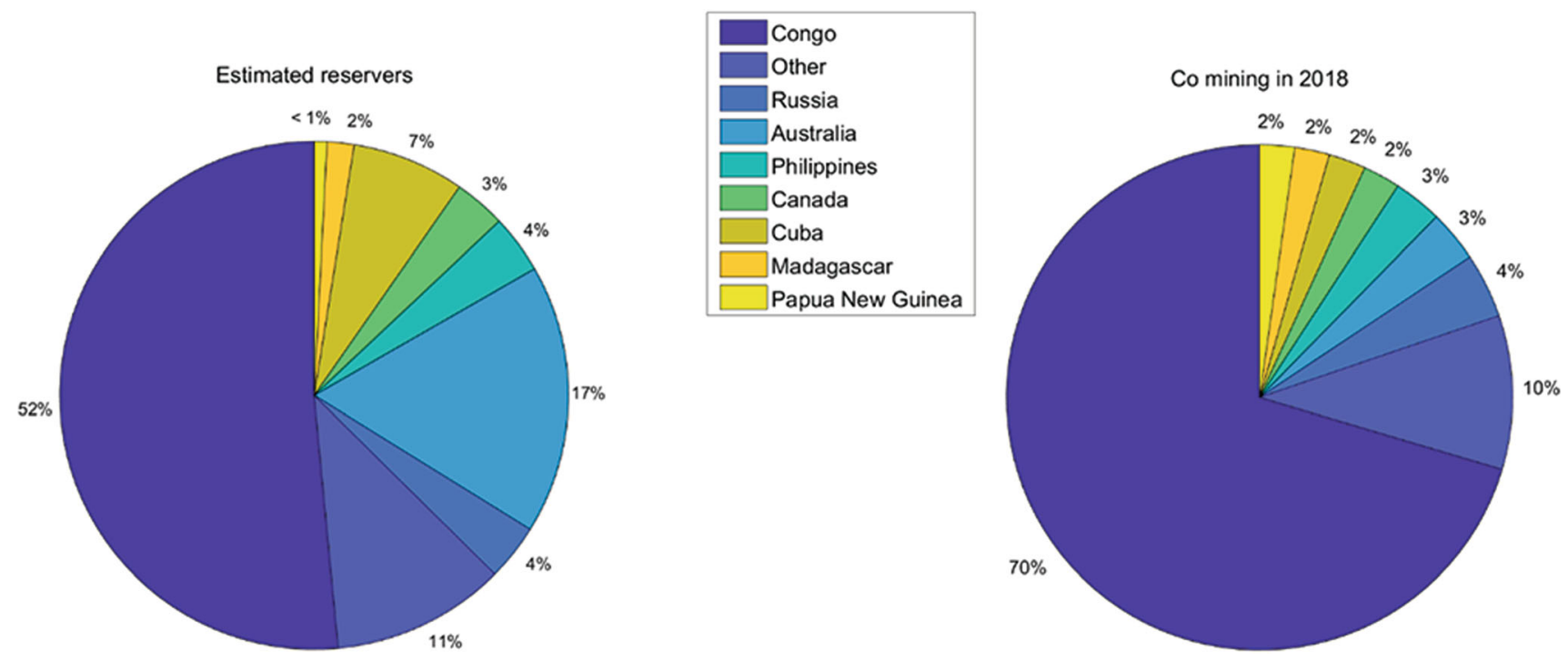

Fig. 2 Amount of Co production and estimated reserves in different countries around the world (based on data from (Ref 53)) 
elements such as Ni. In WC-CoNi composite samples produced by powder metallurgy method, with various contents of $\mathrm{Ni}$ and $\mathrm{Co}$, when Co content is between 0 and 10 wt.\%, an increase in Ni content first leads to a decrease in wear resistance, but further increase up to 20 wt. $\%$ results in improvement in wear performance of the hardmetal (Fig. 3). When Ni is at $20 \mathrm{wt} . \%$ in the binder phase, the maximum wear resistance occurs at around $10 \mathrm{wt} . \%$ of $\mathrm{Co}$. Then, from this point, a continuous decrease in $\mathrm{Ni}$ with simultaneous increase in Co results in better wear performance (Ref 55). Tarrago et al. (Ref 56) studied fatigue properties of WC-based hardmetal samples by using $\mathrm{Ni}$ binder as a substitution for Co. It was shown that fatigue sensitivity of WC-Ni was comparable to that of the Co binder.

A systematic study on a Fe-based binder alloyed with $\mathrm{Ni}, \mathrm{Mn}$ and Co was performed by Schubert et al. (Ref 57) by using powder metallurgy production technique. Their results showed that the two compositions $\mathrm{WC}-8.5 \mathrm{Fe} 1.5 \mathrm{Ni}$, with carbide size of $0.5 \mu \mathrm{m}$, and WC-7Fe2Ni1Co, with the same carbide size, exhibited the best hardness-toughness combination. Figure 4 shows a combination of wear performance and Vickers hardness for samples with different binder compositions. Several binder alternatives were found to yield comparable wear performance as the reference WC-Co. It may further be noted from Fig. 4 that despite similar hardness values, wear performance can significantly vary and vice versa, i.e., several alternatives exhibited comparable wear rate in spite of different hardness values. There have also been attempts to "engineer" the composition of binder materials by changing the percentage of various elements of the same compositions.

Liu et al. (Ref 58) used the calculation of phase diagram (CALPHAD) method to investigate the best possible composition of $\mathrm{Fe}-\mathrm{Ni}-\mathrm{Co}$ to act as an alternative to $\mathrm{Co}$. Four compositions including $72 \mathrm{Fe} 28 \mathrm{Ni}, 50 \mathrm{Fe} 25 \mathrm{Co} 25 \mathrm{Ni}$,

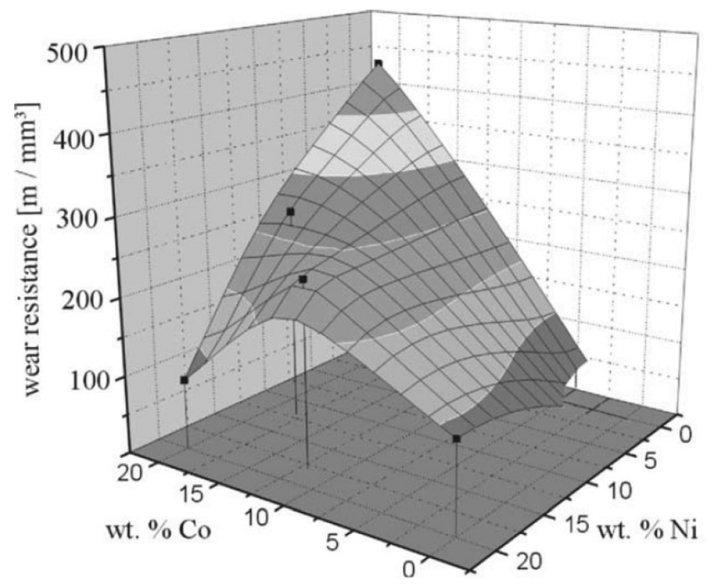

Fig. 3 Wear performance of WC with NiCo binder at different ratios (Ref 55)
$70 \mathrm{Fe} 12 \mathrm{Co} 18 \mathrm{Ni}$ and $82 \mathrm{Fe} 18 \mathrm{Ni}$ were selected because of their increased hardness due to being close to the martensitic transformation line (from austenite) in ternary diagram. Also, $15 \mathrm{Fe} 85 \mathrm{Ni}$ was chosen because of its large carbon window (possibility to change the carbon content over a wide range without precipitation of $\eta$-phase or graphite). Since a combination of high hardness and fracture toughness is desired for wear applications (Ref 11), this was used as the criterion to rank different compositions. $82 \mathrm{Fe} 18 \mathrm{Ni}$ binder showed the best combination of hardness and fracture toughness among all initially selected compositions (see Fig. 5). Ni content being high, leading to a softer binder, was found to be the explanation for worse hardness and fracture toughness combination of $15 \mathrm{Fe} 85 \mathrm{Ni}$. Based on results shown in Fig. 5, they suggested that, for samples with a lower hardness range, fracture toughness of the hardmetals strongly depends on binder composition, while for hardness values above $1400 \mathrm{HV}_{0.3}$, the fracture toughness is similar regardless of binder composition (graphs b and $\mathrm{c}$ in Fig. 5). Other Fe-based (WC-40vol\%(FeAl-B) and Ni-based (WC-40vol\%(Ni3Al-B)) binders, as potential substitution of $\mathrm{Co}$, have also been reported to show promising results (Ref 59).

\section{Ni-Based Alternatives Processed by Thermal Spray}

$\mathrm{Ni}$ as a stand-alone binder, with three main weight ratios of $\mathrm{WC}-10 \mathrm{Ni}$, WC- $12 \mathrm{Ni}$ and $\mathrm{WC}-17 \mathrm{Ni}$, is commercially available in thermal spray grade WC-based feedstock (Ref 7, 60-62). While this element as binder can result in coating systems with higher oxidation resistance compared to Co (Ref 63), employing it in pure form does not provide desired oxidation and corrosion resistance. Although limited reports are available on wear performance of thermal spray WC-based coatings with pure $\mathrm{Ni}$ as binder (Ref 7, 61), several studies can be found on Ni-based compositions with some additional elements. For thermal spray, because of poor oxidation resistance (Ref 64) and corrosion resistance of pure $\mathrm{Ni}$ as binder (Ref 60, 65) as well as its inferior wear performance compared to WC-CoCr (Ref 61,66 ), it is used typically with addition of other elements such as chromium or chromium carbides (Ref 67, 68). The composition $73 \mathrm{WC}-20 \mathrm{CrC} 7 \mathrm{Ni}$ is an example with high chromium content in a way that the high content of $\mathrm{Cr}$ can lead to the formation of $(\mathrm{W}, \mathrm{Cr})_{2} \mathrm{C}$ phases (Ref 7, 63). The feedstock powder with a composition of WC-(W, $\mathrm{Cr})_{2} \mathrm{C}-\mathrm{Ni}$ was one of the first to be thermally sprayed as a coating with the general composition of $70 \mathrm{WC} 24 \mathrm{Cr}_{3} \mathrm{C}_{2} 6 \mathrm{Ni}$ (Ref 7,69 ). Although there could be slight variations in the content of different constituents, commercial feedstock powders of this composition are currently available with designations of WC-CrCNi, WC- $\mathrm{Cr}_{3} \mathrm{C}_{2} \mathrm{Ni}$ or simply WC$\mathrm{NiCr}$ (Ref 70). Unlike WC-Co and WC-CoCr, high 
Fig. 4 Vickers hardness and wear rate values for cermet samples with different compositions (Ref 57)
Fig. 5 Fracture toughness vs. hardness in terms of plot of each binder content. (a) $20 \mathrm{vol} . \%$, (b) 15 vol.\% and (c) 10 vol.\% (Ref 58)
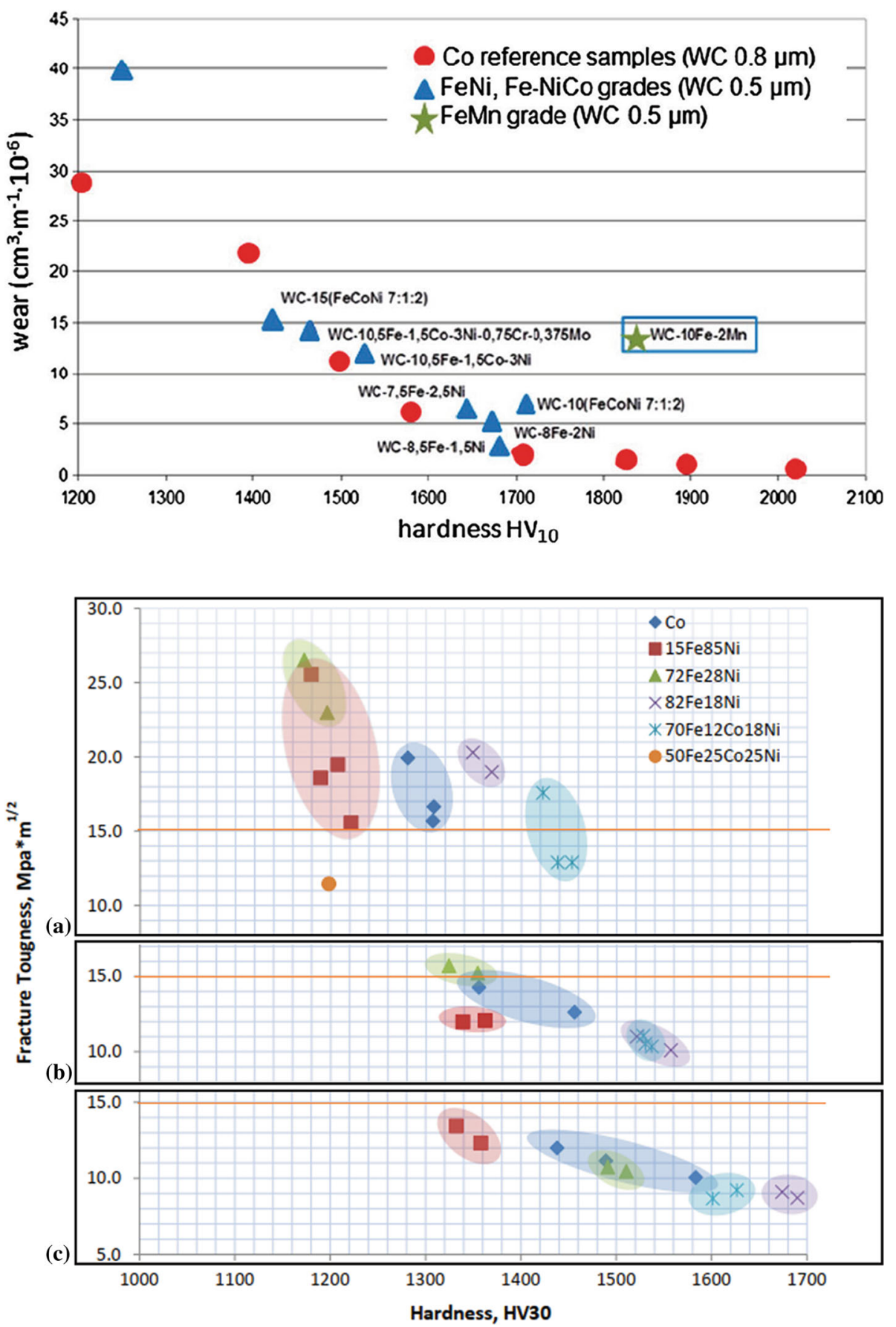

resistance against oxidation makes it possible to spray these feedstocks at relatively higher temperatures (Ref 71).

Addition of 4 wt.\% of Cr to HVOF-sprayed WC-Ni can increase the Vickers hardness value by around $150 \mathrm{HV}_{0.3}$ (Ref 61). Although $\mathrm{Cr}$ can provide some benefits to the coatings, i.e., improvement in corrosion performance (Ref 60) and enhancement mechanical properties such as hardness, there is no known meaningful correlation between addition of $\mathrm{Cr}$ and improvement in wear performance of the coatings. As exhibited in Fig. 6, the performance can be inferior or superior to that of WC-Ni and WC-Co (both produced by agglomeration and sintering technique), depending on the content of elements in the feedstock composition. In Fig. 6, $\mathrm{Cr}$ content decreases from $4 \%$ in "WC-NiCr-1" to $3.5 \%$ in "WC-NiCr-2" and its content is $1.5,4$ and $8 \%$ in "WC-CoCr-1", "WC-CoCr-2" and "WCCoCr-3", respectively (Ref 61). While WC-NiCr-1 showed inferior wear performance, $\mathrm{WC}-\mathrm{NiCr}-2$ exhibited superior performance compared to both WC-Ni and WC-Co. AlHamed et al. (Ref 72) attempted to reduce the amount of 


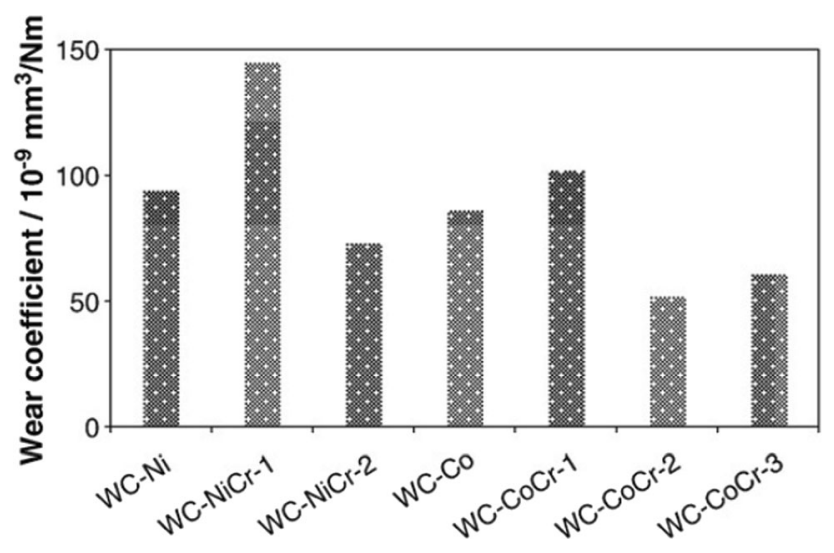

Fig. 6 Specific wear rate of HVOF WC-Co and WC-Ni coatings with various ratios of added $\mathrm{Cr}$ (WC-NiCr-1: 4\%, WC-NiCr-2: 3.5\%, WCCoCr-1: 1.5\%, WC-CoCr-2: 4\% and WC-CoCr-3: 8\%) (Ref 61)

Co in HVOF-sprayed WC-based coatings by adding varied proportions of Inconel 625 alloy. It was shown that a composition of $75 \% \mathrm{WC}-12 \mathrm{Co}$ (with nanosize WC grains) and 25\% Inconel 625 exhibited the best wear performance followed by a blend of $12.5 \%$ WC-12Co (with nanosize $\mathrm{WC}$ grains) and $12.5 \% \mathrm{WC}-12 \mathrm{Co}$ (with micro-WC grains) together with 75\% Inconel 625.

Despite the addition of $\mathrm{Cr}$ to WC-based coatings with $\mathrm{Ni}$ (or Co) as binder, corrosion performance is still not satisfactory (Ref 7). To reach good corrosion resistance, more complex binders such as $\mathrm{NiMoCrFeCo}$ and $\mathrm{FeCrAl}$ entered the market (Ref 73, 74). The latter is categorized as Febased binder and discussed in the next section. Hastelloy C-type Ni-based NiMoCrFeCo binder has been shown to exhibit promising performance compared to the reference WC-CoCr (Ref 75, 76). HVOF-sprayed WC-NiMoCrFeCo shows similar performance to WC-CoCr reference under sliding wear conditions and comparable performance under three-body abrasion wear environments with the reference. This alternative is shown to outperform $\mathrm{WC}-\mathrm{CoCr}$ in $3.5 \%$ $\mathrm{NaCl}$ aqueous solution because of its better pseudo-passivation ability (Ref 75$)$.

\section{Fe-Based Alternatives Processed by Thermal Spray}

Fe-based binders, involving Fe alloyed with $\mathrm{Al}, \mathrm{Mn}$, Mo, $\mathrm{Ni}, \mathrm{Cr}$, etc., such as $\mathrm{FeCrAl}$ and $\mathrm{FeNiCrMoCu}$ are the other alternatives showing promising tribological performance. Testa et al. (Ref 75) evaluated wear and corrosion performance of HVOF-sprayed WC-FeNiCrMoCu in comparison to $\mathrm{WC}-\mathrm{CoCr}$ as the benchmark. Although it showed slightly inferior corrosion resistance compared to WC$\mathrm{CoCr}$ in a $3.5 \% \mathrm{NaCl}$ solution, it exhibited similar sliding wear performance and comparable performance under high-stress abrasion condition. Nahavi and Jafari (Ref 67) studied microstructural and mechanical properties of WC- based coatings with two alternative binders, Fe-based and Ni-based, applied by HVOF technique. They employed Febased $\mathrm{FeCrAl}$ and Ni-based NiMoCrFeCo as a binder and compared their performance with Co. They found that the WC-FeCrAl coating system accounts for the highest microhardness among all the three with values approaching $1500 \mathrm{HV}_{0.3}$. However, both proposed alternatives yielded a substantially lower fracture toughness as compared to conventional WC-Co. Considering that the WC phase accounts for around 80-85 wt.\% of WC-based coatings, it is crucial to discuss how mechanical properties such as microhardness and fracture toughness are influenced by properties of the binder. Besides, the employed processing routes and powder characteristics, like size range of carbide grains, can also influence properties of the coating (Ref 6) which is discussed in "Role of Feedstock Characteristics" section. So, in spite of promising mechanical properties of the alternatives, it is crucial to critically evaluate differences in performance attributable to use of alternative binders. Bolelli et al. (Ref 77), in their study investigated the mechanical and tribological behavior of WC-based coating with Fe-based matrix as an alternative to WC-CoCr by conducting sliding wear and cyclic impact tests. Also, different oxygen-fuel ratios were used to apply the coatings by HVOF spray technique. The most desirable combination of as-sprayed compressive residual stresses in the coating, its oxidation ratio and hardness-modulus ratio was set as the criteria to judge the best combination of oxygen and fuel. Sliding wear and impact resistance of the WC coating with $\mathrm{FeCrAl}$ binder were comparable to those with a $\mathrm{CoCr}$ binder, while abrasion resistance of the coatings with $\mathrm{FeCrAl}$ binder was inferior due to increased brittleness of the coating resulting from oxide inclusions. The hardnessmodulus ratio of WC-FeCrAl was higher, as desired for wear applications, compared to WC-CoCr reference, although the coatings were more oxidized.

A partial list of varied WC-based hardmetals produced by powder metallurgy technique (PM) as well as WC-based coatings deposited employing thermal spray methods (TS) is provided in Table 1. As can be seen in the table, a fair variety of different compositions have been evaluated. However, a search for suitable alternatives to Co as a binder demands a comprehensive evaluation of mechanical and tribological properties. Mechanical and tribological properties of most of the existing potential chemistries are yet to be fully explored. Also, a vast majority of prior studies involve coatings deposited using HVOF method and hardmetals produced using powder metallurgy technique, and the employment of HVAF as an emergent method for applying these potential substitutions has not yet been fully evaluated. 


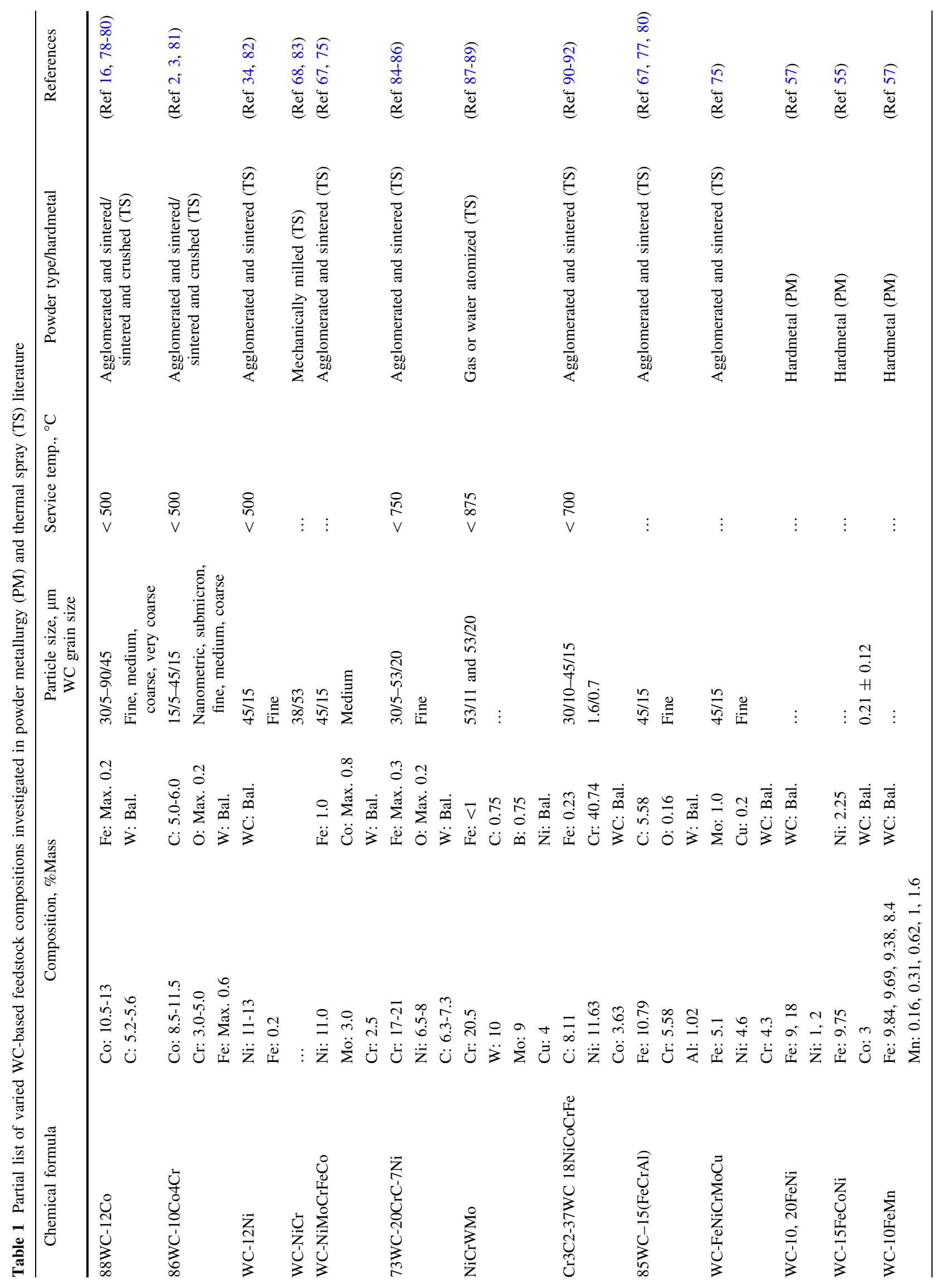




\section{Processing Routes}

\section{An Overview of Thermal Spray Deposition of WC- Based Coatings}

Nowadays, cermet coatings can be deposited through a variety of thermal spray routes. Plasma spraying, including APS (Ref 79, 93), vacuum plasma spray (VPS) (Ref 79), low-pressure plasma spray (LPPS) (Ref 94) and highpower plasma spray (HPPS) (Ref 95), most recent emerging suspension plasma spraying (SPS) (Ref 96, 97), cold spray (CS) (Ref 98, 99) and high-velocity spraying; including HVOF (Ref 34, 79, 100), HVAF (Ref 101) and denotation gun process (Ref 102,103) are the techniques applicable for fabrication of this class of materials.

Generally, the main difference between these spraying techniques is the variable flame parameters, particularly the temperature and velocity of the flame. Torches with different prevailing gas temperature and velocity substantially influence the kinetic and thermal energy transfer to the injected powder particles. As explained earlier particles experiencing diverse driving forces for heat-up and acceleration in-flight end up with very distinct temperature and velocity at impact and result in coatings with different microstructure characteristics, which in turn govern coating properties.

In plasma spray techniques, the flame velocity is relatively low and the temperature is significantly high (up to $\left.15000{ }^{\circ} \mathrm{C}\right)$. So, feedstock particles with the velocity of around $50-100(\mathrm{~m} / \mathrm{s})$ are exposed to a gas stream with a high level of heat energy and because of the velocity being low, the dwell time is relatively long (Ref 15, 104). This situation leads to an excessive level of material degradation in form of oxidation, decomposition and decarburization which would affect the wear performance of the resulting coating (Ref 20, 79). It has been reported that a large portion of the $\mathrm{WC}$ phase can transform into $\mathrm{W}_{2} \mathrm{C}$ phase during the plasma spray process (Ref 12, 105). Results from a study by Al-Mutairi et al. (Ref 106) show that excessive phase transformation and cobalt evaporation occur during APS as compared to HVOF, which causes the wear performance of WC-based coatings processed by APS to be inferior compared to those sprayed using HVOF (Ref 107-110).

Suspension plasma and suspension HVOF spraying methods have also been explored as processing routes to deposit WC-based feedstock materials. In these methods, typically submicron sized feedstock particles in forms of suspension are directly injected into the plasma or HVOF plume, thus preventing powder agglomeration in the spraying nozzle (Ref $18,111,112$ ). The particle's velocity can reach up to $800 \mathrm{~m} / \mathrm{s}$ and the particle's temperature up to $2500{ }^{\circ} \mathrm{C}$ in SPS technique (Ref 111). Although the feedstock particle temperature and as a result degradation of carbide grains is reduced in this method compared to APS technique, excessive carbon loss is still reported in literature (Ref 113-115) making it not the most desirable technique for spraying WC-based wear-resistant coatings.

Cold spraying is another technique used to deposit WCbased feedstock materials which relies on high-pressure compressed air/gas accelerated by a de Laval type nozzle to impart sufficient momentum to the injected powder particles. The powder particles are accelerated to supersonic velocities and propelled onto the part to be coated. With the thermal energy content being absent/negligible, the process can potentially prevent excessive material degradation resulting from high temperature in a plasma flame and, to a reduced extent, in a combustion flame in HVOF. Having a low gas temperature and high kinetic energy makes this method well suited for depositing materials that are predominantly comprised of a ductile constituent. Therefore, deposition of WC-based feedstocks, comprising hard carbide grains, using cold spraying faces several challenges including low deposition efficiency. More than a few investigations have been carried out to study the deposition behavior and characteristics of WCbased coatings by cold spraying technique (Ref 116-118). While the much colder process temperature in this technique suppresses formation of brittle phases like $\mathrm{W}_{2} \mathrm{C}$, shattering of WC grains because of their brittle nature (Ref $119,120)$, erosion of the surface because of the impact of hard particles during spraying, and high levels of porosity (Ref 99, 116, 119) remain the main challenges yet to be addressed.

Therefore, plasma spray, suspension spray and cold spray methods do not seem to be the most promising routes to apply WC-based feedstock materials. Hence, this paper would mostly focus on high-velocity spray methods of HVOF and HVAF, which have shown great capability in processing cermet materials. Detailed discussion of these two techniques is provided in "High-Velocity Spraying Methods" section.

\section{High-Velocity Spraying Methods}

In high-velocity techniques, the attempt is to enhance the particle impact velocities by increasing flame velocity, which further reduces particle dwell times. Moreover, in these processes, the energy source is derived from combustion which intrinsically gives much lower temperatures as compared to the plasma arc. Having a flame with these conditions would result in softened or partially molten particles highly accelerated toward the substrate. This high amount of kinetic energy transforms into heat as a result of impact with the substrate. The amount of generated heat 
has a direct relation with the velocity to the power of two which makes it more pronounced when the velocity is higher than $400 \mathrm{~m} / \mathrm{s}$ (Ref 104). Because of high kinetic energy, the particles deform plastically (Ref 121,122$)$ as a result of impact with the substrate or underlying coating layers which yields nearly fully dense coating with better mechanical and tribological properties (Ref 1, 123, 124). So, the high-velocity route seems to be a promising approach to develop durable wear-resistant coatings. However, depending on the selected technique and process parameters, results can vary substantially. In this section, the high-velocity techniques (HVOF and HVAF) and the effect of process parameters on the quality of the coating are reviewed.

\section{HVOF Method}

The high-velocity oxy-fuel (HVOF) method can be identified as the most popular route employed to apply WCbased coatings since the early 1980s (Ref 15, 26). In this method, a mixture of fuel (gaseous: hydrogen, propane, propylene, or liquid: kerosene) and oxygen is introduced into the combustion chamber. The resulting flame issuing from the nozzle can heat the particles from 1500 up to $3000{ }^{\circ} \mathrm{C}$. Also, the transferred kinetic energy from the stream of combustion gases can accelerate the particles to a velocity of up to $1000 \mathrm{~m} / \mathrm{s}$ (Ref $1,15,125)$. In the first generation of HVOF system, a gaseous fuel is used for combustion and the nozzle is straight and parallel sided with a length of around $120 \mathrm{~mm}$. In the second-generation HVOF systems, a converging-diverging throat was added between the combustion chamber and the nozzle leading to a substantial increase in the flame velocity. Also, in some of the second-generation systems, liquid fuel can be employed. The flame velocity is higher in the secondgeneration and it generates lower flame temperature which can be specifically beneficial for diminishing material degradation (Ref 14, 34, 126, 127). All these make the HVOF technique a particularly suitable candidate for applying cermet materials. Although the extent of material degradation, resulting in the formation of undesirable phases such as $\mathrm{W}_{2} \mathrm{C}$, is much lower with the HVOF method than with the plasma spray technique, HVOF-sprayed WCbased coatings still can suffer from this phenomenon (Ref 15, 128). However, it is still possible to deposit cermet coatings with promising performance employing this technique by fine-tuning the process parameters.

Role of Process Parameters in the HVOF Technique Having several process parameters, some even interrelated, makes the HVOF method an operation dependent technique affecting coating microstructure significantly with varying process parameters, requiring mastery on the process-microstructure relationships. These parameters can be connected to hardware system, e.g., nozzle configuration, injection system and its location, or related to plume thermodynamics such as fuel type, fuel/ oxygen pressure. Also, there are other parameters associated with particle/flame interaction, e.g., feedstock particle size distribution, the pressure of carrier gas, powder feeding rate or connected to the substrate, e.g., standoff distance, spraying angle and substrate roughness and/or temperature. A list of popular HVOF guns, classified with respect to fuel type and manufacturer, is provided in Table 2.

Some studies have tried to establish a correlation between the in-flight state (temperature and velocity) of particles, microstructure and properties of HVOF-sprayed WC-based coatings (Ref 121, 133-135). Wang et al. (Ref 136) conducted an optimization study to evaluate the effect of HVOF process parameters for spraying WC-Co powder. The process parameters showed a significant influence on the performance and mechanical properties of the fabricated coatings such as hardness and fracture toughness. It was found that hardness of the coating increased with fuel (kerosene) and oxygen flux, but decreased with powder feeding rate and standoff distance, while the fracture toughness values tended to show an opposite trend.

Another way of achieving desired velocity and temperature for the feedstock particles and, as a result, alter coating's properties is to regulate oxygen-fuel ratio to a suitable stoichiometry. In a study by Picas et al. (Ref 137), it was shown that by increasing the total oxygen flow rate, while kerosene flow is constant, the initial temperature of the feedstock particles increased and after reaching a certain point it started to decrease. This was because, after a certain value for the oxygen/fuel ratio, when the amount of oxygen goes beyond the amount needed for complete combustion of kerosene, it can act as a cooling gas and as a result promotes the decrease in flame temperature. This was while the velocity of particles continuously increased by increasing oxygen flow. This increase in particles velocity can yield a considerable improvement in density of the resultant coating. Stoichiometric combustion ratio,

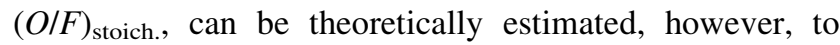
reach highest possible temperature, for a given volume flow rate, an optimum fuel rich combustion is required. For this, normalized $O / F$ can be defined as;

$\lambda=\frac{(O / F)_{\text {act. }}}{(O / F)_{\text {stoich. }}}$

where $\lambda$ is normalized $O / F,(O / F)_{\text {act. }}$ is the actual ratio of oxygen and fuel and $(O / F)_{\text {stoich. }}$ is the calculated stoichiometric ratio of oxygen and fuel. $(O / F)_{\text {stoich. }}$ by mass, are calculated to be 7.14, 6.97 and 3.28 for hydrogen, propylene and kerosene, respectively. In case of the hydrogen 
Table 2 HVOF spray guns (Ref 129-132)

\begin{tabular}{lll}
\hline Spray gun & Fuel type & Manufacturer \\
\hline Jet Kote or JK (e.g., Jet Kote II and III) & Gas & Deloro Stellite \\
Diamond Jet (e.g., DJ 2600 and 2700) & Gas & Oerlikon Metco \\
HV-2000 & Gas & TAFA Praxair \\
JP 5000/8000 & Liquid & TAFA Praxair \\
CJS (e.g., CJS 4.2 and 5.2) & Liquid & Thermico \\
WokaJet and WokaStar & Liquid & Oerlikon Metco \\
\hline
\end{tabular}

gas-fueled DJ 2600 gun, it was shown that for various total volume flows between 1100 SLPM and 1250 SLPM, the maximum temperature occurs at the $\lambda$ of around 0.77 (Ref 17) and 0.74 in another study (Ref 137). Employing numerical simulation, it has been revealed that for a propylene gas-fueled HVOF gun a fuel rich $\lambda$ between 0.83 and 0.96 can generate the peak temperature inside the nozzle. In the fuel rich combustion there is an additional unburnt fuel in the nozzle and as a result of its combustion with the ambient air along the spray plume, a higher maximum temperature occurs in the stream outside of the nozzle. It was also suggested that a lean mixture with the $\lambda$ of 1.16 can provide the maximum temperature at the nozzle exit (Ref 138). For the liquid-fueled WokaJet-400 gun, a $\lambda$ of 0.88-0.92 can provide the maximum flame temperature in case of employing kerosene as the fuel (Ref 137, 139). The intrinsic properties of the fuel type are another factor influencing flame temperature and velocity. It is known that, at a given temperature (of feedstock particles), kerosene can generate higher particle velocities compared to hydrogen and propylene due to its intrinsic properties. On the other hand, when keeping the velocities the same, kerosene produces lower temperature of feedstock particles as compared to hydrogen and propylene (Ref $125,140,141)$. In addition, gas-fueled torches exhibit a wider range of processing parameters as compared to liquid-fueled guns (Ref 142). This results in cermet coatings with more extensive range of performance and mechanical characteristics when deposited by a gas-fueled gun. After discovering appropriate SCR, change in the total volume flow can deliver different temperature values of the flame. An increase in backpressure and as a result total volume flow from 5.22 bar to 5.51 bar can increase particles temperature from around 1630 to $1870{ }^{\circ} \mathrm{C}$ and velocity from 570 to $610 \mathrm{~m} / \mathrm{s}$ (Ref 17). However, in the case of WCbased coatings, reaching the maximum temperature is not always desirable since it can result in an increase in the molten fraction of feedstock particles which leads to an increase in the extent of phase change such as the formation of brittle $\mathrm{W}_{2} \mathrm{C}$ phase which is discussed in "Phase Change During HVOF Spraying" section.

Deposition efficiency is another factor that can be influenced depending on the employed process parameters.
It has been shown that, for a CJS liquid fuel HVOF gun, by keeping particles velocity the same (by reaching the same combustion chamber pressure), but increasing the particle temperature (by increasing the $O / F_{\text {act. }}$ ratio from 5 to 3.45 ), deposition efficiency can be improved by about $5 \%$, from 41.6 to $46.7 \%$. Also, it was shown that with the same temperature $\left(\sim 1780{ }^{\circ} \mathrm{C}\right)$, an increase in particles velocity from 780 to $850 \mathrm{~m} / \mathrm{s}$ can lead to a drop in deposition efficiency from 46.7 to $39.4 \%$ (Ref 100). For an internal diameter HVOF (HVOF-ID) system it has been found that a change in the fuel/oxygen ratio can dramatically affect the deposition efficiency within the range of $27-52 \%$. Also, spraying angle can considerably influence deposition efficiency of feedstock powders. It is well-known that the highest deposition efficiency can be obtained by spraying at $90^{\circ}$ angle in a way that large deviations from this angle can lead to a significant drop in deposition efficiency (Ref 143-145). For instance, it has been shown by Houdkova et al. (Ref 146) that by decreasing spraying angle from $90^{\circ}$ to $30^{\circ}$ deposition efficiency can be halved (from 40 to $20 \%$ ). Powder characteristics are other factors which can greatly influence the deposition efficiency (discussed in "Role of Feedstock Characteristics" section). The deposition behavior of feedstock particles can directly influence the chemical composition of resultant coatings since the hard carbide grains are more susceptible to rebound and as a result a loss in carbide content can occur. This is explained in "Phase Change During HVOF Spraying" and "Phase Change During HVAF Spraying: A Comparison with APS and HVOF" sections. A list of the deposition efficiency values obtained by various HVOF equipment is provided in Table 4.

Phase Change During HVOF Spraying As explained in the previous section, exposing the feedstock powder to high temperatures can lead to the formation of brittle phases such as $\mathrm{W}_{2} \mathrm{C}$ which is a result of $\mathrm{WC}$ transformation due to decarburization during spraying. Although the amount of decarburization reported for HVOF coatings is significantly lower than that of plasma spray coatings, it is still documented as one of the shortcomings of this method (Ref $1,13,147)$. The process of dissolution of WC grains in the molten metallic binder (Co) and, ultimately, 
decarburization initiates at temperatures above the eutectic temperature ( $1350{ }^{\circ} \mathrm{C}$ for WC-CoCr) (Ref 148,149 ). During this process, carbon diffuses through the liquid binder and oxidizes at the surface in form of $\mathrm{CO}$ and/or $\mathrm{CO}_{2}$, leading to a reduction in the $\mathrm{C}$ and $\mathrm{WC}$ contents in the coating (Ref 150-152). By subsequent cooling down of the liquid binder, it becomes supersaturated, leading to the formation of $\mathrm{W}_{2} \mathrm{C}$ and $\mathrm{W}$ phases, depending upon the extent of carbon loss (Ref 148, 151). By further cooling down below the eutectic temperature, due to a reduction in solubility, precipitation of $\eta$-carbide phases of $\mathrm{Co}-\mathrm{W}-\mathrm{C}$ $\left(\mathrm{M}_{6} \mathrm{C}\right.$ : e.g., $\mathrm{Co}_{3} \mathrm{~W}_{3} \mathrm{C}$ or $\mathrm{M}_{12} \mathrm{C}$ : e.g., $\left.\mathrm{Co}_{6} \mathrm{~W}_{6} \mathrm{C}\right)$, in the form of solid solution, may occur (Ref 148, 150). WO, $\mathrm{WO}_{2}$, $\mathrm{WO}_{3}, \mathrm{~W}_{2} \mathrm{O}_{6}$ and $\mathrm{W}_{3} \mathrm{O}_{9}$ are other possible gaseous products as a result of reaction with oxygen (Ref 153). Another mechanism of carbon loss can be direct oxidation of WC grains in reaction with other combustion products such as water vapor and carbon dioxide. $\mathrm{W}_{2} \mathrm{C}$ and $\mathrm{W}$ can be considered as the main products of these reactions (Ref $19,153)$. It is broadly reported that thermal dissolution and decarburization of feedstock powder can significantly affect the wear performance of thermally sprayed WCbased coatings (Ref 1, 80, 154, 155). This influence can be attributed to various factors such as decohesion of the carbide grains (Ref 155), increase in brittleness of the coating and decrease in the carbide content (Ref 156). While the ratio of $\mathrm{W}_{2} \mathrm{C} / \mathrm{WC}$ (using $\mathrm{x}$-ray diffraction technique) is a common criterion to judge the extent of decarburization (see Table 5), it may not provide a fair view of the amount of WC loss since it might partially occur due to carbide rebounding during the process. Although very few investigations (Ref 157-159) have employed direct measurement of elemental content through LECO technique, it can potentially provide a good insight in this regard. In a study by Agüero et al. (Ref 160), employing a LECO GDS analyzer, it was shown that during $\mathrm{HVOF}$ spraying of $\mathrm{WC}-\mathrm{CoCr}$, the content of $\mathrm{W}$ and $\mathrm{C}$ is decreased from 80 and $5.5 \%$ to 64.2 and $4.63 \%$, respectively. This was attributed to rebounding of the hard WC grains during the spraying.

Thermal degradation of WC grains becomes even more pronounced when the attempt is to fabricate a fine-structured coating using finer (submicron) carbide grains and/or feedstock powder, due to higher specific surface area of the finer carbide grains or feedstock particles (Ref 25, 161). This is where the HVAF method has the potential to provide a considerable advantage by mitigating the extent of material degradation.

\section{HVAF Method}

HVAF not only has the potential to produce high-quality coatings but also is economically attractive and demands more attention to be well established in industry. In this method, by using compressed air (instead of pure oxygen as compared to the HVOF technique), the idea is to reduce the flame temperature and compensate for it by increasing the stream's velocity. The velocity of feedstock particles in HVAF can reach up to $1200 \mathrm{~m} / \mathrm{s}$ while the temperature is typically under $1500{ }^{\circ} \mathrm{C}$, just under the melting temperature of most of the metals used as binder in WC-based coatings (Ref 162-164). Propane, propylene and natural gas are usually used as fuel in this method (Ref 165). In this technique, oxidation and material degradation due to hightemperature reactions are significantly reduced (Ref 157, 166-168). Figure 7(a) and (b) shows SEM images of HVOF-sprayed WC-12Co and HVAF-sprayed WC$10 \mathrm{Co} 4 \mathrm{Cr}$ coatings, respectively. Light gray areas in Fig. 7(a) demonstrate tungsten-rich phases (shown by arrows) as a result of thermal dissolution reactions. It can be identified that in some areas the carbide grains are completely vanished as a result of these reactions. The HVAF coating, on the other hand, does not show any sign of formation of tungsten-rich phases in a way that the carbide grains retain their original shape, homogeneously distributed throughout the coating (Ref 2, 152, 167). Like $\mathrm{HVOF}$ technique, there are various process parameters that need to be fine-tuned in HVAF method.

Role of Process Parameters in the HVAF Technique It has been reported that, because of the limited temperature range in the HVAF method, the properties of the resultant coatings are not extremely affected as a result of changes in processing parameters (Ref 104, 163, 169). Although the HVAF technique does not seem to be as sensitive as HVOF is, this method still is a process parameter dependent technique and demands extensive expertise. Hence, most of the process parameters highlighted for the HVOF method in the previous section, are the case here as well. However, the difference here is that in the HVAF method, gun configuration is another parameter of high importance. The particle temperature and dwell time can be altered using nozzles with different total length and varying convergentdivergent section designs. A list of popular HVAF guns and corresponding powder size range is provided in Table 3.

There have been investigations exploring the effect of processing parameters in the HVAF method. Consistently noting compressive stresses in WC-based coatings is a feature of HVAF spraying and this results from the peening effect associated with high-velocity impact of feedstock particles inherent in this method (Ref 7, 21, 173). Having high kinetic energy coupled with low temperature allows the particles to induce peening effect on the impacting surface. Lyphout et al. (Ref 174) investigated the correlation between coatings characteristics and process variables 
Fig. 7 A comparison of microstructures of (a) $\mathrm{HVOF}$ WC-12Co (Ref 152) and (b) HVAF WC-10Co4Cr ( Ref 2) coatings

Table 3 Specifications for popular HVAF guns (Ref 170172)
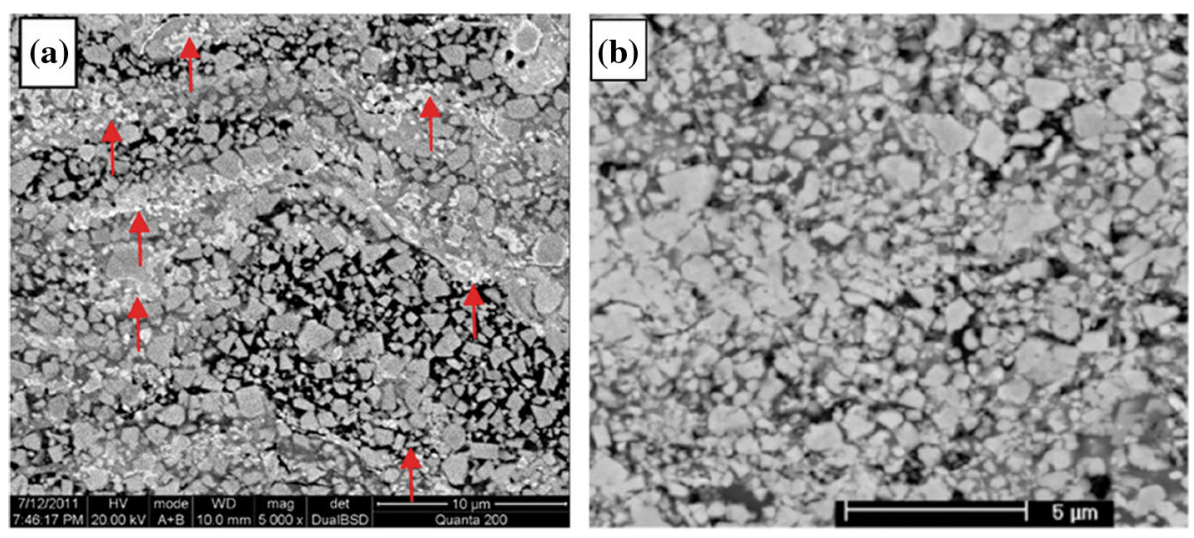

\begin{tabular}{lll}
\hline Spray gun & Powder size distribution, $\mu \mathrm{m}$ & \multicolumn{1}{c}{ Manufacturer } \\
\hline M3* & $5-25$ to $15-45$ & Uniquecoat Technologies LLC \\
M2* & $5-10$ to $10-30$ & Uniquecoat Technologies LLC \\
AK7 & $5-20$ to $20-45$ & Kermetico, Inc. \\
AK6 & $5-20$ to $10-38$ & Kermetico, Inc. \\
AK5 & $3-15$ to $5-30$ & Kermetico, Inc. \\
\hline
\end{tabular}

*Utilizes a variety of xLy; $\mathrm{x}$ : the length of nozzle and $\mathrm{y}$ : convergent-divergent configuration of the nozzle including nozzle design, standoff distance, the pressure of fuel 1, fuel 2 and carrier gas, and powder feeding rate, employing design of experiment methods. It was shown that increasing the length of nozzle can improve the microhardness of the resultant coating as well as its abrasion wear resistance. Also, higher powder feed rate and shorter standoff distance resulted in higher deposition efficiency. Increase in fuel 1 and fuel 2 pressure did not have a significant influence either on the quality of coating (i.e., porosity, decarburization), or on the abrasive wear performance of the coating. The average hardness value reportedly increased by increasing length and/or exit diameter of the nozzle, when spraying WC-CoCr feedstock of 5-20, 5-30 and 15-45 $\mu \mathrm{m}$ size distribution using the M3 HVAF gun. Also, the specific wear rate experienced a threefold improvement (from $23 \times 10^{-9}$ to $8 \times 10^{-9}$ $\mathrm{mm}^{3} \mathrm{~N}^{-1} \mathrm{~m}^{-1}$ ) when using longer nozzle with larger exit diameter to spray WC-CoCr feedstock with 5-20 $\mu \mathrm{m}$ particle size. Using the same two nozzles, negligible deviations were observed for processing the same feedstock with 5-30 $\mu \mathrm{m}$ particle size (Ref 169). Although other studies (Ref 172, 175) can be found suggesting the possibility of improving the properties of the coating by engineering the configuration of the HVAF gun, the extent of variation in the achieved properties is not well understood yet.

Lower temperature of in-flight particles in the HVAF technique can potentially raise some concerns around the deposition efficiency with this method. However, there have not been many rigorous studies investigating the deposition efficiency and the relevant determining factors in this technique which can be considered as a research gap in the field. Nevertheless, comparable or even higher deposition efficiencies than are obtained with the HVOF process, namely $46-62 \%$ for the M3-HVAF gun (Ref 170) and $36-70 \%$ for the AK-HVAF gun (Ref 171), were claimed by the respective manufacturers when spraying WC-based coatings. A change in gas type from propane to propylene can produce an improvement in deposition efficiency from 52 to $63 \%$ when spraying $\mathrm{WC}-\mathrm{CoCr}$ by a HVAF gun. In a study by Myalska et al. the deposition efficiency of WC-Co and $5 \mathrm{wt}$.\% of TiC was similar when spraying by HVAF and HVOF (Ref 176). In a direct comparison between HVOF and HVAF technique, it was shown that for a WC-based feedstock, a deposition efficiency of around $60 \%$ is obtained when using DJ2700 HVOF gun while the value is only around $42 \%$ when employing the K2 HVOF gun or M3 HVAF gun. The characteristics of the feedstock powder constitute another important parameter given the fact that different production procedures can result in powders with varying densities. For feedstock powders with the same particle size, deposition efficiencies of 43, 60 and $64 \%$ have been reported for fused/crushed, sintered/crushed and agglomerated/sintered powders, respectively (Ref 165). Deposition efficiency values reported in literature for the HVAF technique along with values achieved from the HVOF method are listed in Table 4. 
Table 4 Deposition efficiencies reported in $\mathrm{HVOF}$ and $\mathrm{HVAF}$ processing of WC-based coatings

\begin{tabular}{llll}
\hline \multicolumn{1}{c}{ Deposition method } & Deposition efficiency, $\%$ & \multicolumn{1}{c}{ Chemistry } & Ref. \\
\hline HVOF (JP 5000) & 40 & WC-17Co & (Ref 146) \\
HVOF (JP 8000) & 42.3 & WC-10Co4Cr & (Ref 177) \\
HVOF-ID (IDCoolFlow) & $27-52$ & WC-10Co4Cr & (Ref 178) \\
HVOF (CJS) & $29.1-46.7$ & WC-10Co4Cr & (Ref 100) \\
HVOF (K2) & $\sim 42$ & $\mathrm{Cr}_{3} \mathrm{C}_{2}-37$ WC-18M & (Ref 179) \\
HVOF (DJ2700) & $\sim 60$ & $\mathrm{Cr}_{3} \mathrm{C}_{2}-37$ WC-18M & (Ref 179) \\
HVAF (AK) & $\sim 42$ & $\mathrm{Cr}_{3} \mathrm{C}_{2}-37$ WC-18M & (Ref 179) \\
HVAF (M3) & $46-62$ & WC-based & (Ref 170) \\
HVAF (AK) & $36-70$ & WC-CoCr & (Ref 171) \\
\hline
\end{tabular}

Phase Change During HVAF Spraying: A Comparison with APS and HVOF Studies show that HVAF has the possibility to dramatically reduce decarburization to near zero. It has been shown that carbon retention of WC-CoCr coatings can increase from 0.84 when processing by HVOF to 0.96 when HVAF technique is used for spraying (Ref 180). Wang et al. (Ref 156) using $\mathrm{x}$-ray diffraction analysis showed that ratio of $\mathrm{W}_{2} \mathrm{C}$ to $\mathrm{WC}$ can decrease from 0.7 in HVOF to nearly 0 in HVAF method. These results confirm the findings of a similar study from the same authors (Ref 181). However, carbon loss can also occur due to rebounding of carbides upon impact. This can be especially more pronounced in the HVAF technique depending on the size of carbide grains and content of metallic matrix. However, not many studies have been conducted on this for WC-based coatings. Although the flame temperature of the HVAF process is lower than that characteristic of the HVOF technique, carbon loss can still occur during HVAF spraying due to oxidation, because of the typically longer dwell time (longer nozzle) as well as the finer particle size of powders typically deployed in this method. $24.6 \%$ loss in carbon content is reported when spraying $\mathrm{Cr}_{3} \mathrm{C}_{2}$-based feedstock using HVAF technique (Ref 182). However, contradictory findings can be observed in the literature. In a study by Jacobs et al. (Ref 157), no change in carbon content, measured using the LECO method, was observed when spraying WC-Co and WC-CoCr employing the HVAF technique.

In Table 5 the $\mathrm{W}_{2} \mathrm{C} / \mathrm{WC}$ ratio is listed for different deposition techniques based on prior studies. In the APS method this ratio can reach 1 . The amount of decarburization in the HVOF method is highly dependent on the type of HVOF torch as well as the employed process parameters. The $\mathrm{W}_{2} \mathrm{C} / \mathrm{WC}$ ratio, for the HVOF technique, can vary from 0.1 to up to 0.7. In contrast, negligible decarburization is reported in the literature for HVAF processed coatings which can be considered as a great advantage of this technique. Also, spraying feedstock with smaller carbide size, with the aim of producing refined microstructures, seems feasible by employing the HVAF route and needs more attention in future studies. By having an improved coating's properties, it may be possible to reduce the coating thickness which can have some technical and economic benefits. Promising capabilities of HVAF technique can make all these possible. However, there are not enough investigations around this and hence it demands much more attention of the community.

\section{Role of Feedstock Characteristics}

Employing different powder manufacturing methods such as agglomeration and sintering; sintering and crushing; casting, crushing and fusing, can affect the principal features of the powders such as size distribution, morphology, apparent density, etc., and consequently the microstructure and performance of coatings (Ref 104, 187-190). It should be noted that the influence of powder characteristics can considerably differ when employing different processing routes. In the rubber wheel abrasion test, HVOF (JP 5000) coatings produced using cast-crushed powders showed inferior resistance compared to those manufactured by sintered-crushed and agglomerated-densified powders (Ref 189). However, in a comprehensive study by Schwetzke et al. (Ref 191) on coatings fabricated from feedstock produced by four different manufacturing routes, it was shown that no major difference in performance can be seen by employing powders with different morphologies. Employing feedstock powder with finer particle size during HVAF spraying, can result in higher in-flight temperature and velocity which in turn can improve microstructural characteristics of the coatings by resulting in higher density and better homogeneity. The in-flight velocity of WC-CoCr powders, sprayed by M3 HVAF gun, can be increased from 780 to $1050 \mathrm{~m} / \mathrm{s}$ when decreasing the size from $15-45$ to 5-20 $\mu \mathrm{m}$. Also, the Vickers hardness of the coating experienced an improvement from 1300 to $1575 \mathrm{HV}_{0.3}$ when employing finer powder. All these led to about a fourfold decrease in the specific wear rate from $33 \times 10^{-9}$ to $8 \times 10^{-9} \mathrm{~mm}^{3} \mathrm{~N}^{-1} \mathrm{~m}^{-1}$ (Ref 192). 
Table 5 Decarburization ratio in WC-based coatings reported for APS, HVOF and HVAF processing routes

\begin{tabular}{llll}
\hline Deposition method & Decarburization ratio $\left(\mathrm{W}_{2} \mathrm{C} / \mathrm{WC}\right)$ & Chemistry & Ref. \\
\hline APS & 0.2 & WC-17Co & (Ref 105) \\
APS & $\approx 1$ & WC-17Co & (Ref 110) \\
APS & 0.46 & WC-Ni & (Ref 183) \\
HVOF (JK) & 0.7 & WC-10Co4Cr & (Ref 156) \\
HVOF (JP 8000) & 0.12 & WC-10Co4Cr & (Ref 156) \\
HVOF (JP 5000) & 0.055 & WC-10Co4Cr & (Ref 184) \\
HVOF (DJ) & $0.14-0.16$ & WC-10Co4Cr & (Ref 185) \\
HVOF (JP 5000) & 0.114 & WC-12Co & (Ref 184) \\
HVOF (DJ 2700) & $\approx 0.6$ & WC-12Co & (Ref 186) \\
HVOF (DJ 2700) & 0.13 & WC-12Co & (Ref 167) \\
HVOF (HV-2000) & 0.25 & WC-12Co & (Ref 167) \\
HVAF (AK) & $\approx 0$ & WC-10Co4Cr & (Ref 156) \\
HVAF (M2) & $\approx 0$ & WC-10Co4Cr & (Ref 80) \\
HVAF (M3) & $\approx 0$ & WC-12Co & (Ref 186) \\
HVAF(Aerospray) & 0 & WC-12Co & (Ref 167) \\
\hline
\end{tabular}

The characteristics of the feedstock powder can influence deposition behavior of particles. Increase in size (Ref 193) and content (Ref 192) of WC grains can result in a reduction of the deposition efficiency because of higher chance of particles rebounding when spraying by HVOF technique. Also, particles with higher density tend to resist more against deformation and, ultimately, exhibit lower flattening and higher chance of rebounding off the surface upon impact. It has been shown that with the same particle size, an increase in apparent density from 4.43 to $5.02 \mathrm{~g} \mathrm{~cm}^{-3}$ can result in a drop in deposition efficiency from 43.6 to $38.7 \%$, when using CJS HVOF gun (Ref 100). It has been shown that a decrease in feedstock particle size range (between 5 and $45 \mu \mathrm{m}$ ) can result in a significant decrease in deposition rate when employing the M3 HVAF gun. The deposition rate of $\mathrm{WC}-\mathrm{CoCr}$ feedstock sprayed by M3 HVAF gun has been reported to drop from around $25 \mu \mathrm{m} /$ pass to $14 \mu \mathrm{m} /$ pass when decreasing the particle size range from 15-45 to 5-20 $\mu \mathrm{m}$ (Ref 169). The influence of powder characteristics is also observed for the cold spray technique, in a way that an increase in the WC content (Ref 194), WC size (Ref 99) and feedstock particle density (Ref 195) can result in a drop in deposition efficiency. Rebounding of carbides can especially occur more frequently when the content of the carbide is high and/or the size of carbide grains is large $(>2 \mu \mathrm{m})$ (Ref 159, 180, 182).

The relative size of feedstock particles and carbide grains (equation 2) governs the flattening ability of the particles upon impact (Ref 159, 169).

$\delta=\frac{d p}{d c}$ where $d p$ and $d c$ are particle and carbide size, respectively. As this relative size approaches 1 (smaller feedstock particle and bigger carbide grains), the flattening behavior is more governed by hard carbide grains which increases the chance of rebounding. The role of carbide size, as one of the key characteristics of the feedstock powders, is the main focus in this section.

A reduction in carbide size can potentially improve the mechanical properties such as hardness and toughness as well as the tribological performance of the coatings (Ref 1, 16, 196). Wang et al. (Ref 197) studied the microstructure and mechanical properties of HVOFsprayed cermet coatings from WC-Co feedstock powder with the mean carbide size of $80 \mathrm{~nm}$. The idea of using nanosize carbides was to replace some of the $\mathrm{WC} / \mathrm{binder}$ interfaces by WC/WC interface. They suggested that a clustered structure which comprises of small carbide grains (increasing the number of carbide/carbide interfaces) can enhance the wear performance of the coating compared to the regular coatings containing singular large carbides. In the case of a coating with regular carbide size once the binder (Co) is removed, the single carbide grain is very likely to be pulled out while in a clustered structure, there are plenty of hard WC grains bonded together embedded in the binder beneath, making the material difficult to be removed. However, it has been reported in some studies that a decrease in carbide size can result in a decrease in the value of fracture toughness (Ref 32, 198). Also, there are contradictory reports on the correlation between carbide size and wear performance of a WC-based coating. While some studies show that employing feedstocks with smaller carbide size range result in superior wear resistance (Ref 16, 193, 199-202), other investigations report either no 
major difference or deterioration of wear performance by reducing the size of carbides ( $\operatorname{Ref} 25,39,203-205)$. The employed spraying method in all the cited references (Ref $16,39,201,202,204,205$ ) is HVOF and the above contradiction plausibly results from different spraying parameters used in each study. As the flame temperature, and as a result the extent of decarburization, can be varied based on the employed process parameters (mentioned in "Role of Process Parameters in the HVOF Technique" section), using smaller carbide grains brings even more sensitivity to this due to the higher specific surface area (see "Phase Change During HVOF Spraying" section). Those studies that reported an improvement in performance (Ref $16,201,202)$ tried to reduce the flame temperature as much as possible to reduce the decarburization effect.

In cermet coatings, besides the intrinsic properties of reinforcing grains and metallic binders, the mean free path (MFP) is the other parameter that governs the properties of the coating. For a given volume fraction of carbides, the MFP value depends on the size of carbides. The parameter MFP or mean free interparticle distance is defined as (Ref 206, 207);

$\lambda=\frac{1-V_{p}}{N_{L}}$

where $\lambda$ is MFP, $V_{p}$ is the volume fraction of the WC grains, $N_{L}$ is the number of carbide grains that intercept per unit length a random test line. For a given carbide-binder volume fraction, the MFP value decreases with a decrease in the size of employed carbides.

In a study by Kumari et al. (Ref 3$)$ it is shown that a reduction in MFP can considerably improve the abrasion wear performance of the coating with a linear correlation. In this study the extend of decarburization, during HVOF spraying of powders with finer carbides, was controlled by keeping flame temperature to be as low as possible. Also, similar linear relationship is suggested between relative abrasive wear rate and relative carbide size by other studies (Ref 16, 208, 209) confirming the improvement in abrasive performance by decrease in carbide size. It has been reaffirmed for sliding wear conditions (Ref 198, 208), that when the decarburization ratio is negligible, a decrease in carbide size can lead to a substantial decline in specific wear rate by a factor of two, which is attributed to an increase in hardness and toughness of the coating.

In general, considering the decarburization ratio to be negligible, larger MFP (bigger carbide size) means higher local surface exposure of the binder and this results in a tougher and softer composite system. So, by having a composite system that has higher toughness, it is easier to absorb more energy through plastic deformation, leading to an improvement in resistance against fracture. If MFP is considered to be representative of the binder width (Ref
210), in the configurations with larger carbide grains, the thickness of the binder is bigger (more available space between the carbide grains). As a result, under loading, the configuration can accommodate the deformation within the tough binder. On the other hand, by decreasing the MFP, accommodation for deformation within the binder is limited (greater constraint against deformation). So, for further deformation, such configuration requires more stresses to be applied, resulting in improvement in strength. Also, in the configurations with finer carbide grains, the carbides will be more uniformly and homogeneously distributed throughout the matrix. This can prevent the coatings from being deeply penetrated in the case of two and three-body abrasion wear and the resulting grooves would have shorter length (higher number of hard carbide grains are in the way). The other benefit is that by reducing particle size, a lower surface roughness on the coatings will be achieved, leading to improvement in wear performance and reduction in finishing costs.

\section{Tribological Behavior}

After the selection of the proper deposition technique and setting the desired spray parameters and assessing the coating properties in terms of microstructure and mechanical properties, the performance of the coating when exposed to different application-relevant wear modes needs to be evaluated. Wear-resistant coatings are supposed to perform well under various tribological conditions. There are several standard tests to examine the behavior of a coating under these conditions, including sliding wear (Ref 211), dry and wet abrasion (Ref $212,213)$, erosion and slurry erosion (Ref 214,215$)$ conditions. Each of these tests is distinct and subjects the coating to entirely different wear environments, which result in different mechanisms of material removal from the coatings. In this section, the focus is on reviewing the performance of HVAF- and HVOF-sprayed WC-based coatings and also the mechanisms that are responsible for coating degradation when exposed to different modes of wear.

\section{Performance Comparison of HVAF and HVOF Coatings}

As mentioned in "Phase Change During HVOF Spraying" section, material degradation can occur in the case of using HVOF as the deposition method. This leads to brittleness of the coating resulting in rapid propagation of surface and subsurface cracks, which can affect wear mechanisms and tribological performance of the coating (Ref $205,216,217)$. On the other hand, material degradation is 
minimized in coatings applied using the HVAF route. However, since the temperature is relatively low and particles are scarcely heated, the method can lead to weak inter-lamellar cohesion.

Since both methods are significantly influenced by feedstock characteristics and spraying parameters, an equitable comparison of the two processes in terms of properties and performance is challenging. Still, results ensuing from comparative studies involving HVOF and HVAF can give a good picture of advantages and disadvantages of each. Making this comparison for various coatings deposited using distinct feedstocks and employing different spray parameters can make it more comprehensive. In a comprehensive study by Bolelli et al. (Ref 2), the wear performance of HVAF- and HVOF-sprayed WC$\mathrm{CoCr}$ coating was compared by conducting abrasion and sliding wear tests. The selection of feedstocks with two different particle sizes of $5 / 30 \mu \mathrm{m}$ (W1) and $15 / 45 \mu \mathrm{m}$ (W2) for both HVAF and HVOF method provides a wellgrounded comparison. Employing two different guns for each technique, JP5000 (P2) and DJ2700 (P3) for HVOF and M3 (P1) and M2 (P4) for the HVAF method, covers diverse coating properties resulting from intrinsic differences in the employed equipment. Figure 8 shows the specific wear rate and volume loss obtained from testing samples in different wear environments.

According to Fig. 8(a), with the exception of coatings deposited by HVOF DJ2700 (P3) and tested at high temperature, the sliding wear performance of all the thermal spray coatings is roughly the same with negligible difference in specific wear rates. In the two cases P3W1 and P3W2, networks of through-thickness macrocracks were reportedly visible to the naked eye across the surface of the samples before starting the ball-on-disk test. The case with

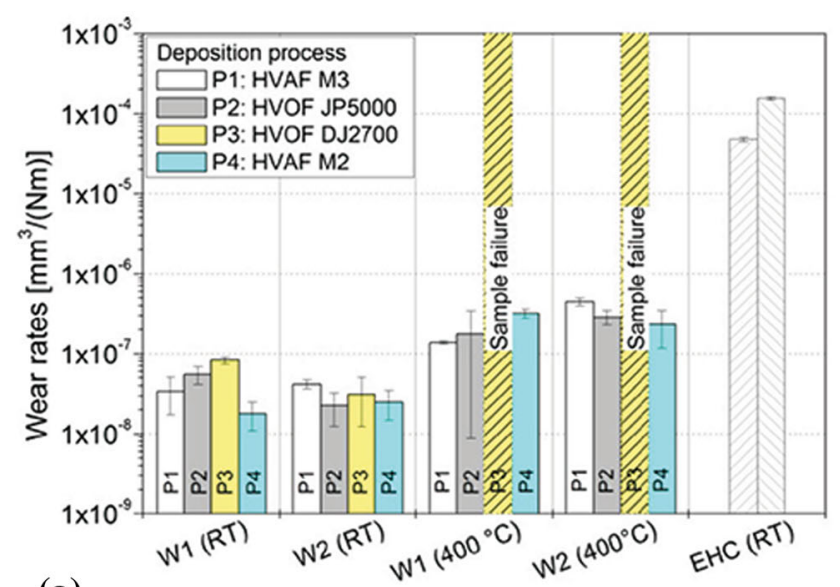

(a)

Fig. 8 (a) specific wear rates obtained from ball-on-disk test and, (b) volume loss from sand rubber wheel test performed at room temperature (RT) and $400{ }^{\circ} \mathrm{C}$ on WC-CoCr coatings from feedstock electrolytic hard chromium (EHC) was provided as a reference. Also, dry sand rubber wheel tests were conducted to compare the abrasion resistance of the coatings fabricated by the two high-velocity techniques. Although according to Fig. 8(b), all the samples show comparable wear performance under dry sand rubber wheel test, it can be noticed that the feedstock powder particle size was a more influencing factor in abrasive wear environment rather than the process route. The coatings generated with the powder with coarser particle size (W2-series) showed larger volume losses than those of the finer powder cut size (W1-series). The authors also confirmed similar behavior for HVOF and HVAF coatings in the other study (Ref 80).

To compare the wear performance of the coatings from the two methods at higher temperatures, a combination of $\mathrm{Fe}$-based feedstock of $\mathrm{FeCrNiSiBC}$ with 0, 20 and 40 wt.\% addition of WC-Co composite powder were examined. Performing ball-on-disk tests at higher temperatures revealed that an increase in temperature can lead to an increase in wear rate for both HVOF and HVAF coatings by roughly the same magnitude. For a given composition and test temperature, the specific wear rate values of the coatings deposited by the two processing techniques were in the same range (Fig. 9). It can be seen in Fig. 9 that the coatings with addition of Fe-based binder show a comparable performance at higher temperatures as compared to the reference WC-Co.

Comparable performance was suggested by other researchers under sliding wear test (Ref 218,219$)$ as well as under jet erosion test at $30^{\circ}, 60^{\circ}$ and $90^{\circ}$ as well as slurry erosion (Ref 220). However, other reports can be found with contradictory conclusions which are discussed below.

Wang et al. (Ref 221) compared the slurry erosion behavior of HVOF- and HVAF-sprayed WC-CoCr

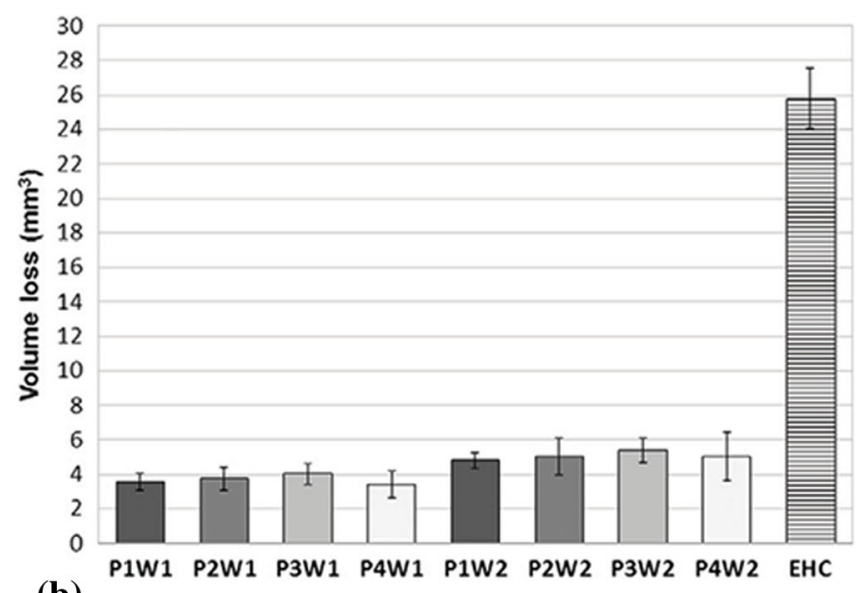

(b)

of two different particles sizes, 5/30 $\mu \mathrm{m}$ (W1) and 15/45 $\mu \mathrm{m}$ (W2), processed by various spraying techniques, JP5000 (P2) and DJ2700 (P3) for HVOF and M3 (P1) and M2 (P4) for HVAF (Ref 2) 
coatings. AK 07 HVAF and DJ2700 HVOF gun were employed to fabricate the coatings. The slurry erosion test was performed by mixing 40-70 mesh $\mathrm{SiO}_{2}$ sand in water. The feed rate of sand was $150 \mathrm{~g} / \mathrm{min}$ and the test was performed at $30^{\circ}$ and $60^{\circ}$ impact angles. According to Fig. 10, the erosion resistance of HVAF samples is slightly superior compared to that of HVOF samples. This superior performance can be attributed to the lower porosity, higher hardness and fracture toughness for HVAF samples compared to those deposited by HVOF method.

Hulka et al. (Ref 222) showed that HVAF-sprayed WCbased coatings exhibit similar or better wear performance compared to the coatings deposited by HVOF process, under sliding and abrasive conditions. Weight loss under abrasion wear for HVOF coatings was slightly higher than that of HVAF coatings ( $65 \mathrm{mg}$ for HVOF coatings vs. 57 $\mathrm{mg}$ for HVAF coatings). Also, the specific wear rate under ball-on-disk test conditions for HVOF coatings with $2.62 \times$ $10^{-5}\left(\mathrm{~mm}^{3} \mathrm{~N}^{-1} \mathrm{~m}^{-1}\right)$ was higher than that of HVAF coatings with $2.26 \times 10^{-5}\left(\mathrm{~mm}^{3} \mathrm{~N}^{-1} \mathrm{~m}^{-1}\right)$. In another

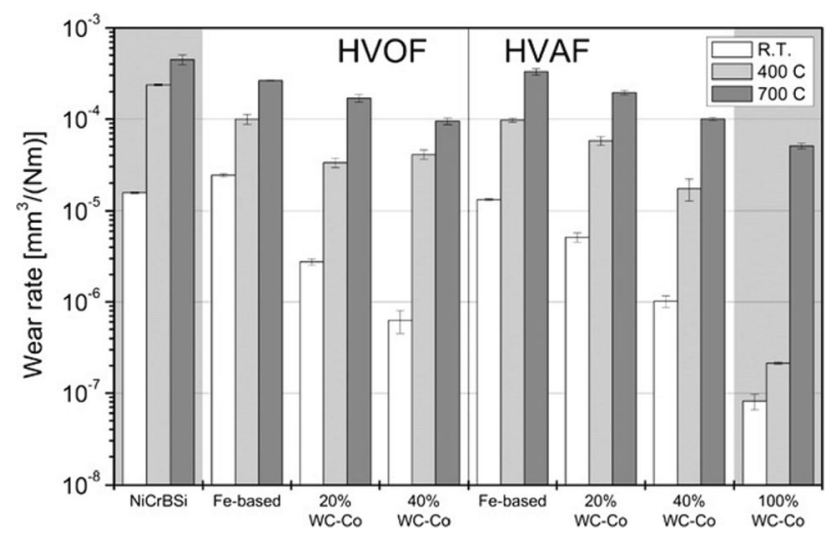

Fig. 9 Specific wear rate for various composition deposited by HVAF and HVOF processes (Ref 80)

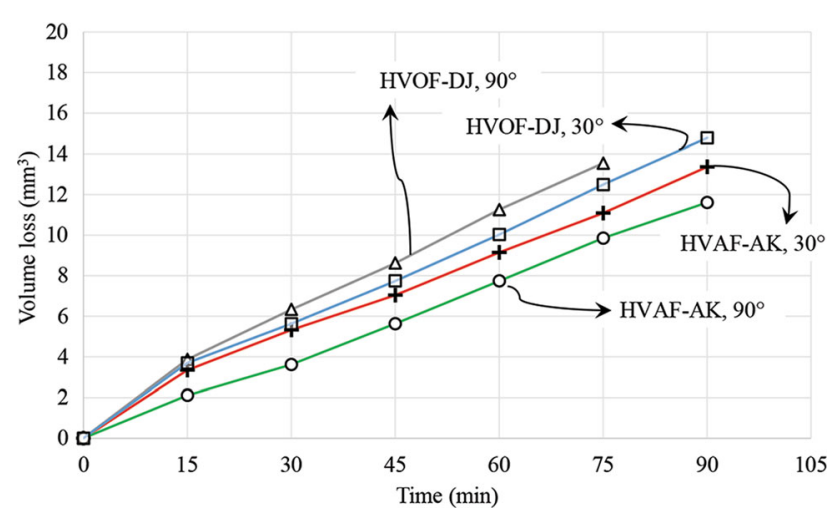

Fig. 10 The slurry erosion volume loss of WC-CoCr coatings sprayed using HVOF and HVAF methods; adapted based on (Ref 221) study, Wang et al. (Ref 156) by conducting sliding and abrasion tests concluded that HVAF coatings exhibited better performance compared to HVOF-sprayed layers. For the same abrasive test conditions, the average abrasive wear rate for the HVAF samples sprayed using the AK 07 gun was $3.76 \times 10^{-6} \mathrm{~g} / \mathrm{m}$ while the wear rate values for the other two HVOF coatings sprayed using JP8000 and Jet Kote III were 6.05 and $18.72 \mathrm{~g} / \mathrm{m}$, respectively. They attributed such results to lower decarburization in HVAF coatings compared to that of HVOF, leading to higher hardness and fracture toughness for the coating.

Recently, there have been some studies focused on the wear behavior of high-velocity sprayed WC-based coatings under erosive environments (Ref 223-226). Matikainen et al. (Ref 180) conducted a comprehensive comparative investigation to evaluate the wear performance of WC$\mathrm{CoCr}$ sprayed using HVOF and HVAF techniques under various erosive environments, including dry, slurry and cavitation erosion. The most substantial difference was found in cavitation erosion rate for HVAF-sprayed samples $(0.4 \mu \mathrm{m} / \mathrm{h})$ compared to HVOF coatings $(1.5-3.7 \mu \mathrm{m} / \mathrm{h})$. There are other studies claiming that the process route can have great influence on the performance of the resulting coating (Ref 157, 167, 218, 227)

In general, as discussed in "High-Velocity Spraying Methods" section, the quality of deposited coatings using HVOF and HVAF methods in terms of mechanical properties and tribological performance can be highly influenced by the process parameters as well as feedstock characteristics. Sometimes, this can lead to contradictory results when it comes to comparing coatings sprayed using HVOF and HVAF methods (Ref 80, 156, 167, 228). It can be found in the literature that HVAF WC-based coatings in some cases show inferior and in some other cases superior wear performance compared to HVOF-sprayed WC-based coatings. For instance, in Fig. 11 it can be seen that HVAF

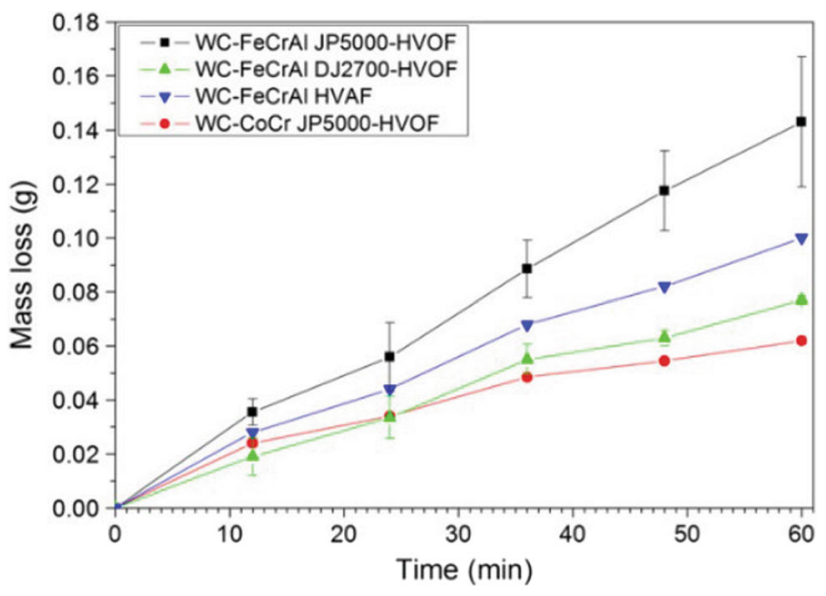

Fig. 11 Mass loss in rubber wheel test for coatings applied using HVAF and HVOF methods (Ref 229) 
WC-FeCrAl is ranked between two HVOF coatings sprayed with different guns in terms of abrasive wear performance.

\section{Mechanisms of Material Removal Under Different Wear Conditions}

Wear is a complicated phenomenon and there is no unified classification of wear mechanisms. This is not only because it is intrinsically a complex process, but also because it is greatly dependent on the material being worn, its properties and the environment that it experiences. There are a great number of studies devoted to description and classification of wear mechanisms from various perspectives. The delamination theory of wear was introduced by Suh in 1973 (Ref 230). This theory was established based on the formation of subsurface microcracks and voids and their propagation toward surface and detachment of material. Wear mechanisms are mostly classified in four major groups as adhesive, abrasive, fatigue and corrosive by Furey (Ref 231), Rabinowicz (Ref 232) and Budinski (Ref 233). Budinski later considered four main modes of wear considering material removal mechanisms including abrasion, nano-abrasive, rolling contact fatigue and impact. Based on the type of wear test and test conditions a combination of these modes can play a role. Also, the process of material removal is greatly dependent on the material texture and properties. In literature, the process of material removal during different forms of wear is known by terms like failure modes, degradation mechanisms, damage mechanisms, etc. It includes post facto analysis of the worn surface and corresponding subsurface microstructure. In this paper the wear mechanisms are categorized based on different types of wear conditions, so the prominent material removal mechanisms in play during sliding, abrasive and erosive forms of wear are briefly discussed below for thermal spray coatings.

\section{Sliding Wear}

Several investigations can be found putting forward a failure scenario for thermal spray WC-based coatings under sliding wear conditions using ball-on-disk test according to the standard ASTM G99 (Ref 211). Based on literature studies (Ref 156, 234-236), the proposed failure mechanisms fall mostly into one or a combination of these categories: complete delamination, micro-chipping, crack propagation along the carbide/binder interface, extrusion of matrix and, as a result, carbide pulling out due to weak binder support. Test conditions such as temperature, characteristic of mating counterpart, load and duration can highly affect the wear process and mechanism in the sliding wear. Besides, characteristics of the feedstock such as employed production route, size distribution of the particles or of individual carbide grains, and intrinsic properties of the binder can influence the process of material removal (Ref 6, 14, 25, 169). According to several reports, it has been revealed that performing tests at higher temperatures expedites material removal and the formation of oxides (Ref 80, 237, 238). Wesmann et al. (Ref 237) in their study showed that the amount of WC measured on the surface after a sliding test decreases from 92 to 47.8 at.\% as a result of increasing test temperature from room temperature to $200{ }^{\circ} \mathrm{C}$. This led to an increase in the average value of the specific wear rate from $0.4 \times 10^{-7}$ to $2.0 \times 10^{--}$ ${ }^{7} \mathrm{~mm}^{3} \mathrm{~N}^{-1} \mathrm{~m}^{-1}$. Generally, increasing the applied load can lead to higher material removal. Generally, increasing the applied load can lead to higher material removal. This can be due to more severe damage of the coating accompanied with more complex removal mechanisms governed, among other factors, by correspondingly higher tangential force (Ref 236, 237, 239). In (Ref 236) it is shown that specific wear rate can increase from $0.17 \times 10^{-5} \mathrm{~mm}^{3}$ $\mathrm{N}^{-1} \mathrm{~m}^{-1}$ at $30 \mathrm{~N}$ to $3.53 \times 10^{-5} \mathrm{~mm}^{3} \mathrm{~N}^{-1} \mathrm{~m}^{-1}$ at $90 \mathrm{~N}$.

In a study by Torkashvand et al. (Ref 240) on HVAF WC-CoCr coatings, no significant change in specific wear rate was observed on increasing normal loads up to $40 \mathrm{~N}$ in sliding wear test. Wang et al. (Ref 236) conducted ball-ondisk testing on WC-CoCr with the load varied from 15 to $90 \mathrm{~N}$. They found that the rate of material removal increases significantly once the load surpasses $45 \mathrm{~N}$. The dominant wear mode in the case of $15 \mathrm{~N}$ was individual carbide pullouts (Fig. 12a). Removal of material in forms of carbide pull-outs is reported to be a very common mechanism in WC-based coatings (Ref 241-243). Carbide pull-out can occur through various mechanisms; in some cases, the carbide grains get fractured as a result of contact with the counterpart and fragments get pulled out during the test (Ref 169). Also, it can happen because of binder removal around the carbide grain or even because of weak cohesion with the binder. Increasing the load to $30 \mathrm{~N}$ created several plowed grooves (Fig. 12b) and with further increase to $45 \mathrm{~N}$, macro-scale cracks emerged on the scar region (Fig. 12c). Under $60 \mathrm{~N}$ of normal load, severe fatigue delamination occurred due to plastic deformation leading to a sharp increase in the removal rate (Fig. 12d). For the cases 75 and $90 \mathrm{~N}$, extensive material exfoliation can be observed (labeled as massive exfoliation in Fig. 12e) in the form of pits.

Therefore, the following scenario according to Fig. 13 was proposed as the mechanism of material removal in case of sliding wear condition. First, small cracks nucleate within the binder phase and the carbide/binder interface, followed by plastic deformation, removal of small fragments, and fatigue delamination as a result of large-scale 
Fig. 12 High-magnification SEM micrographs of the HVOF WC-Co-Cr coating tested at different loads of (a) $15 \mathrm{~N}$, (b) $30 \mathrm{~N}$, (c) $45 \mathrm{~N}$, (d) $60 \mathrm{~N}$, (e) $75 \mathrm{~N}$ and (f) $90 \mathrm{~N}$ (Ref 236)
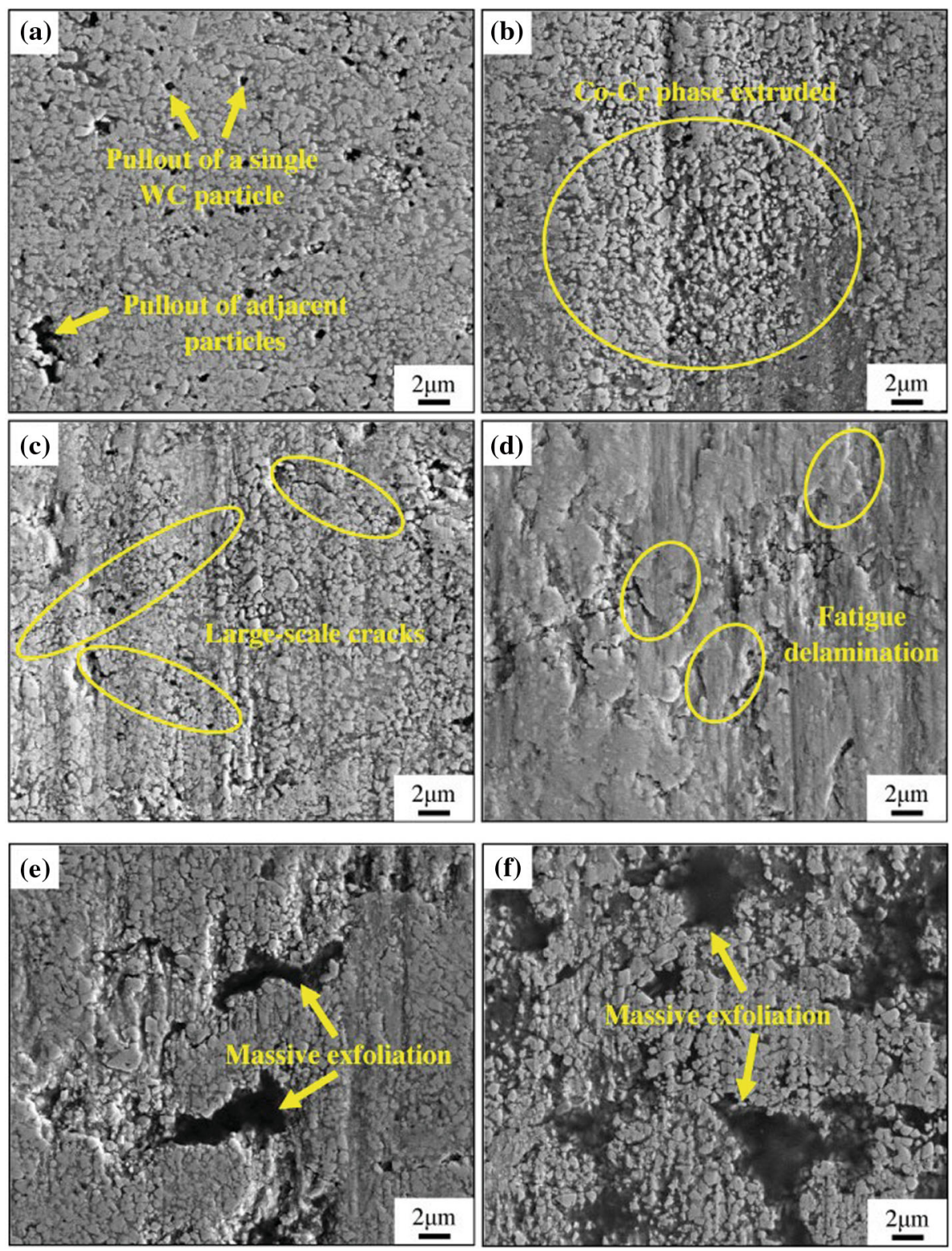

cracks, and finally large scale of material removal and formation of pits.

Excessive material removal in the form of pits happens either because of very harsh test conditions (e.g., high load) or when the coating does not have a great cohesion (Ref 167, 169, 244). Along with the intrinsic behavior of the binder which provides the cohesion in WC-based coatings, the spraying process seems to have a profound influence on the microstructure characteristics and property retention of the feedstock properties and, as a result, on cohesion. In a study by Shipway et al. (Ref 205) on the performance of HVOF-sprayed WC-Co coatings in the ball-on-disk test, it was shown how degradation of feedstock material during deposition can influence the wear process. The loss of ductility in the Co-rich binder phase, because of carbide dissolution during spraying, can result in subsurface fracture, leading to excessive material removal. Using a crosssectional analysis of the wear scar, deep subsurface cracks parallel to the surface, across $\mathrm{W}_{2} \mathrm{C}$-rich areas (bright regions), were observed (Fig. 14). These cracks can propagate through the binder phase and lead to material loss once they reach the free surface.

In a study by Wang et al. (Ref 156), the influence of the processing technique on wear mechanisms under sliding conditions was evaluated. The wear behavior of three different WC-CoCr coatings applied by HVAF (using AK gun) and HVOF (using JP and JK guns) methods was investigated. It was concluded that the dominant wear mechanism is different for coatings with various degrees of decarburization. The HVAF coating exhibited the 
smoothest worn surface and the smallest scar width among all the three. As shown in Fig. 15(a), no apparent cracks or deep plows can be found in the AK coating which is attributed to the coating's high hardness and toughness. On the other hand, significant amount of brittle phases (resulting from decarburization) led to the nucleation and propagation of a large number of cracks and pits on the surface of the JK coating without any apparent plows. A small number of cracks, pits and plows were visible within the wear track of the JP coating compared to the JK coating. This was attributed to the hardness and toughness of the JK coating being low, resulting in the worst sliding wear resistance of this coating.

The following three steps were proposed as wear mechanism in the coatings: (1) severe deformation and extrusion of binder, (2) formation and propagation of fatigue cracks, leading to pull-out of carbides, spallation of splats and as a result formation of wear debris, and (3) entrapping of some debris between the two surfaces acting as a third-body abrasive.

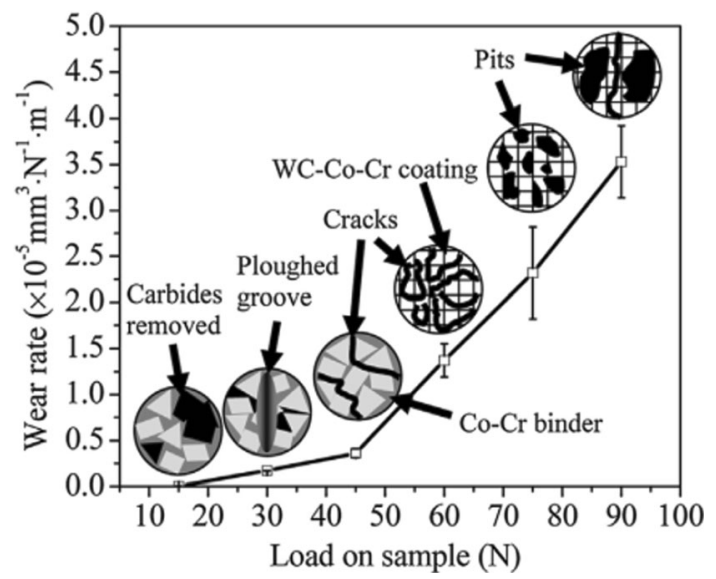

Fig. 13 Evolution of material removal stages by increasing loading in sliding test (Ref 236)
Generally, the wear process of thermal spray WC-based coatings in sliding wear conditions is dependent on two main factors: test conditions and inherent tribological properties of the coating. It is expected that, by making the test conditions harsher, the mechanism of material removal changes from carbide pull-out to plowed grooves, cracking, pitting and finally extensive separation of material. Besides, having brittle phases in the coating can affect the mechanism of wear as the brittle phases can facilitate the initiation and propagation of cracks. Due to the tendency of these phases to cracking, the removal mechanism in the coatings with brittle phases initiates from the surface and/ or subsurface cracking through the brittle phase and, as a result, material is detached. This brittleness can be due to excessive decarburization during spraying. On the other hand, decreasing the flame temperature by employing the HVAF technique can resolve the brittleness problem. Lacking the brittle phases can potentially limit the removal process to carbide pull-outs, plowing and grooving, which can substantially improve the performance of the coating.

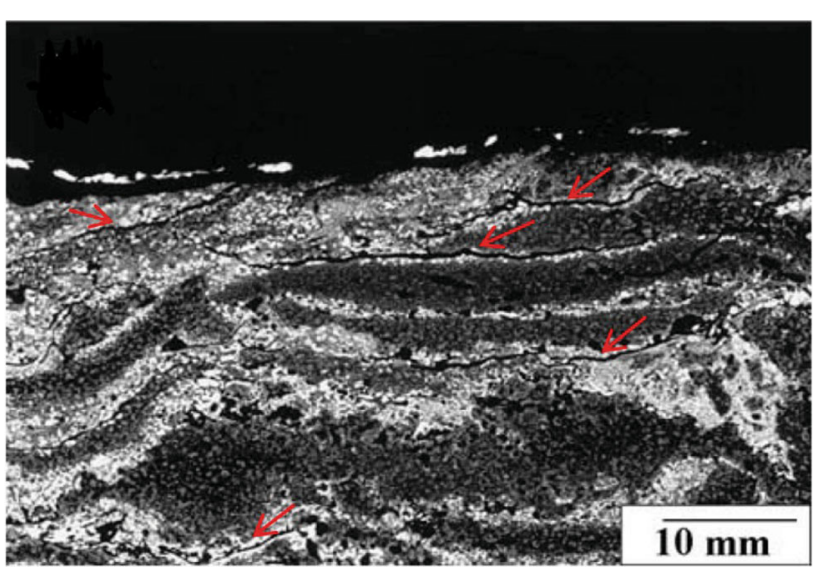

Fig. 14 Horizontal subsurface cracks (indicated by arrows) across the $\mathrm{W}_{2} \mathrm{C}$ rich regions as a result of ball-on-disk test (Ref 205)
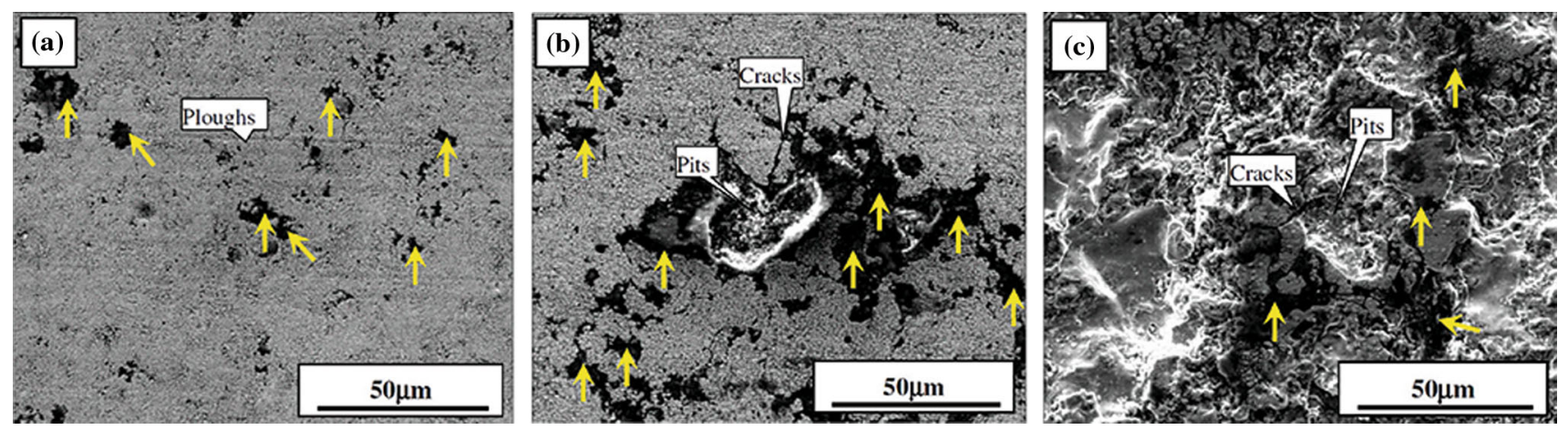

Fig. 15 SEM images of the surface subjected to sliding wear test of the (a) AK, (b) JP and (c) JK coatings (Ref 156) 


\section{Abrasive Wear}

Another testing method which simulates a vast variety of application conditions is abrasion wear. There are several relevant standards such as abrasion resistance of hard materials, ASTM B611 (Ref 245) and dry sand rubber wheel test, ASTM G65 (Ref 212) for the evaluation of the performance of the WC-based coatings under three-body wear conditions. The analysis of the wear mechanism under various three-body abrasive conditions is crucial since it can be employed to have a good understanding of how the amount of wear can vary as the wear conditions change. Having third-body particles in this condition can induce high levels of shear stresses to the surface and as a result expedite the wear process. There are several test parameters that need to be set depending on the standard on which the wear test is based. The characteristics of the abrasive media, temperature, load, speed and test duration are among the determining test conditions (Ref 10, 246, 247). In general, the abrasive wear mechanism of a given WC-based coating is dominated by the following steps (Ref 136, 197, 248-250): (1) removal of soft matrix phase, (2) partial or complete fragmentation of unsupported WC grains and (3) removal of fragments (Ref 248).

Depending on the characteristics of the coatings, which are determined based on the process technique and the corresponding parameters, the first two steps can be skipped or occur very quickly in a way that the step three is the prominent occurrence. This was affirmed in a study on the abrasion behavior of HVAF (using AK gun) and HVOF (using JP and JK guns) WC-CoCr coatings with diverse mechanical properties (Ref 156). Typical SEM images of abraded surfaces of the three coatings are provided in Fig. 16. A large number of grooves and pits are visible on the surface of the JK coating leading to a rougher surface of this coating compared to JP and AK coatings. Also, the degree of binder scratching and the number of fractured carbides (yellow arrows) in the JK coating is higher than the other two. Based on the morphology of the worn surfaces, it can be concluded that the "micro-cutting" was the dominant wear mechanism of the JK coating accompanied by spallation of the splats. This behavior was attributed to the amount of brittle phases $\left(\mathrm{W}_{2} \mathrm{C}\right.$ and $\left.\mathrm{W}\right)$ being higher in this coating as a result of decarburization. It can be seen how the degree of decarburization can affect the dominant wear mechanism.

The effect of decarburization can be further pronounced and lead to crack formation throughout the coating. In a study conducted by Stewart et al. (Ref 161), through a dry sand rubber wheel test with alumina and silica sands and through post wear analysis, they described the material removal process of HVOF-sprayed WC-Co coatings. In the case of using alumina as abrasive sand, besides horizontal cracks (parallel to the surface) mentioned in the case of "Sliding Wear" section, several vertical cracks were formed as it can be seen in Fig. 17. These vertical cracks were not observed in the case of using silica sand (with more rounded morphology) leading to a wear rate ten times lower than that with the alumina sand.

It was suggested that the vertical cracks initiated from indentations of the abrasive particles into the surface of the coating. They grow vertically through the coatings until they reach $\mathrm{W}_{2} \mathrm{C}$ rich areas and continue to propagate across a W-rich path until finding their way back to the surface. For cases like these, involving a severely decarburized coating, the first step out of the three (removal of soft matrix phase) constituting the material removal mechanisms during abrasion does not occur because of the very brittle structure. Having extremely brittle phases (in decarburized coatings) facilitates the propagation of cracks through the whole system. Therefore, before any matrix extrusion happens, degradation of the coating already occurs. On the other hand, in coatings whose toughness is not significantly altered as a result of decarburization, the propagation of cracks occurs in a more controlled manner and only to a limited extent. In this case all the three mentioned steps occur in sequence and the coating exhibits a superior performance.
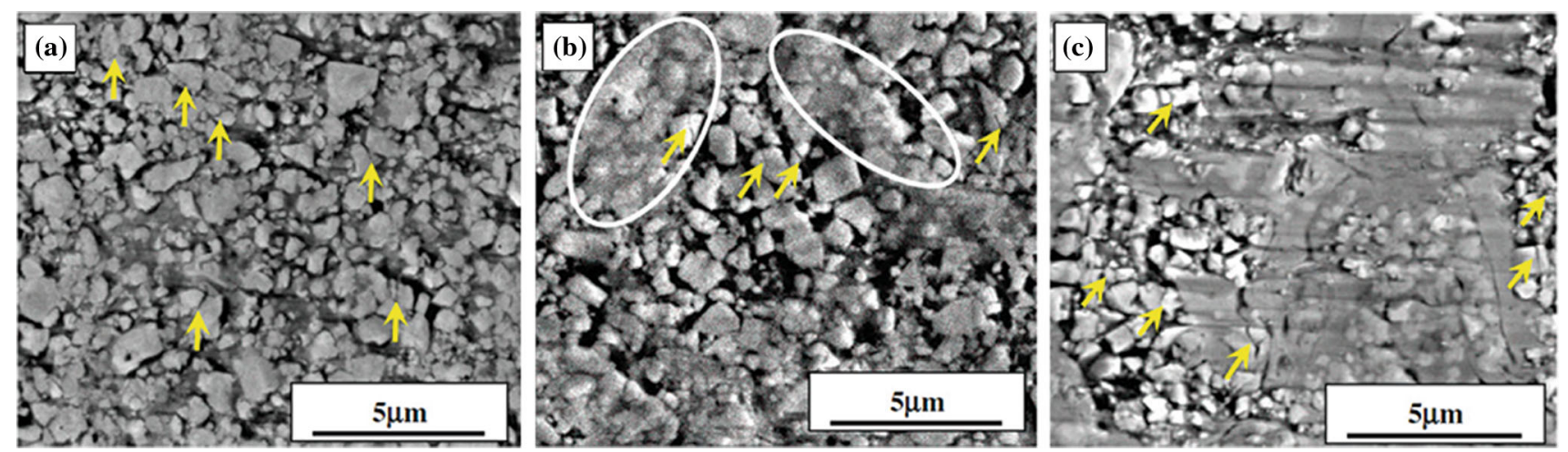

Fig. 16 SEM images of abraded surface of the (a) AK, (b) JP and (c) JK coatings (Ref 156) 
As mentioned earlier, the properties and morphology of the abradant sand can affect the material removal mechanism. Ghabchi (Ref 17) studied the influence of abradant sand on the wear mechanism of HVOF-sprayed WC-CoCr using dry and wet abrasion test with fine and coarse sand particles. A mix of $10 \mathrm{wt} . \%$ titania sand in water was used for soft slurry abrasion test. In this case, besides the removal of carbides and splats, it was revealed that another fracture mechanism contributed to the interaction of sand particles with WC grains (Fig. 18).

Employing an image analysis method, the effect of the relative size of the abradant sand $(220 \mathrm{~nm})$ and $\mathrm{WC}$ grains was investigated and the following material removal mechanism were suggested: when the ratio of carbide grain size to the abrasive particle is; (1) less than 0.5 , the removal of the binder containing carbide grains occurs (Fig. 19a), and (2) between 0.7 and 1.3, fragmentation of WC grains happens (Fig. 19b). In the latter case, when the ratio is close to 0.7 , complete fracture of WC grains happens and when it is close to the upper limit (1.3), partial fracture happens. For the cases higher than 1.4, no segmentation of carbides was observed. In another study, fracture of carbides was reported as the dominant

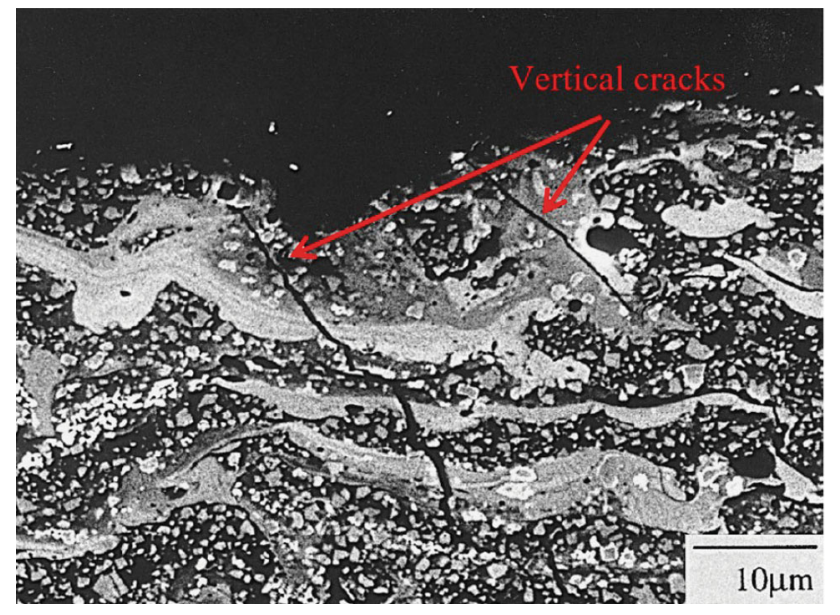

Fig. 17 Vertical cracks initiated from the surface as a result of the effect of abrasive sands (Ref 161) mechanism, by increase in abradant size (Ref 246). The influence of the abrasive particle size on the wear mechanism of thermally sprayed WC-CoCr coatings was investigated. $\mathrm{SiC}$ abrasive media was employed with three different particle sizes of 4.5, 17.5 and $180 \mu \mathrm{m}$ in a rubber wheel abrasion test. They observed a sharp increase from an average value of around $1 \times 10^{-13}$ (SWR/ $\mathrm{m}^{3} \mathrm{~N}^{-1} \mathrm{~m}^{-1}$ ) for the two smaller particle sizes to around $3.3 \times 10^{-13}\left(\mathrm{SWR} / \mathrm{m}^{3} \mathrm{~N}^{-1} \mathrm{~m}^{-1}\right)$ for the abrasive with the particle size of $180 \mu \mathrm{m}$. They attributed this rapid increase to change in wear mechanism from plastic deformation to a more fracture-dominated removal mechanism.

To study the material removal mechanism in dry abrasion testing, coarse $\mathrm{SiO}_{2}$ and $\mathrm{SiC}$ were used as soft and hard abrasive particles, respectively. The test was stopped at the very early stage and the surface was analyzed. For the case with $\mathrm{SiO}_{2}$, as it can be seen in Fig. 20, it was found that the scratches initiated from surface open porosities and continued along the direction of rotation of the rubber wheel. In this case, the penetration of the abrasive particles into the hard surface of the coatings is very limited.

In the case of using hard $\mathrm{SiC}$ abrasive sand, according to Fig. 21, a penetration of particles into the hard surface of the coating occurs. As can be seen unlike $\mathrm{SiO}_{2}$, the scratch groove is not initiated from open porosity regions. It is originated from the location that contact pressure is high enough to trigger the penetration of abrasive particles to the

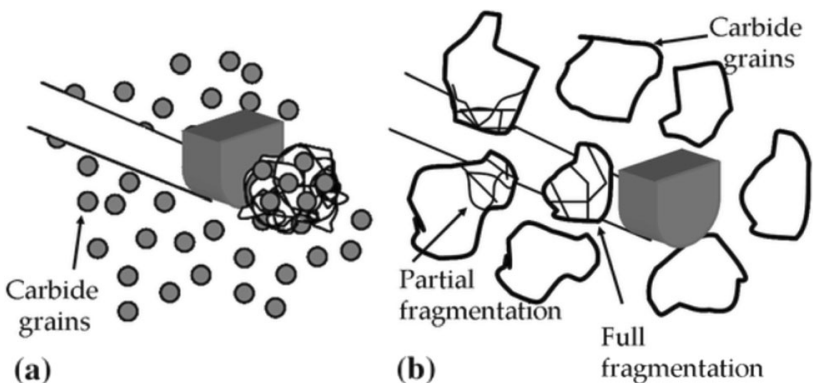

Fig. 19 Proposed mechanisms for material removal based on relative size of carbides and abrasive particles in wet abrasion (Ref 17)
Fig. 18 Fragmentation of carbide grains from wet abrasion test (a) before test and (b) after test (Ref 17)
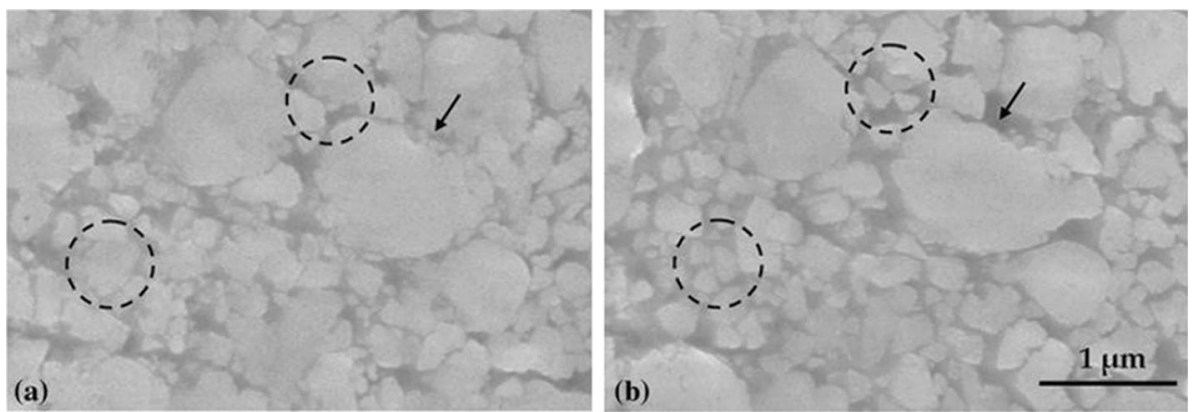
Fig. 20 Scratch resulting from abrasion test using relatively soft $\mathrm{SiO}_{2}$ particles (left) and proposed mechanism for similar test conditions (Ref 17)

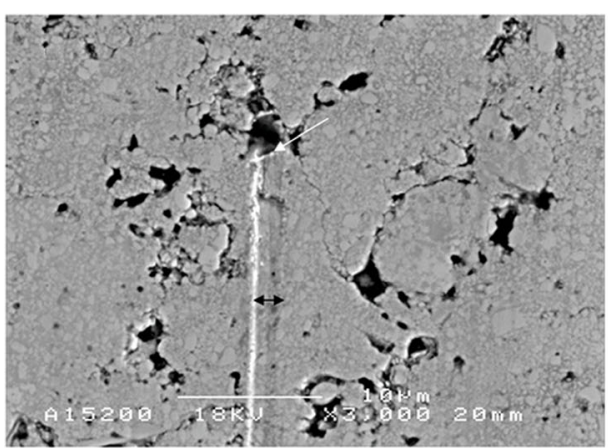

(a)

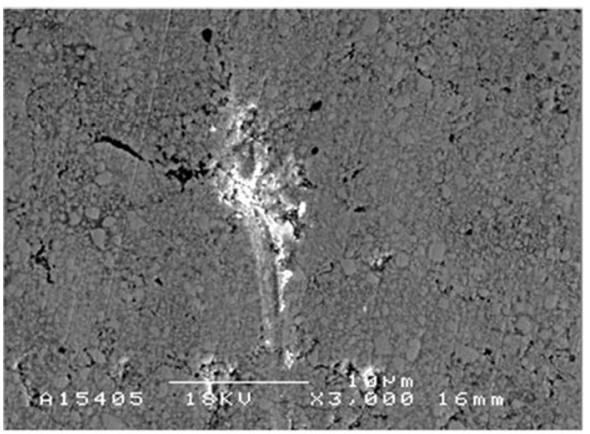

(a)

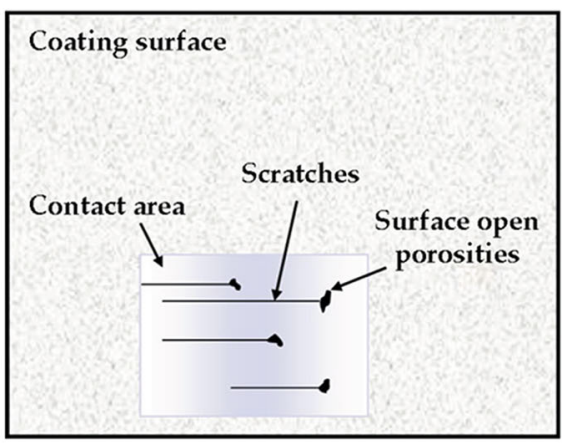

(b)

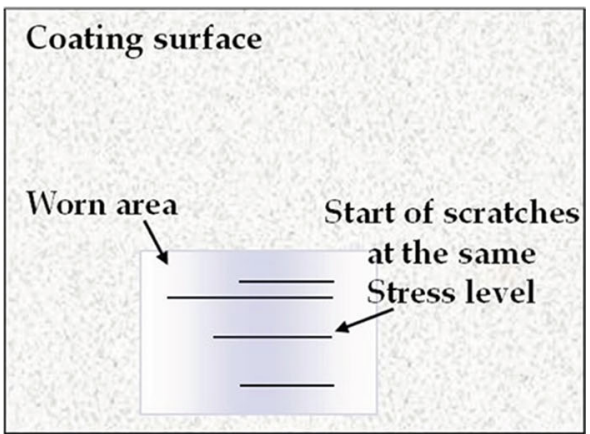

(b)
Fig. 21 Scratch resulting from abrasion test using relatively hard $\mathrm{SiC}$ particles (left) and proposed mechanism for similar test conditions (Ref 17)

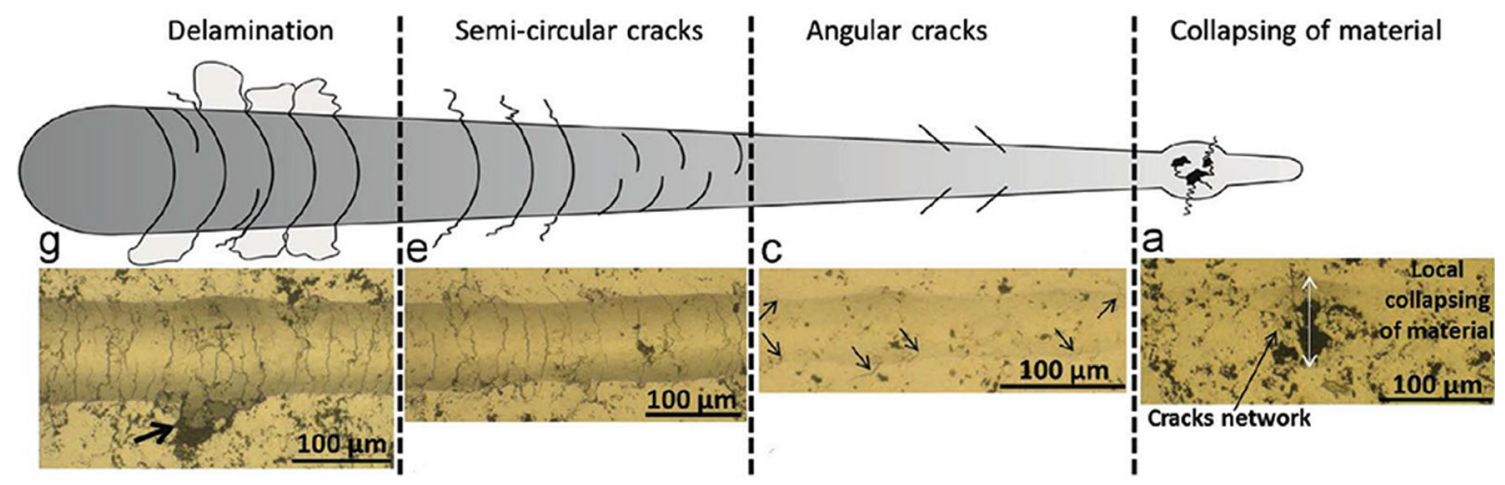

Fig. 22 Damage evolution of WC-Co coatings in a typical scratch test-the test direction is from right to the left (Ref 252)

material. The scratch continues until the pressure is enough and particles are not damaged and result in chipping of material.

As it can be observed in Fig. 20 and 21, the abrasive process can be considered as a combination of multiple scratch tests (Ref 251). So, understanding the material removal mechanism in a single scratch test can give a good picture of the removal process in the abrasion test. Ghabchi et al. (Ref 252) tried to draw a clear mechanism for the damage process of WC-CoCr coatings employing controlled scratch testing. The test was performed by using a conical diamond indenter applying a progressive load from $5 \mathrm{~N}$ preload increasing to $100 \mathrm{~N}$. According to Fig. 22, they described the damage evolution to occur in four steps (1) local material removal, (2) formation of angular cracks, (3) formation of semi-circular cracks and (4) delamination of splats.

In another study, Younis et al. (Ref 253) by performing scratch tests, found similar removal mechanisms as those shown in Fig. 22. In this study, two grade sizes of WC-Co coatings, fine and coarse, were applied using the HVOF method. Generally, in the scratch test performed on coatings with fine feedstock particle size, higher load is required to induce fracture on the surface. This is while the wear mechanism in both coatings exhibits similar material removal processes. 
In the abrasive wear environment, there are various parameters affecting the process of material removal. The characteristics of abradant particles as well as test conditions and the intrinsic properties of the coating can influence the mechanisms of material removal. In general, abrasion wear can be considered as a superposition of numerous micro-scratching of the abradant particles on the surface. It can lead to fracture of the carbides and/or grooving of the surface resulting in the removal of material. Also, depending on the brittleness of the coating, cracking can happen and as a result expedite the removal of the material.

\section{Erosive Wear}

There are several standard tests including ASTM G76 and G73 to study the erosion behavior under dry and wet conditions (Ref 214, 215). In erosive environments, depending on abradant characteristics, mechanical properties of the target and test parameters, different material removal mechanisms can be expected. One of the determining factors is the hardness ratio of abrasive sand and the target. If the hardness of abrasive particles is higher than that of the target, the dominant mechanisms are plastic deformation, surface fatigue and micro-cutting. If the target's hardness is higher than the erosive particles, in addition to surface fatigue, direct fracture is the main removal mechanism (Ref 254, 255). The other important parameter is the toughness of the coating. In brittle materials, surface fatigue and direct fracture are the dominant mechanisms, while in ductile materials, deformation with micro-cutting is the case (Ref 255-257). For WC-based coatings, the erosion mode is a combination of ductile and brittle mechanisms. For the matrix, micro-cutting and extrusion of the material are the dominant erosive wear processes. This results in isolated uplift of carbide grains that are prone to fracture due to excessive impacts of the erosive particles (Ref 256, 257).

This different ductile and brittle removal mechanisms can be seen in the paper by Ramesh et al. (Ref 258). Performing erosion tests on HVOF-sprayed WC-based coatings using silica sand with the size of $125-180 \mu \mathrm{m}$ impacted at $40 \mathrm{~m} / \mathrm{s}$, they found a combination of ductile and brittle modes of erosion. Based on surface morphology analysis, several grooves in the binder region and lips on the surface were found which indicate plowing and cutting mechanisms. The grooves in the matrix caused dislocation of carbide grains such that small WC grains were pulled out without any damage to individual carbide grains, while the dominant failure mechanism for large grains is chipping. Similar mechanisms of material removal were reported by Kulu et al. (Ref 259) and Thakur et al. (Ref 260). Also, a similar mechanism was proposed by Ding et al. (Ref 135) investigating the failure mechanism of HVOF-sprayed (gas and liquid fuel) WC-CoCr coatings under erosion tests performed at $30^{\circ}$ and $60^{\circ}$ impact angles on coatings with different WC sizes. Conventional WCCoCr coatings with a WC size of $1.5 \mu \mathrm{m}$ and multimodal WC-CoCr coatings comprising micrometric carbides of $2.5 \mu \mathrm{m}$ size and 80-200 $\mathrm{nm}$ size were used as feedstock. Formation of micro-damages followed by propagation of micro-cracks, resulting in material removal from the surface, were proposed as the dominant wear mechanism in all the samples. Figure 23 shows schematic diagram of the erosion wear mechanism at $30^{\circ}$ for conventional and multimodal coatings.

First, as a result of the collision of erodent particles on their sharp corner, the binder phase with low hardness is prone to be removed. The presence of hard WC grains can prevent further removal of the binder phase (Fig. 23a). Once the large WC grains fall off due to pull-out or fracture, the erodent particles continue to exfoliate the matrix phase and submicron WC grains, Fig. 23(b) and (c). The presence of the nanosized carbide grains can slow the process of material removal such that the binder in the conventional coating is eroded more easily as shown in Fig. 23(d).

In addition to the former mechanisms which are mainly attributed to surface evolution of the coating, the formation and interlinking of subsurface cracks resulting in material removal is the other scenario for erosion wear proposed by Li et al. (Ref 261). They performed erosion tests at different impact angles on conventional WC-CoCr coatings with different porosities deposited using HVOF and HVAF methods. Micro-cutting and coating spallation were proposed to be the dominant mechanisms for material removal under these test conditions. Figure 24 shows schematic diagrams of the formation and growth of subsurface microcracks in porous and dense coatings.

Crack nucleation and propagation behavior were suggested to be different in porous and dense coatings. In porous microstructures, cracks nucleate at pores and propagate between the carbides while in dense coatings, the cracks form in the weak areas and stress concentration regions like splat boundaries. As a result of interlinking of these cracks and propagation toward the surface, material removal can occur. Small, flat plateaus and a rough surface were formed in the case of dense and porous coatings, respectively (see Fig. 24). A similar mechanism for material removal is proposed by others (Ref 262-264). Despite the comprehensive analysis on wear mechanisms in these studies, the difference in removal mechanisms of HVAF and HVOF coatings were not studied.

Feedstock characteristics like carbide size are a key factor in determining the removal mechanism of WC-based coatings under erosion conditions. Matikainen et al. (Ref 
Fig. 23 Schematic diagram for erosion wear mechanisms, (a), (b) and (c) multimodal coatings and (d) conventional coating; adapted based on (Ref 135)
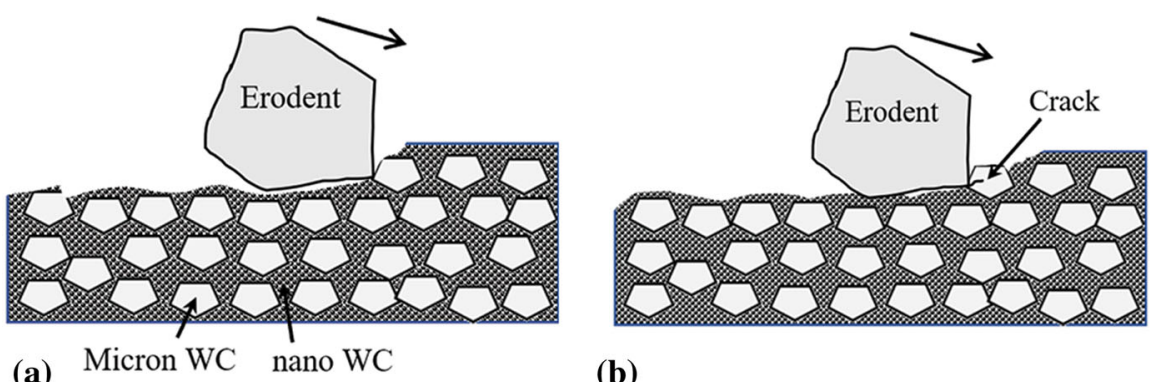

(a)

(b)

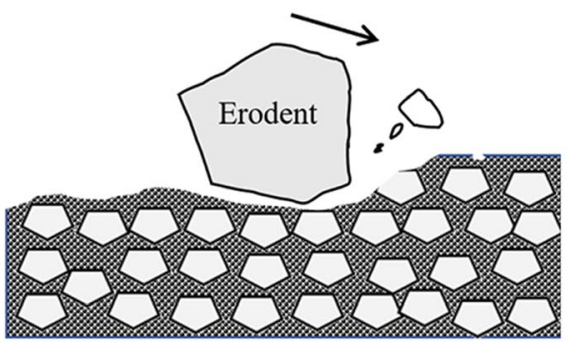

(c)

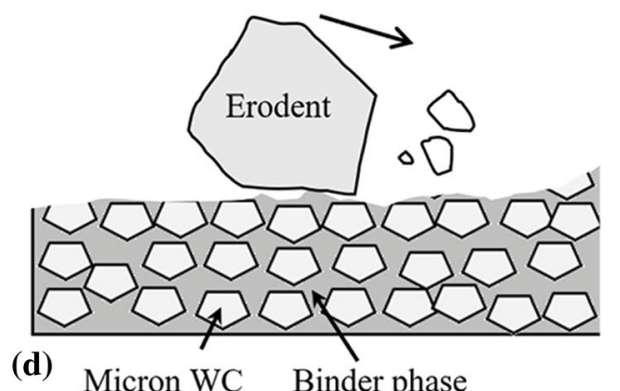

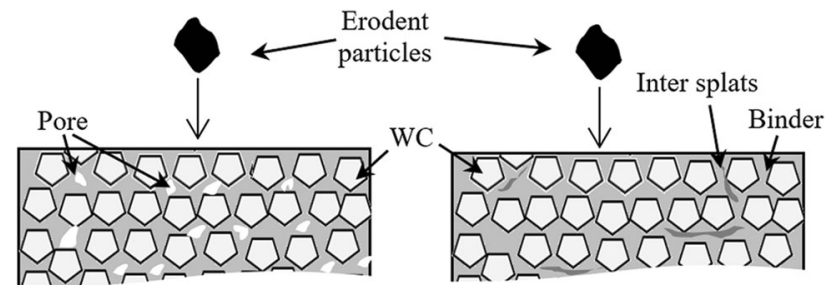
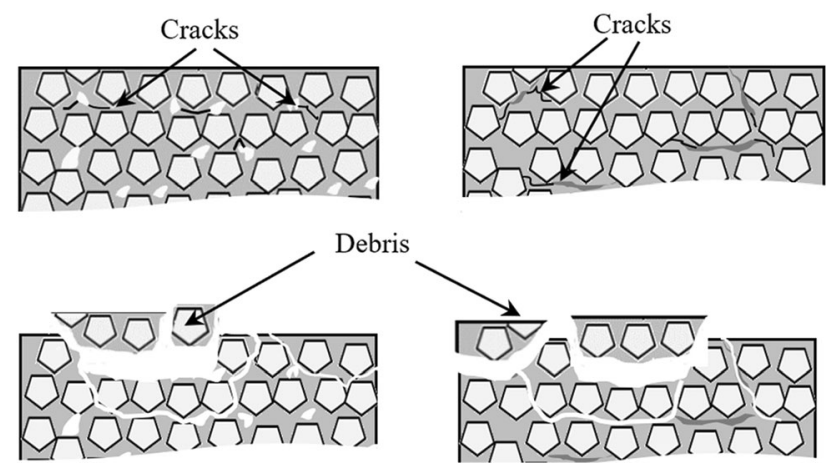

Fig. 24 Schematic diagrams of nucleation and propagation of subsurface cracks in porous (left) and dense (right) coatings; adapted based on (Ref 261)

180) showed this by employing feedstock powders with two different carbide sizes of $0.8 \mu \mathrm{m}$ (H1W1) and $0.4 \mu \mathrm{m}$ (H1W2) deposited by the HVAF method. Finer carbide size resulted in carbide-rich areas in the H1W2 coating (red circles) which naturally made it more resistant against erosive wear, while more binder-rich areas were visible in the H1W1 coating. Larger carbides led to higher amount of carbide removal and as a result rougher surface (Fig. 25a), while very limited fractures of carbides happened in the case of the coating with fine carbide size. Hence, a reduction in carbide size can significantly enhance the wear performance under erosion conditions. This is reaffirmed by several other reports (Ref 208, 265).

The material removal mechanism of WC-based coatings under erosive environment generally starts from the removal of binder and consequently, the fracture and/or pull-out of the carbide grains on the surface. In addition to surface removal, as the porosity of the coating increases the possibility of formation of subsurface cracking networks increases under the impact of erodent particles, resulting in excessive separation of material. Employing finer carbide size, which is plausible employing HVAF technique, can have a great influence on improving the erosion wear performance by the microstructure more homogeneous, along with less tendency to fracture as a result impact of erodent particles.

\section{Overview}

As evident from the preceding discussion in the above three parts ("Sliding Wear", "Abrasive Wear" and "Erosive Wear" sections), the wear mechanism can differ depending on the wear condition. For the sliding conditions, it is dominated by the propagation of fatigue cracks and carbide pull-outs and fragmentations in form of pits. For abrasion conditions, due to high stresses induced on the surface, a severe fragmentation occurs as a result of either extensive cracks propagation in the system or binder removal and fragmentation of unsupported carbides. The wear mechanism in erosion is even more different, it comprises various mechanisms ranging from plastic deformation, crack formation, fatigue and fracture to 
Fig. 25 Wear surfaces of coatings fabricated from carbide sizes of (a) $0.8 \mu \mathrm{m}$ and (b) $0.4 \mu \mathrm{m}(\operatorname{Ref} 180)$

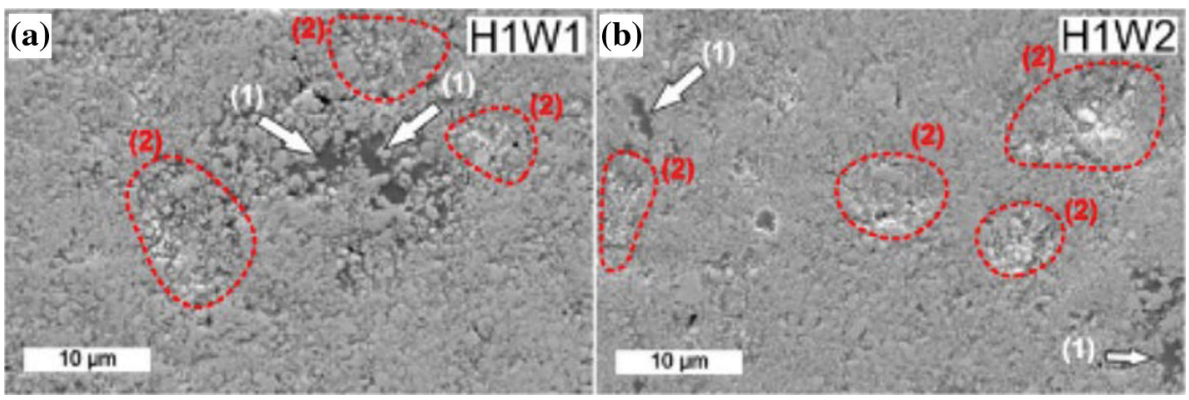

micro-cutting. Therefore, it is challenging to make a direct comparison or to draw a valid comparison between mechanisms and the extent of material loss in the three wear conditions especially since the wear performance is mostly reported in terms of wear rate which is in different units for each test (i.e., $\mathrm{mm}^{3} \mathrm{~N}^{-1} \mathrm{~m}^{-1}$ for sliding, $\mathrm{mm}^{3} \mathrm{~g}^{-1}$ for erosion and usually mass loss or volume loss in case of abrasion). In general, in the cases where decarburization of carbide increases the brittleness of the coating (which is the case for some of the HVOF methods) the removal process is faster as a result of accelerated crack propagation. It has been reported by Testa et al. (Ref 75) that the binder composition of HVOF WC-based coatings, when changing from $\mathrm{CoCr}$ to $\mathrm{NiMoCrFeCo}$ or FeNiCr$\mathrm{MoCu}$, does not greatly influence the wear mechanisms under sliding and abrasive wear. However, in a very recent study by Heinrichs et al. (Ref 266), performed on sintered cemented carbide samples, it was shown that binder chemistry can significantly influence wear initiation. Conventional Co-based binder composition exhibited much more resistance against damage initiation compared to $\mathrm{Ni}$ and $\mathrm{Fe}$ binders. Although this is not a thermal spray example, it indicates potential contradictions that demand closer scrutiny. To the best of the authors' knowledge, there are rare comprehensive investigations studying the effect of binder composition on the removal mechanisms of thermal spray WC-based coatings.

\section{Summary and Conclusions}

In this paper, a comprehensive review on thermal spray WC-based coatings has been presented with specific emphasis on alternative binders, processing techniques and tribological behavior of these coatings.

- The need for moving away from Co as a conventional binder, due to several environmental and supply risk concerns, seems obvious and there are several alternatives studied in the literature in terms of mechanical and tribological performance. Ni-based and Fe-based compositions such as NiMoCrFeCo and FeCrAl, deposited using HVOF method, have been shown to be promising alternatives. However, their tribological behavior deserves further comprehensive assessment. There are various other promising alternative Fe-based matrix compositions such as $\mathrm{FeCoNi}$ that are processed by means of powder metallurgy and it is plausible that they can be tried employing thermal spray methods.

- While HVOF is currently the most widely employed process for applying WC-based coatings, HVAF has emerged as a promising technique to tackle some of the shortcomings of the HVOF method such as decarburization. In terms of wear performance, HVAF WCbased coatings tend to exhibit promising results. Under sliding and abrasive wear environments, the absence of brittle phases (mainly $\mathrm{W}_{2} \mathrm{C}$ ) can mitigate surface and subsurface cracking, resulting in an improvement of the wear performance. The HVAF technique appears to be a more robust method in terms of the quality of the deposited coating using different spraying parameters compared to HVOF. Also, it can make the fabrication of coatings with refined microstructures possible, by employing smaller carbides, while this is not possible by HVOF due to excessive decarburization.

- There are several investigations on the wear behavior of WC-based coatings trying to present a scenario on the material removal under different environments including sliding, abrasive and erosive wear conditions: plowed grooves, cracking, pitting and finally extensive separation of material. Plowing and grooving leading to cracking and pitting of coating materials and subsequently extensive separation of the coating are found to be the most common removal mechanism process under sliding wear conditions. Under abrasion conditions, the coating degradation usually starts with the removal of the soft matrix phase and results in the partial or complete fragmentation of weakened WC grains and, subsequently, material removal. Under erosive conditions, the wear process is a combination of plastic deformation, subsurface crack initiation/ propagation and chipping, all of which subsequently contribute to material removal. Although there have been a number of good investigations on the material 
removal process for WC-based coatings applied by the HVOF process, very limited studies deal with the removal mechanisms of coatings applied using the HVAF method. The removal mechanisms can differ for HVAF and HVOF coatings, since the coatings applied using HVAF method do not contain many brittle phases, resulting in a possible change in removal mechanisms.

Employing the experiences from powder metallurgy to the thermal spray field regarding the use of alternative binders should be considered in future studies. There are few investigations on fabricating HVAF WC-based coatings with refined structures by using fine carbides and this demands more attention in future studies. Moreover, the influence of feedstock characteristics such as carbide size on the wear mechanism is not fully understood yet and this also demands more attention in future studies. The material removal behavior and mechanisms in coatings with alternative binders (to $\mathrm{Co}$ ) are not well explored yet. Since in most of the wear mechanisms the material removal initiates from the binder, having different chemistries with distinct material properties can potentially affect the process of wear. Hence, further future works in these areas would be beneficial to the thermal spray community.

Acknowledgments Financial support of the Knowledge Foundation, Sweden, for project HiPerCOAT (Dnr. 20180197) is gratefully acknowledged.

Funding Open access funding provided by University West.

Open Access This article is licensed under a Creative Commons Attribution 4.0 International License, which permits use, sharing, adaptation, distribution and reproduction in any medium or format, as long as you give appropriate credit to the original author(s) and the source, provide a link to the Creative Commons licence, and indicate if changes were made. The images or other third party material in this article are included in the article's Creative Commons licence, unless indicated otherwise in a credit line to the material. If material is not included in the article's Creative Commons licence and your intended use is not permitted by statutory regulation or exceeds the permitted use, you will need to obtain permission directly from the copyright holder. To view a copy of this licence, visit http://creativecommons. org/licenses/by/4.0/.

\section{References}

1. A. Vardelle, C. Moreau, J. Akedo, H. Ashrafizadeh, C.C. Berndt, J.O. Berghaus, M. Boulos, J. Brogan, A.C. Bourtsalas, A. Dolatabadi, M. Dorfman, T.J. Eden, P. Fauchais, G. Fisher, F. Gaertner, M. Gindrat, R. Henne, M. Hyland, E. Irissou, E.H. Jordan, K.A. Khor, A. Killinger, Y.C. Lau, C.J. Li, L. Li, J. Longtin, N. Markocsan, P.J. Masset, J. Matejicek, G. Mauer et al., The 2016 Thermal Spray Roadmap, J. Therm. Spray Technol., 2016, 25, p 1376-1440.

2. G. Bolelli, L.-M.M. Berger, T. Börner, H. Koivuluoto, L. Lusvarghi, C. Lyphout, N. Markocsan, V. Matikainen, P. Nylén, P.
Sassatelli, R. Trache and P. Vuoristo, Tribology of HVOF- and HVAF-Sprayed WC-10Co4Cr Hardmetal Coatings: A Comparative Assessment, Surf. Coat. Technol., 2015, 265, p 125144. https://doi.org/10.1016/j.surfcoat.2015.01.048

3. K. Kumari, K. Anand, M. Bellacci and M. Giannozzi, Effect of Microstructure on Abrasive Wear Behavior of Thermally Sprayed WC-10Co-4Cr Coatings, Wear, 2010, 268(11-12), p 1309-1319. https://doi.org/10.1016/j.wear.2010.02.001

4. O. Aranke, W. Algenaid, S. Awe and S. Joshi, Coatings for Automotive Gray Cast Iron Brake Discs: A Review, Coatings, 2019, 9(9), p 1-31.

5. M. Eriksson, F. Bergman and S. Jacobson, On the Nature of Tribological Contact in Automotive Brakes, Wear, 2002, 252, p 26-36.

6. R. Ahmed, O. Ali, C.C. Berndt and A. Fardan, Sliding Wear of Conventional and Suspension Sprayed Nanocomposite WC-Co Coatings: An Invited Review, J. Therm. Spray Technol., 2021, 30, p 800-861.

7. D. Mari, L. Miguel and C.E. Nebel, Comprehensive Hard Materials, Vol 1 Elsevier, Amsterdam, 2014.

8. M.L. Grilli, D. Valerini, R.R. Piticescu, T. Bellezze, M. Yilmaz, A. Rinaldi, S. Cuesta-López and A. Rizzo, Possible Alternatives to Critical Elements in Coatings for Extreme Applications, IOP Conf. Ser. Mater. Sci. Eng., 2018, 329(1), p 012005.

9. A.H. Tkaczyk, A. Bartl, A. Amato, V. Lapkovskis and M. Petranikova, Sustainability Evaluation of Essential Critical Raw Materials: Cobalt, Niobium, Tungsten and Rare Earth Elements, J. Phys. D. Appl. Phys., 2018, 51(20), p aaba99. https://doi.org/ 10.1088/1361-6463/aaba99

10. R.J.K. Wood, S. Herd and M.R. Thakare, A Critical Review of the Tribocorrosion of Cemented and Thermal Sprayed Tungsten Carbide, Tribol. Int., 2018, 119, p 491-509. https://doi.org/10. 1016/j.triboint.2017.10.006

11. O.J. Ojo-Kupoluyi, S.M. Tahir, B. Baharudin, M.A. Azmah Hanim and M.S. Anuar, Mechanical Properties of WC-Based Hardmetals Bonded with Iron Alloys: A Review, Mater. Sci. Technol., 2017, 33(5), p 507-517.

12. J. Yuan, Q. Zhan, J. Huang, S. Ding and H. Li, Decarburization Mechanisms of WC e Co during Thermal Spraying: Insights from Controlled Carbon Loss and Microstructure Characterization, Mater. Chem. Phys., 2013, 142(1), p 165-171. https://doi. org/10.1016/j.matchemphys.2013.06.052

13. J.M. Guilemany, J.M. De Paco, J. Nutting and J.R. Miguel, Characterization of the W2C Phase Formed during the High Velocity Oxygen Fuel Spraying of a WC +12 Pct Co Powder, Metall. Mater. Trans. A, 1999, 30, p 1913-1921.

14. H.L. De Villiers Lovelock, Powder/Processing/Structure Relationships in WC-Co Thermal Spray Coatings: A Review of the Published Literature, J. Therm. Spray Technol., 1998, 7(3), p 357-373.

15. D.S. Hermiyanty, B.A. Wandira, Future Development of Thermal Spray Coatings. J. Chem. Inf. Model. (2017)

16. C.-J. Li and G.-J. Yang, Relationships between Feedstock Structure, Particle Parameter, Coating Deposition, Microstructure and Properties for Thermally Sprayed Conventional and Nanostructured WC-Co, Int. J. Refract. Met. Hard Mater., 2013, 39, p 2-17. https://doi.org/10.1016/j.ijrmhm.2012.03.014

17. A. Ghabchi, Wear Resistant Carbide-Based Thermal Sprayed Coatings: Process, Properties, Mechanical Degradation and Wear, PhD thesis (2011)

18. P. Fauchais, G. Montavon, R.S. Lima and B.R. Marple, Engineering a New Class of Thermal Spray Nano-Based Microstructures from Agglomerated Nanostructured Particles, Suspensions and Solutions: An Invited Review, J. Phys. D. Appl. Phys., 2011, 44(9), p 93001. 
19. V. Katranidis, S. Gu, T.R. Reina, E. Alpay, B. Allcock and S. Kamnis, Experimental Study of High Velocity Oxy-Fuel Sprayed WC-17Co Coatings Applied on Complex Geometries. Part B: Influence of Kinematic Spray Parameters on Microstructure, Phase Composition and Decarburization of the Coatings, Surf. Coat. Technol., 2017, 328, p 499-512.

20. Z. Geng, S. Hou, G. Shi, D. Duan and S. Li, Tribological Behaviour at Various Temperatures of WC-Co Coatings Prepared Using Different Thermal Spraying Techniques, Tribol. Int., 2016, 104, p 36-44. https://doi.org/10.1016/j.triboint.2016. 08.025

21. B.G. Mellor, Surface Coatings for Protection Against Wear, Woodhead Publishing Limited, Sawston, 2006.

22. S. Hong, Y. Wu, W. Gao, J. Zhang, Y. Zheng and Y. Zheng, Slurry Erosion-Corrosion Resistance and Microbial Corrosion Electrochemical Characteristics of HVOF Sprayed WC-10Co4Cr Coating for Offshore Hydraulic Machinery, Int. J. Refract. Met. Hard Mater., 2018, 74, p 7-13.

23. M. Hadad, M. Hockauf, L.W. Meyer, G. Marot, J. Lesage, R. Hitzek and S. Siegmann, Adhesion Evaluation of Multilayered Based WC-Co-Cr Thermally Sprayed Coatings, Surf. Coat. Technol., 2008, 202(18), p 4399-4405.

24. P. Fauchais, G. Montavon and G. Bertrand, From Powders to Thermally Sprayed Coatings, J. Therm. Spray Technol., 2010, 19(1-2), p 56-80.

25. J. He and J.M. Schoenung, A Review on Nanostructured WC-Co Coatings, Surf. Coat. Technol., 2002, 157(1), p 72-79.

26. H. Wang, Q. Qiu, M. Gee, C. Hou, X. Liu and X. Song, Wear Resistance Enhancement of HVOF-Sprayed WC-Co Coating by Complete Densification of Starting Powder, Mater. Des., 2020, 191, p 108586. https://doi.org/10.1016/j.matdes.2020.108586

27. A.M. Venter, V. Luzin, D. Marais, N. Sacks, E.N. Ogunmuyiwa and P.H. Shipway, Interdependence of Slurry Erosion Wear Performance and Residual Stress in WC-12wt\%Co and WC10wt\%VC-12wt\%Co HVOF Coatings, Int. J. Refract. Met. Hard Mater., 2020, 87, p 105101. https://doi.org/10.1016/j.ijrmhm. 2019.105101

28. M.L. Grilli, T. Bellezze, E. Gamsjäger, A. Rinaldi, P. Novak, S. Balos, R.R. Piticescu and M.L. Ruello, Solutions for Critical Raw Materials under Extreme Conditions: A Review, Materials (Basel), 2017, 10(3), p 285.

29. J.M. Guilemany, J.M. Miguel, S. Vizcaino and F. Climent, Role of Three-Body Abrasion Wear in the Sliding Wear Behaviour of WC-Co Coatings Obtained by Thermal Spraying, Surf. Coat. Technol., 2001, 140(2), p 141-146.

30. Q. Wang, Z.H. Chen and Z.X. Ding, Performance of Abrasive Wear of WC-12Co Coatings Sprayed by HVOF, Tribol. Int., 2009, 42(7), p 1046-1051.

31. Y.Y. Özbek, N. Canikoğlu, M. Ipek, N. Canikoğlu and M. Ipek, The Mechanical Properties and Wear Resistance of HVOF Sprayed WC-Co Coatings, Acta Phys. Pol. A, 2016, 129(4), p 600-603.

32. P. Chivavibul, M. Watanabe, S. Kuroda and K. Shinoda, Effects of Carbide Size and Co Content on the Microstructure and Mechanical Properties of HVOF-Sprayed WC-Co Coatings, Surf. Coat. Technol., 2007, 202, p 509-521.

33. M.M. Lima, C. Godoy, J.C. Avelar-Batista and P.J. Modenesi, Toughness Evaluation of HVOF WC-Co Coatings Using NonLinear Regression Analysis, Mater. Sci. Eng. A, 2003, 357(1-2), p 337-345.

34. T. Sudaprasert, P.H. Shipway and D.G. McCartney, Sliding Wear Behaviour of HVOF Sprayed WC-Co Coatings Deposited with Both Gas-Fuelled and Liquid-Fuelled Systems, Wear, 2003, 255(7-12), p 943-949.

35. P. Mi, T. Wang and F. Ye, Influences of the Compositions and Mechanical Properties of HVOF Sprayed Bimodal WC-Co
Coating on Its High Temperature Wear Performance, Int. J. Refract. Met. Hard Mater., 2017, 69, p 158-163. https://doi. org/10.1016/j.ijrmhm.2017.08.012

36. H.S. Sidhu, B.S. Sidhu and S. Prakash, Wear Characteristics of $\mathrm{Cr} 3 \mathrm{C} 2-\mathrm{NiCr}$ and WC-Co Coatings Deposited by LPG Fueled HVOF, Tribol. Int., 2010, 43(5-6), p 887-890.

37. J. Pulsford, F. Venturi, Z. Pala, S. Kamnis and T. Hussain, Application of HVOF WC-Co-Cr Coatings on the Internal Surface of Small Cylinders: Effect of Internal Diameter on the Wear Resistance, Wear, 2019, 432, p 202965.

38. H. Kumar, C. Chittosiya and V.N. Shukla, HVOF Sprayed WC Based Cermet Coating for Mitigation of Cavitation, Erosion \& Abrasion in Hydro Turbine Blade, Mater. Today Proc., 2018, 5(2), p 6413-6420.

39. S. Usmani, S. Sampath, D.L. Houck and D. Lee, Effect of Carbide Grain Size on the Sliding and Abrasive Wear Behavior of Thermally Sprayed WC-Co Coatings, Tribol. Trans., 1997, 40(3), p 470-478.

40. T.S. Sidhu, S. Prakash and R.D. Agrawal, Studies on the Properties of High-Velocity Oxy-Fuel Thermal Spray Coatings for Higher Temperature Applications, Mater. Sci., 2005, 41(6), p 805-823.

41. U. Kanerva, J. Lagerbom and P. Vuoristo, Development of Thermal Spray Powders for Improved Tribological and Corrosive Applications and Cost-Effective Solutions, Int. J. Mater. Prod. Technol., 2007, 28(3-4), p 377-398.

42. J. Liu, T. Chen, C. Yuan and X. Bai, Performance Analysis of Cavitation Erosion Resistance and Corrosion Behavior of HVOF-Sprayed WC-10Co-4Cr, WC-12Co, and Cr 3 C 2-NiCr Coatings, J. Therm. Spray Technol., 2020, 29(4), p 798-810.

43. L.-M. Berger, P. Ettmayer, P. Vuoristo, T. Mäntylä and W. Kunert, Microstructure and Properties of WC- $10 \% \mathrm{Co}-4 \% \mathrm{Cr}$ Spray Powders and Coatings: Part 1. Powder Characterization, J. Therm. Spray Technol., 2001, 10(2), p 311-325.

44. J. Naden, Science and Implementation Plan Security of Supply of Mineral Resources (SoS Minerals) Research Programme 2012-2017. Natural Environment Research Council (2014)

45. IARC Working Group on the Evaluation of Carcinogenic Risks to Humans. Cobalt in Hard Metals and Cobalt Sulfate, Gallium Arsenide, Indium Phosphide and Vanadium Pentoxide. IARC Monographs on the Evaluation of Carcinogenic Risks to Humans, vol. 86 (2006), p. 1

46. National Institutes of Health (NIH), Report on Carcinogens Trichloroethylene (2016). https://ntp.niehs.nih.gov/whatwes tudy/assessments/cancer/roc/index.html?utm_source=direc t\&utm_medium=prod\&utm_campaign=ntpgolinks\&utm_term $=$ roc

47. V.V. Paul Marsh, Promoting the Sustainable and Responsible Production and Use of Cobalt in All Forms (2020). https://www. cobaltinstitute.org/cobalt-and-carcinogenicity.html

48. G.M. Keegan, I.D. Learmonth and C.P. Case, A Systematic Comparison of the Actual, Potential, and Theoretical Health Effects of Cobalt and Chromium Exposures from Industry and Surgical Implants, Crit. Rev. Toxicol., 2008, 38(8), p 645-674.

49. I. Polyzois, D. Nikolopoulos, I. Michos, E. Patsouris and S. Theocharis, Local and Systemic Toxicity of Nanoscale Debris Particles in Total Hip Arthroplasty, J. Appl. Toxicol., 2012, 32(4), p 255-269.

50. L.O. Simonsen, H. Harbak and P. Bennekou, Cobalt Metabolism and Toxicology-A Brief Update, Sci. Total Environ., 2012, 432, p 210-215. https://doi.org/10.1016/j.scitotenv.2012.06.009

51. C.Y. Cheang and N. Mohamed, Removal of Cobalt from Ammonium Chloride Solutions Using a Batch Cell through an Electrogenerative Process, Sep. Purif. Technol., 2016, 162, p 154-161.

52. S. Hannis, T. Bide, Cobalt. British Geological Survey (2009) 
53. K. Shedd, Cobalt Statistics and Information (2020). https:// www.usgs.gov/centers/nmic/cobalt-statistics-and-information

54. Cobalt Price (2020). http://www.metalary.com/cobalt-price/

55. M. Herr, T. Sailer, H.G. Sockel, R. Schulte, H. Feld and L.J. Prakash, Characterisation of Wear Properties of UltrafineGrained Hardmetals Using a Special Abrasive Wheel Test, Int. J. Refract. Met. Hard Mater., 2001, 19(4-6), p 371-379.

56. J.M. Tarragó, C. Ferrari, B. Reig, D. Coureaux, L. Schneider and L. Llanes, Mechanics and Mechanisms of Fatigue in a WC-Ni Hardmetal and a Comparative Study with Respect to WC-Co Hardmetals, Int. J. Fatigue, 2015, 70, p 252-257.

57. W.D. Schubert, M. Fugger, B. Wittmann and R. Useldinger, Aspects of Sintering of Cemented Carbides with Fe-Based Binders, Int. J. Refract. Met. Hard Mater., 2015, 49(1), p 110123. https://doi.org/10.1016/j.ijrmhm.2014.07.028

58. C. Liu, Alternative Binder Phases for WC Cemented Carbides, MSc thesis (2014). https://www.diva-portal.org/smash/get/ diva2:815039/FULLTEXT01.pdf

59. M. Ahmadian, D. Wexler, T. Chandra and A. Calka, Abrasive Wear of WC-FeAl-B and WC-Ni3Al-B Composites, Int. J. Refract. Met. Hard Mater., 2005, 23(3), p 155-159.

60. N. Espallargas, J. Berget, J.M. Guilemany, A.V. Benedetti and P.H. Suegama, Cr3C2-NiCr and WC-Ni Thermal Spray Coatings as Alternatives to Hard Chromium for Erosion-Corrosion Resistance, Surf. Coat. Technol., 2008, 202(8), p 1405-1417.

61. L.-M.M. Berger, S. Saaro, T. Naumann, M. Wiener, V. Weihnacht, S. Thiele and J. Suchánek, Microstructure and Properties of HVOF-Sprayed Chromium Alloyed WC-Co and WC-Ni Coatings, Surf. Coat. Technol., 2008, 202(18), p 4417-4421.

62. V.V. Sobolev, J.M. Guilemany, J.R. Miguel and J.A. Calero, Investigation of the Development of Coating Structure during High Velocity Oxy-Fuel (HVOF) Spraying of WC-Ni Powder Particles, Surf. Coat. Technol., 1996, 82(1-2), p 114-120.

63. L.-M. Berger, Hardmetals as Thermal Spray Coatings, Powder Metall., 2007, 50(3), p 205-214.

64. L.M. Berger, R. Zieris, S. Saaro, Oxidation of HVOF-Sprayed Hardmetal Coatings, in Proceedings of International Thermal Spray Conference, ITSC 2005 (2005), p 2-4

65. L.-M.M. Berger, Application of Hardmetals as Thermal Spray Coatings, Int. J. Refract. Met. Hard Mater., 2015, 49(1), p 350364. https://doi.org/10.1016/j.ijrmhm.2014.09.029

66. G. Barbezat, A.R. Nicol and A. Sickinger, Abrasion, Erosion and Scuffing Resistance of Carbide and Oxide Ceramic Thermal Sprayed Coatings for Different Applications, Wear, 1993, 162, p 529-537.

67. S.M. Nahvi and M. Jafari, Microstructural and Mechanical Properties of Advanced HVOF-Sprayed WC-Based Cermet Coatings, Surf. Coat. Technol., 2016, 286, p 95-102. https://doi. org/10.1016/j.surfcoat.2015.12.016

68. H. Asgari, G. Saha and M. Mohammadi, Tribological Behavior of Nanostructured High Velocity Oxy-Fuel (HVOF) Thermal Sprayed WC-17NiCr Coatings, Ceram. Int., 2017, 43(2), p 2123-2135. https://doi.org/10.1016/j.ceramint.2016.10.193

69. L.M. Berger, Hardmetal Coatings-History and Perspective, in Proceedings 11. HVOF Kolloquium Erding (2018), p 93-100

70. L.-M. Berger, S. Saaro, T. Naumann, M. Kašparova and F. Zahálka, Microstructure and Properties of HVOF-Sprayed WC(W, Cr) 2 C-Ni Coatings, J. Therm. Spray Technol., 2008, 17(3), p 395-403.

71. L.-M. Berger, S. Saaro, T. Naumann, M. Kašparova and F. Zahálka, Influence of Feedstock Powder Characteristics and Spray Processes on Microstructure and Properties of WC-(W, Cr) 2C-Ni Hardmetal Coatings, Surf. Coat. Technol., 2010, 205(4), p 1080-1087.

72. A. Al Hamed, Investigation of HVOF Thermal Sprayed Micro/ Nanostructured WC-12Co Mixed with Inconel-625 Nickel/
Chrome Based Coatings for Erosion/Corrosion Applications, $\mathrm{PhD}$ thesis (2015)

73. S. Zimmermann, H. Keller and G. Schwier, New Carbide Based Materials for HVOF Spraying, Therm. Spray Adv. Sci. Appl. Technol., 2003, 1, p 5-8.

74. S. Zimmermann, B. Gries and B. Brüning, New Cermet Powders for HVOF Spraying with Improved Corrosion and Oxidation Resistance for Offshore, Mining and Power Generation Applications, Therm. Spray Bull, 2011, 4(2), p 94-100.

75. V. Testa, S. Morelli, G. Bolelli, B. Benedetti, P. Puddu, P. Sassatelli and L. Lusvarghi, Alternative Metallic Matrices for WC-Based HVOF Coatings, Surf. Coat. Technol., 2020, 402, p 126308. https://doi.org/10.1016/j.surfcoat.2020.126308

76. Š Houdková, F. Zahálka, M. Kašparová and L.-M. Berger, Comparative Study of Thermally Sprayed Coatings under Different Types of Wear Conditions for Hard Chromium Replacement, Tribol. Lett., 2011, 43(2), p 139-154.

77. G. Bolelli, T. Börner, F. Bozza, V. Cannillo, G. Cirillo and L. Lusvarghi, Cermet Coatings with Fe-Based Matrix as Alternative to WC-CoCr: Mechanical and Tribological Behaviours, Surf. Coat. Technol., 2012, 206(19-20), p 4079-4094. https://doi. org/10.1016/j.surfcoat.2012.03.094

78. Data Sheet, Amperit ${ }^{\circledR}$ 518, p 8-10 (2018). https://www.hoga nas.com/en/powder-technologies/surface-coating/products/

79. H. Liao, B. Normand and C. Coddet, Influence of Coating Microstructure on the Abrasive Wear Resistance of WC/Co Cermet Coatings, Surf. Coat. Technol., 2000, 124(2-3), p 235242.

80. G. Bolelli, T. Börner, A. Milanti, L. Lusvarghi, J. Laurila, H. Koivuluoto, K. Niemi and P. Vuoristo, Tribological Behavior of HVOF- and HVAF-Sprayed Composite Coatings Based on FeAlloy + WC-12\% Co, Surf. Coat. Technol., 2014, 248, p 104112. https://doi.org/10.1016/j.surfcoat.2014.03.037

81. DataSheet, Amperit ® 554, p 7-9 (2018). https://www.hoganas. com/en/powder-technologies/surface-coating/products/

82. P. Chivavibul, M. Watanabe, S. Kuroda, J. Kawakita, M. Komatsu, K. Sato and J. Kitamura, Effect of Powder Characteristics on Properties of Warm-Sprayed WC-Co Coatings, $J$. Therm. Spray Technol., 2010, 19(1-2), p 81-88.

83. S. Liu, D. Sun, Z. Fan, H. Ying Yu and H. Min Meng, The Influence of HVAF Powder Feedstock Characteristics on the Sliding Wear Behaviour of WC-NiCr Coatings, Surf. Coat. Technol., 2008, 202(20), p 4893-4900.

84. DataSheet, Amperit 551, p 4-5 (2018). https://www.hoganas. com/en/powder-technologies/surface-coating/products/

85. L.F. dos S. Vieira, Comportamento Mecânico Do Aço AISI 4340 Revestido Com WC-CrCNi; WC-10Ni; Ni-20Cr; Ni-Cr-B$\mathrm{Si}-\mathrm{Fe}$; Cr3C2-NiCr Pelo Processo HVOF, Universidade Estadual Paulista (UNESP) (2012). file:///C:/Users/kavtor/Downloads/vieira_lfs_dr_guara.pdf

86. T.Y. Cho, Y.K. Joo, J.H. Yoon, W. Fang, S.H. Zhang and H.G. Chun, Improvement of Surface Properties of Magnetic Shaft Material Inconel718 by HVOF Spray Coating of WC-CrCNi Powder, Adv. Mater. Res., 2013, 774, p 1098-1102.

87. DataSheet, Diamalloy 4006, 1800, p 1-4. https://www.oerlikon. com/ecomaXL/files/metco/oerlikon_DSMTS-0086.4_NiCrW MoSuperalloys.pdf\&download $=1$

88. J.Y.A. Calahorra, C.G. Tiburcio, F. Estupiñan, A.T. Estrada, C.P. Salas, F.A. Calderón and J.A.C. Miramontes Sr., Corrosion Mechanism of NiCrWMo Coating Deposited by HVOF, ECS Trans., 2015, 64(26), p 89.

89. W.J. Huo, X. Liu, B. Hu and Z.P. Wang, Research on Microstructure and Wear-Resisting Property of NiCrWMo Laser Cladding on K418, Appl. Mech. Mater., 2014, 633, p 782-786. 
90. DataSheet, Woka, p 7504-7506 (2014). https://www.oerlikon. com/ecomaXL/files/oerlikon_DSMTS-0056.3_Woka7500_ C2C3_37WC_18Alloy.pdf

91. L. Janka, J. Norpoth, C. Tomastik, V. Matikainen and P. Vuoristo, Laser-Induced Precipitation of (W1- XCrx)2C: Mixed Carbide Phase for Improved Wear Resistance of Thermally Sprayed Hardmetal Coatings, Surf. Coat. Technol., 2018, 337, p 177-185. https://doi.org/10.1016/j.surfcoat.2017.12.061

92. V. Matikainen, G. Bolelli, H. Koivuluoto, P. Sassatelli, L. Lusvarghi and P. Vuoristo, Sliding Wear Behaviour of HVOF and HVAF Sprayed Cr3C2-Based Coatings, Wear, 2017, 388389, p 57-71. https://doi.org/10.1016/j.wear.2017.04.001

93. B. Venkateshwarlu, B.G. Mohammed Thalib and A. Srikanth, Influence of Critical Plasma Spray Parameter on Microstructural and Tribological Characteristics of Nanostructured Tungsten Carbide-Cobalt Coatings, Procedia Manuf., 2019, 30, p 339346.

94. M.E. Vinayo, F. Kassabji, J. Guyonnet and P. Fauchais, Plasma Sprayed WC-Co Coatings: Influence of Spray Conditions (Atmospheric and Low Pressure Plasma Spraying) on the Crystal Structure, Porosity, and Hardness, J. Vac. Sci. Technol. Vac. A Surf. Film., 1985, 3(6), p 2483-2489.

95. J. Voyer and B.R. Marple, Sliding Wear Behavior of High Velocity Oxy-Fuel and High Power Plasma Spray-Processed Tungsten Carbide-Based Cermet Coatings, Wear, 1999, 225229(I), p 135-145.

96. J.W. Murray, A. Leva, S. Joshi, T. Hussain, Microstructure and Wear Behaviour of Powder and Suspension Hybrid, Ceram. Int., Elsevier Ltd and Techna Group S.r.l. (2018)

97. S. Mahade, K. Narayan, S. Govindarajan, S. Björklund, N. Curry and S. Joshi, Exploiting Suspension Plasma Spraying to Deposit Wear-Resistant Carbide Coatings, Materials (Basel), 2019, 12, p 2344.

98. J. Villafuerte, Modern Cold Spray: Materials, Process, and Applications, Springer, Berlin, 2015.

99. A.S.M. Ang, C.C. Berndt and P. Cheang, Deposition Effects of WC Particle Size on Cold Sprayed WC-Co Coatings, Surf. Coat. Technol., 2011, 205(10), p 3260-3267. https://doi.org/10.1016/j. surfcoat.2010.11.045

100. T. Varis, T. Suhonen, M. Jokipii and P. Vuoristo, Influence of Powder Properties on Residual Stresses Formed in High-Pressure Liquid Fuel HVOF Sprayed WC-CoCr Coatings, Surf. Coat. Technol., 2020, 388, p 125604. https://doi.org/10.1016/j. surfcoat.2020.125604

101. C. Lyphout, G. Bolelli, E. Smazalova, K. Sato, J. Yamada, Š Houdková, L. Lusvarghi and T. Manfredini, Influence of Hardmetal Feedstock Powder on the Sliding Wear and Impact Resistance of High Velocity Air-Fuel (HVAF)Sprayed Coatings, Wear, 2019, 430-431, p 340-354.

102. R. Himani, S. Garima and P. Annima, Optimization of Abrasive Wear Characteristics of Tungsten Carbide and Chromium Carbide Based Coating on H-13 Steel Using Detonation Gun Process by Taguchi Method, Int. J. Mech. Eng. Robot. Res., 2014, 1(1), p 121-128.

103. J.K.N. Murthy, D.S. Rao and B. Venkataraman, Effect of Grinding on the Erosion Behaviour of a WC-Co-Cr Coating Deposited by HVOF and Detonation Gun Spray Processes, Wear, 2001, 249(7), p 592-600.

104. L. Pawlowski, The Science and Engineering of Thermal Spray Coatings, 2nd ed. Wiley, Hoboken, 2008.

105. D. Tu, S. Chang, C. Chao and C. Lin, Tungsten Carbide Phase Transformation During the Plasma Spray Process, J. Vac. Sci. Technol. A Vac. Surf. Film, 1985, 3(6), p 2479-2482.

106. S. Al-Mutairi, M.S.J. Hashmi, B.S. Yilbas and J. Stokes, Microstructural Characterization of HVOF/Plasma Thermal Spray of Micro/Nano WC-12\%Co Powders, Surf. Coat.
Technol., 2015, 264, p 175-186. https://doi.org/10.1016/j.surf coat.2014.12.050

107. K. Niemi and G. Barbezat, Rolling Contact Fatigue Failure Mechanisms in Plasma and HVOF Sprayed WC-Co Coatings, Wear, 1997, 212, p 66-77.

108. S. Hazra, K. Sabiruddin, P.P. Bandyopadhyay, S. Hazra, K. Sabiruddin and P.P. Bandyopadhyay, Plasma and HVOF Sprayed WC-Co Coatings as Hard Chrome Replacement Solution Plasma and HVOF Sprayed WC-Co Coatings as Hard Chrome Replacement Solution, Surf. Eng., 2013, 28, p 37-43.

109. Z. Zhang, D. Zhang and Y. Xie, Experimental Study on Water Droplet Erosion Resistance of Coatings (Ni60 and WC-17Co) Sprayed by APS and HVOF, Wear, 2019, 432-433, p 202950. https://doi.org/10.1016/j.wear.2019.202950

110. V. Bolleddu, V. Racherla and P.P. Bandyopadhyay, Comparative Study of Air Plasma Sprayed and High Velocity Oxy-Fuel Sprayed Nanostructured WC-17wt\%Co Coatings, Int. J. Adv. Manuf. Technol., 2016, 84(5-8), p 1601-1613.

111. J.O. Berghaus, B. Marple and C. Moreau, Suspension Plasma Spraying of Nanostructured WC-12Co Coatings, Proc. Int. Therm. Spray Conf., 2006, 15, p 676-681.

112. R. Ahmed, N.H. Faisal, N.M. Al-Anazi, S. Al-Mutairi, F.-L. Toma, L.-M. Berger, A. Potthoff, E.K. Polychroniadis, M. Sall and D. Chaliampalias, Structure Property Relationship of Suspension Thermally Sprayed WC-Co Nanocomposite Coatings, $J$. Therm. spray Technol., 2015, 24(3), p 357-377.

113. R. Ahmed, O. Ali, N.H. Faisal, N.M. Al-anazi, S. Al-mutairi, F.L. Toma, L.M. Berger, A. Potthoff and M.F.A.A. Goosen, Sliding Wear Investigation of Suspension Sprayed WC-Co Nanocomposite Coatings, Wear, 2015, 322-323, p 133-150. https://doi.org/10.1016/j.wear.2014.10.021

114. O. Ali, R. Ahmed, N.H. Faisal, N.M. Alanazi, L.M. Berger, A. Kaiser, F.L. Toma, E.K. Polychroniadis, M. Sall, Y.O. Elakwah and M.F.A. Goosen, Influence of Post-Treatment on the Microstructural and Tribomechanical Properties of Suspension Thermally Sprayed WC-12 Wt \% Co Nanocomposite Coatings, Tribol. Lett., 2017, 65(2), p 1-27.

115. A. Siao, M. Ang, N. Sanpo, M.L. Sesso, S.Y. Kim and C.C. Berndt, Thermal Spray Maps: Material Genomics of Processing Technologies, J. Therm. Spray Technol., 2013, 22, p 1170-1183.

116. P. Nunthavarawong, N. Sacks and I. Botef, Effect of Powder Feed Rate on the Mechanical Properties of WC-5 Wt\% Ni Coatings Deposited Using Low Pressure Cold Spray, Int. J. Refract. Met. Hard Mater., 2016, 61, p 230-237. https://doi. org/10.1016/j.ijrmhm.2016.10.001

117. R.R. Chromik, S.A. Alidokht, J.M. Shockley, Y. Zhang, Tribological Coatings Prepared by Cold Spray, in Cold-Spray Coatings (2018), p 321-348

118. G.-J. Yang, P.-H. Gao, C.-X. Li and C.-J. Li, Mechanical Property and Wear Performance Dependence on Processing Condition for Cold-Sprayed WC-(NanoWC-Co), Appl. Surf. Sci., 2015, 332, p 80-88.

119. D. Lioma, N. Sacks and I. Botef, Cold Gas Dynamic Spraying of WC-Ni Cemented Carbide Coatings, Int. J. Refract. Met. Hard Mater., 2015, 49(1), p 365-373. https://doi.org/10.1016/j. ijrmhm.2014.08.017

120. S.A. Alidokht, S. Yue and R.R. Chromik, Effect of WC Morphology on Dry Sliding Wear Behavior of Cold-Sprayed Ni-WC Composite Coatings, Surf. Coat. Technol., 2019, 357, p 849863.

121. M. Li, D. Shi and P.D. Christofides, Modeling and Control of HVOF Thermal Spray Processing of WC-Co Coatings, Powder Technol., 2005, 156, p 177-194.

122. I. Baumann, L. Hagen, W. Tillmann, P. Hollingsworth, D. Stangier, G. Schmidtmann, M. Tolan, M. Paulus and C. Sternemann, Process Characteristics, Particle Behavior and 
Coating Properties during HVOF Spraying of Conventional, Fine and Nanostructured WC-12Co Powders, Surf. Coat. Technol., 2021, 405, p 126716. https://doi.org/10.1016/j.surfcoat. 2020.126716

123. H. Myalska, L. Lusvarghi, G. Bolelli, P. Sassatelli and G. Moskal, Tribological Behavior of WC-Co HVAF-Sprayed Composite Coatings Modified by Nano-Sized TiC Addition, Surf. Coat. Technol., 2019, 371, p 401-416. https://doi.org/10. 1016/j.surfcoat.2018.09.017

124. X.T. Luo, G.M. Smith, Y. Wang, E. Gildersleeve, S. Sampath and C.J. Li, Cracking Induced Tribological Behavior Changes for the HVOF WC-12Co Cermet Coatings, Ceram. Int., 2019, 45(4), p 4718-4728. https://doi.org/10.1016/j.ceramint.2018.11. 164

125. J.R. Davis, Handbook of Thermal Spray Technology, ASM International, Materials Park, 2004.

126. E. Sadeghi, N. Markocsan and S. Joshi, Advances in CorrosionResistant Thermal Spray Coatings for Renewable Energy Power Plants. Part I: Effect of Composition and Microstructure Deposit, J. Therm. Spray Technol., 2019 https://doi.org/10.1007/ s11666-019-00938-1

127. HVOF Systems for Thermal Spray (2020). https://www.oerli $\mathrm{kon} . \mathrm{com} / \mathrm{metco} / \mathrm{en} /$ products-services/coating-equipment/ther mal-spray/systems/hvof/

128. B.H. Kear, R.K. Sadangi, M. Jain, R. Yao, Z. Kalman, G. Skandan and W.E. Mayo, Thermal Sprayed Nanostructured WC/ Co Hardcoatings, J. Therm. Spray Technol., 2000, 9, p 399-406.

129. HVOF Guns for Thermal Spray (2020). https://www.oerlikon. $\mathrm{com} / \mathrm{metco} / \mathrm{en} /$ products-services/coating-equipment/thermalspray/spray-guns/spray-guns-hvof/

130. High-Velocity Oxy Fuel (HVOF) (2020). https://www.prax airsurfacetechnologies.com/en/components-materials-and-equip ment/coating-equipment/thermal-spray-coating-systems/highvelocity-oxygen-fuel-hvof

131. Jet Kote Systems (2020). https://www.stellite.com/us/en/pro ducts/stellite-equipment/hvof-jet-kote.html

132. Burners for HVOF Spraying (2020). http://thermico.de/DE/pro dukte/anlagentechnik/brennertechnik.html

133. L. Zhao, M. Maurer, F. Fischer, R. Dicks and E. Lugscheider, Influence of Spray Parameters on the Particle In-Flight Properties and the Properties of HVOF Coating of WC-CoCr, Wear, 2004, 257, p 41-46.

134. A. Siao, M. Ang, H. Howse, S.A. Wade and C.C. Berndt, Development of Processing Windows for HVOF Carbide-Based Coatings, J. Therm. Spray Technol., 2016, 25(1), p 28-35.

135. X. Ding, X.D. Cheng, J. Shi, C. Li, C.Q. Yuan and Z.X. Ding, Influence of WC Size and HVOF Process on Erosion Wear Performance of WC-10Co4Cr Coatings, Int. J. Adv. Manuf. Technol., 2018, 96(5-8), p 1615-1624.

136. Q. Wang, Z. Chen, L. Li and G. Yang, The Parameters Optimization and Abrasion Wear Mechanism of Liquid Fuel HVOF Sprayed Bimodal WC-12Co Coating, Surf. Coat. Technol., 2012, 206(8-9), p 2233-2241.

137. J.A. Picas, M. Punset, M.T. Baile, E. Martín and A. Forn, Effect of Oxygen/Fuel Ratio on the in-Flight Particle Parameters and Properties of HVOF WC-CoCr Coatings, Surf. Coat. Technol., 2011, 205(SUPPL. 2), p S364-S368. https://doi.org/10.1016/j. surfcoat.2011.03.129

138. T. Shamim, C. Xia and P. Mohanty, Modeling and Analysis of Combustion Assisted Thermal Spray Processes, Int. J. Therm. Sci., 2007, 46(8), p 755-767.

139. J.A. Picas, E. Rupérez, M. Punset and A. Forn, Influence of HVOF Spraying Parameters on the Corrosion Resistance of WC-CoCr Coatings in Strong Acidic Environment, Surf. Coat. Technol., 2013, 225, p 47-57. https://doi.org/10.1016/j.surfcoat. 2013.03.015
140. J.-G. Legoux, B. Arsenault, V. Bouyer, C. Moreau and L. Leblanc, Evaluation of Four High Velocity Thermal Spray Guns Using WC-10\% Co-4\% Cr Cermets, J. Therm. Spray Technol., 2002, 11(1), p 86-94.

141. B.R. Marple, J. Voyer, J.-F. Bisson and C. Moreau, Thermal Spraying of Nanostructured Cermet Coatings, J. Mater. Process. Technol., 2001, 117(3), p 418-423.

142. H.L. de Villiers Lovelock, P.W. Richter, J.M. Benson and P.M. Young, Parameter Study of HP/HVOF Deposited WC-Co Coatings, J. Therm. Spray Technol., 1998, 7(1), p 97-107.

143. M. Jie, L. Min, D. Ziqian, D. Changguang, D. Chunming and Z. Kesong, Influence of Spray Angle on Distribution of WC-Co-Cr Coating Produced by HVOF Spraying, Rare Met. Mater. Eng., 2017, 46(12), p 3583-3588.

144. W. Tillmann, I. Baumann, P. Hollingsworth and I.-A. Laemmerhirt, Influence of the Spray Angle on the Properties of HVOF Sprayed WC-Co Coatings Using $(-10+2 \mathrm{Mm})$ Fine Powders, J. Therm. Spray Technol., 2013, 22(2-3), p 272-279.

145. V. Katranidis, S. Gu, B. Allcock and S. Kamnis, Experimental Study of High Velocity Oxy-Fuel Sprayed WC-17Co Coatings Applied on Complex Geometries Part A: Influence of Kinematic Spray Parameters on Thickness, Porosity, Residual Stresses and Microhardness, Surf. Coat. Technol., 2017, 311, p 206-215.

146. Š Houdková, M. Kašparová and F. Zahálka, The Influence of Spraying Angle on Properties of HVOF Sprayed Hardmetal Coatings, J. Therm. Spray Technol., 2010, 19(5), p 893-901.

147. D. Fu, H. Xiong and Q. Wang, Microstructure Evolution and Its Effect on the Wear Performance of HVOF-Sprayed Conventional WC-Co Coating, J. Mater. Eng. Perform., 2016, 25(10), p 4352-4358.

148. B.H. Kear, G. Skandan and R.K. Sadangi, Factors Controlling Decarburization in HVOF Sprayed Nano-WC/Co Hardcoatings, Scr. Mater., 2001, 44(8-9), p 1703-1707.

149. Y. Ye, H. Xia, Y. Lin, F. Chen and Q. Shen, Refined WC Grain Size and Improved Mechanical Properties in a Hardmetal WC8 Co Processed via Short-Time Semi-Solid Hot Pressing, J. Alloys Compd., 2022, 889, p 161560.

150. S. Bouaricha, A. Ouchene and J. Legoux, Rietveld Analysis for Studying the Decarburisation in HVOF WC-CO Coatings, Surf. Eng., 2018, 34, p 747-754.

151. V. Katranidis, S. Gu, D.C. Cox, M.J. Whiting and S. Kamnis, FIB-SEM Sectioning Study of Decarburization Products in the Microstructure of HVOF-Sprayed WC-Co Coatings, J. Therm. Spray Technol., 2018, 27(5), p 898-908. https://doi.org/10.1007/ s11666-018-0721-3

152. Q. Wang, L. Li, G. Yang, X. Zhao and Z. Ding, Influence of Heat Treatment on the Microstructure and Performance of HighVelocity Oxy-Fuel Sprayed WC-12Co Coatings, Surf. Coat. Technol., 2012, 206(19-20), p 4000-4010. https://doi.org/10. 1016/j.surfcoat.2012.03.080

153. K. Korpiola, High Temperature Oxidation of Metal, Alloy and Cermet Powders in HVOF Spraying Process, Helsinki University of Technology, Espoo, 2004.

154. M. Jafari, J. Han, J. Seol and C. Park, Surface and Coatings Technology Tribological Properties of HVOF-Sprayed WC-Co Coatings Deposited from Ni-Plated Powders at Elevated Temperature, Surf. Coat. Technol., 2017, 327, p 48-58. https://doi. org/10.1016/j.surfcoat.2017.08.026

155. R. Sedl, B. Belkessa and M. Fides, Investigation of WC Decarburization Effect on the Microstructure and Wear Behavior of WC-Ni Hardfacing under Dry and Alkaline Wet Conditions s Csan A, Mater. Chem. Phys., 2018, 1, p 237-247.

156. Q. Wang, S. Zhang, Y. Cheng, J. Xiang, X. Zhao and G. Yang, Wear and Corrosion Performance of WC-10Co4Cr Coatings Deposited by Different HVOF and HVAF Spraying Processes, 
Surf. Coat. Technol., 2013, 218(1), p 127-136. https://doi.org/10. 1016/j.surfcoat.2012.12.041

157. L. Jacobs, M.M. Hyland, M. De Bonte and M. De Bonte, Comparative Study of WC-Cermet Coatings Sprayed via the HVOF and the HVAF Process, J. Therm. Spray Technol., 1998, 7(2), p 213-218.

158. D.E. Wolfe, T.J. Eden, J.K. Potter and A.P. Jaroh, Investigation and Characterization of Cr3 C2-Based Wear-Resistant Coatings Applied by the Cold Spray Process, J. Therm. Spray Technol., 2006, 15(3), p 400-412.

159. C.-J. Li, G.-C. Ji, Y.-Y. Wang and K. Sonoya, Dominant Effect of Carbide Rebounding on the Carbon Loss during High Velocity Oxy-Fuel Spraying of $\mathrm{Cr} 3 \mathrm{C} 2-\mathrm{NiCr}$, Thin Solid Films, 2002, 419(1-2), p 137-143.

160. A. Agüero, F. Camón, J.G. De Blas, J.C. Del Hoyo, R. Muelas, A. Santaballa, S. Ulargui and P. Vallés, HVOF-Deposited WCCoCr as Replacement for Hard $\mathrm{Cr}$ in Landing Gear Actuators, J. Therm. Spray Technol., 2011, 20(6), p 1292-1309.

161. D.A. Stewart, P.H. Shipway and D.G. McCartney, Abrasive Wear Behaviour of Conventional and Nanocomposite HVOFSprayed WC-Co Coatings, Wear, 1999, 225-229(II), p 789-798.

162. R.R. White, Tuneable High Velocity Thermal Spray Gun, Google Patents (1995)

163. J.A. Browning, Thermal Spray Method Utilizing In-Transit Powder Particle Temperatures Below Their Melting Point, Google Patents, Patent No. 5, 271, 965 (1993)

164. A New Research and Innovation Infrastructure of Forschungszentrum Jülich (2020). https://www.fz-juelich.de/ iek/iek-1/DE/Forschung/JuelichThermalSprayCenter/JTSC_ FZJ.html

165. A. Verstak, V. Baranovski, AC-HVAF Sprayed Tungsten Carbide: Properties and Applications. Thermal Spray 2006: Building on 100 Years of Success, Citeseer (2006), p 15-18

166. O. Lanz, B. Gries, HVAF: Chance and Challenge for Users and for Powder Producers, in Proceedings of the International Thermal Spray Conference (2019) p 15-22

167. L. Jacobs, M.M. Hyland, M. De Bonte and M. De Bonte, Study of the Influence of Microstructural Properties on the SlidingWear Behavior of HVOF and HVAF Sprayed WC-Cermet Coatings, J. Therm. Spray Technol., 1999, 8(1), p 125-132.

168. C. Lyphout, K. Sato, S. Houdkova, E. Smazalova, L. Lusvarghi, G. Bolelli and P. Sassatelli, Tribological Properties of Hard Metal Coatings Sprayed by High-Velocity Air Fuel Process, $J$. Therm. Spray Technol., 2016, 25(1), p 331-345.

169. K. Torkashvand, M. Gupta, S. Björklund, F. Marra, L. Baiamonte and S. Joshi, Influence of Nozzle Configuration and Particle Size on Characteristics and Sliding Wear Behaviour of HVAF-Sprayed WC-CoCr Coatings, Surf. Coat. Technol., 2021, 423, p 127585.

170. Kermetico HVAF and HVOF Thermal Spray Coating Equipment and Technology (2020). https://kermetico.com/

171. HVAF - High Velocity Air Fuel Technology (2020). http:// www.uniquecoat.com/index.html

172. V. Matikainen, H. Koivuluoto, P. Vuoristo, J. Schubert and S. Houdková, Effect of Nozzle Geometry on the Microstructure and Properties of HVAF-Sprayed WC-10Co4Cr and $\mathrm{Cr} 3 \mathrm{C} 2-$ 25NiCr Coatings, J. Therm. Spray Technol., 2018, 27(4), p 680694.

173. E. Sadeghi and S. Joshi, Chlorine-Induced High-Temperature Corrosion and Erosion-Corrosion of HVAF and HVOF-Sprayed Amorphous Fe-Based Coatings, Surf. Coat. Technol., 2019, 371, p 20-35.

174. C. Lyphout, S. Björklund, M. Karlsson, M. Runte, G. Reisel and P. Boccaccio, Screening Design of Supersonic Air Fuel Processing for Hard Metal Coatings, J. Therm. Spray Technol., 2014, 23(8), p 1323-1332.
175. B. Tian, C. Li, F. Gu, H. Jiang, Y. Hu and J. Zhang, Selected Abstracts of Thermal Spray Literature, Biomaterials, 2009, 267(5-8), p 818-822.

176. H. Myalska, G. Moskal and K. Szymański, Microstructure and Properties of WC-Co Coatings, Modified by Sub-Microcrystalline Carbides, Obtained by Different Methods of High Velocity Spray Processes, Surf. Coat. Technol., 2014, 260, p 303-309.

177. Q. Wang, S. Luo, S. Wang, H. Wang and C.S. Ramachandran, Wear, Erosion and Corrosion Resistance of HVOF-Sprayed WC and $\mathrm{Cr} 3 \mathrm{C} 2$ Based Coatings for Electrolytic Hard Chrome Replacement, Int. J. Refract. Met. Hard Mater., 2019, 81, p 242252.

178. W. Tillmann, C. Schaak, L. Hagen, M. Dildrop, Investigation of HVOF-ID Spraying with WC-CoCr-15+ 5 Mm Feedstock Powder, in IOP Conference Series: Materials Science and Engineering (IOP Publishing, 2019), p 12008

179. L.M. Berger, R. Trache, F.L. Toma, S. Thiele, J. Norpoth and L. Janka, Development of Cost-Effective Hardmetal Coating Solutions for High-Temperature Applications, Part One: Feedstock Powders, Cost-Effectiveness and Coating Properties, Spray Bull, 2015, 8(2), p 126-135.

180. V. Matikainen, S.R. Peregrina, N. Ojala, H. Koivuluoto, J. Schubert, Š Houdková and P. Vuoristo, Erosion Wear Performance of $\mathrm{WC}-10 \mathrm{Co} 4 \mathrm{Cr}$ and $\mathrm{Cr} 3 \mathrm{C} 2-25 \mathrm{NiCr}$ Coatings Sprayed with High-Velocity Thermal Spray Processes, Surf. Coat. Technol., 2019, 370, p 196-212. https://doi.org/10.1016/j.surf coat.2019.04.067

181. C. Lyphout, Tungsten Carbide Deposition Processes for Hard Chrome Alternative: Preliminary Study of HVAF vs. HVOF Thermal Spray Processes (2013), p 506-511

182. V. Matikainen, G. Bolelli, H. Koivuluoto, M. Honkanen, M. Vippola, L. Lusvarghi and P. Vuoristo, A Study of Cr3 C2Based HVOF-and HVAF-Sprayed Coatings: Microstructure and Carbide Retention, J. Therm. Spray Technol., 2017, 26(6), p $1239-1256$.

183. Ç. Tekmen, H. Çetinel, A. Türk and E. Çelik, Wear Behaviour of Plasma Sprayed WC-Ni Coatings, Key Eng. Mater., 2004, 264-268(I), p 589-592.

184. Y.Y. Santana, J.G. La Barbera-Sosa, J. Caro, E.S. Puchi-Cabrera and M.H. Staia, Mechanical Properties and Microstructure of WC-10Co-4Cr and WC-12Co Thermal Spray Coatings Deposited by HVOF, Surf. Eng., 2008, 24(5), p 374-382.

185. A. Ghabchi, T. Varis, E. Turunen, T. Suhonen, X. Liu and S.P. Hannula, Behavior of HVOF WC-10Co4Cr Coatings with Different Carbide Size in Fine and Coarse Particle Abrasion, $J$. Therm. Spray Technol., 2010, 19(1-2), p 368-377.

186. F. Tarasi, M.S. Mahdipoor, A. Dolatabadi, M. Medraj and C. Moreau, HVOF and HVAF Coatings of Agglomerated Tungsten Carbide-Cobalt Powders for Water Droplet Erosion Application, J. Therm. Spray Technol., 2016, 25(8), p 1711-1723.

187. A. Salman, M. Ghadiri, M. Hounslow, Handbook of Powder Technology, Particle Breakage, III. Modelling (Elsevier BV, 2007)

188. C.J. Li, A. Ohmori and Y. Harada, Effect of Powder Structure on the Structure of Thermally Sprayed WC-Co Coatings, J. Mater. Sci., 1996, 31(3), p 785-794.

189. H.L. De Villiers Lovelock, J. Kinds and P.M. Young, Characterisation of WC-12Co Thermal Spray Powders and HPHVOF Wear Resistant Coatings, Powder Metall., 1998, 41(4), p 292299.

190. J. García, V. Collado Ciprés, A. Blomqvist and B. Kaplan, Cemented Carbide Microstructures: A Review, Int. J. Refract. Met. Hard Mater., 2019, 80, p 40-68.

191. R. Schwetzke and H. Kreye, Microstructure and Properties of Tungsten Carbide Coatings Sprayed with Various High-Velocity 
Oxygen Fuel Spray Systems, J. Therm. Spray Technol., 1999, 8(3), p 433-439.

192. M. Couto, S. Dosta and J.M. Guilemany, Comparison of the Mechanical and Electrochemical Properties of WC-17 and 12Co Coatings onto Al7075-T6 Obtained by High Velocity Oxy-Fuel and Cold Gas Spraying, Surf. Coat. Technol., 2015, 268, p 180189.

193. C.-J.J. Li, Y.-Y.Y. Wang, G.-J.J. Yang, A. Ohmori and K.A. Khor, Effect of Solid Carbide Particle Size on Deposition Behaviour, Microstructure and Wear Performance of HVOF Cermet Coatings, Mater. Sci. Technol., 2004, 20(9), p 10871096.

194. G.-C. Ji, X. Chen, H.-T. Wang, X.-B. Bai and Z.-X. Dong, Deformation Behaviors of Cold-Sprayed WC-Co Particles, $J$. Therm. Spray Technol., 2015, 24(6), p 1100-1110.

195. P.-H. Gao, Y.-G. Li, C.-J. Li, G.-J. Yang and C.-X. Li, Influence of Powder Porous Structure on the Deposition Behavior of ColdSprayed WC-12Co Coatings, J. Therm. Spray Technol., 2008, 17(5), p 742-749.

196. X. Luo, R. Chidambaram-Seshadri, G.-J. Yang, Micro-Nanostructured Cermet Coatings, in Advanced Nanomaterials and Coatings by Thermal Spray (Elsevier Inc., 2019). https://doi.org/ 10.1016/b978-0-12-813870-0.00004-8

197. H. Wang, C. Hou, X. Liu, X. Liu and X. Song, Wear Resistance Mechanisms of Near-Nanostructured WC-Co Coatings, Int. J. Refract. Met., 2018, 71, p 122-128.

198. J. Pulsford, S. Kamnis, J. Murray, M. Bai and T. Hussain, Effect of Particle and Carbide Grain Sizes on a HVOAF WC-Co-Cr Coating for the Future Application on Internal Surfaces: Microstructure and Wear, J. Therm. Spray Technol., 2018, 27(12), p 207-219. https://doi.org/10.1007/s11666-017-0669-8

199. K. Jia and T.E. Fischer, Abrasion Resistance of Nanostructured and Conventional Cemented Carbides, Wear, 1996, 200(1-2), p 206-214.

200. L.E. McCandlish, B.H. Kear and B.K. Kim, Processing and Properties of Nanostructured WC-Co, Nanostructured Mater., 1992, 1(2), p 119-124.

201. N. Ma, L. Guo, Z. Cheng, H. Wu, F. Ye and K. Zhang, Improvement on Mechanical Properties and Wear Resistance of HVOF Sprayed WC-12Co Coatings by Optimizing Feedstock Structure, Appl. Surf. Sci., 2014, 320, p 364-371. https://doi.org/ 10.1016/j.apsusc.2014.09.081

202. G.J. Yang, P.H. Gao, C.X. Li and C.J. Li, Simultaneous Strengthening and Toughening Effects in WC-(NanoWC-Co), Scr. Mater., 2012, 66(10), p 777-780.

203. Y. Qiao, T.E. Fischer and A. Dent, The Effects of Fuel Chemistry and Feedstock Powder Structure on the Mechanical and Tribological Properties of HVOF Thermal-Sprayed WC-Co Coatings with Very Fine Structures, Surf. Coat. Technol., 2003, 172(1), p 24-41.

204. A.H. Dent, S. DePalo and S. Sampath, Examination of the Wear Properties of HVOF Sprayed Nanostructured and Conventional WC-Co Cermets with Different Binder Phase Contents, J. Therm. Spray Technol., 2002, 11(4), p 551-558.

205. P.H. Shipway, D.G. McCartney and T. Sudaprasert, Sliding Wear Behaviour of Conventional and Nanostructured HVOF Sprayed WC-Co Coatings, Wear, 2005, 259(7-12), p 820-827.

206. M. Kouzeli and A. Mortensen, Binder Extrusion in Sliding Wear of WC-Co Alloys, Acta Mater., 2002, 50(1), p 39-51.

207. J. Larsen-basse, Binder Extrusion in Sliding Wear of WC-Co Alloys, Wear, 1985, 105, p 247-256.

208. Q. Yang, T. Senda and A. Ohmori, Effect of Carbide Grain Size on Microstructure and Sliding Wear Behavior of HVOFSprayed WC-12\% Co Coatings, Wear, 2003, 254(1-2), p 23-34.
209. S. Rangaswamy and H. Herman, Metallurgical Characterization of Plasma Sprayed WC-Co Coatings, International Thermal Spraying Conference, 1986, 11, p 101-110.

210. H.-C. Lee and J. Gurland, Hardness and Deformation of Cemented Tungsten Carbide, Mater. Sci. Eng., 1978, 33(1), p 125-133.

211. ASTM International, Standard Test Method for Wear Testing with a Pin-on-Disk Apparatus G99-17, Апnи. B ASTM Stand., 2016, 2017(05), p 1-6.

212. ASTM International, G65-16: Standard Test Method for Measuring Abrasion Using the Dry Sand/Rubber Wheel, ASTM Stand., 2013, 04, p 1-12.

213. International ASTM Standard, Standard Test Method for Abrasive Wear Resistance of Cemented Carbides B611, ASTM Int., 2000, 85, p 1-2.

214. ASTM, G76-07, Standard Test Method for Conducting Erosion Tests by Solid Particle Impingement Using Gas Jets. ASTM Int. 1, 1-6 (2013)

215. ASTM G73, Standard Test Method for Liquid Impingement Erosion Using Rotating Apparatus 1. ASTM i(Reapproved), 1-19 (2012)

216. Y. Qiao, Y. Liu and T.E. Fischer, Sliding and Abrasive Wear Resistance of Thermal-Sprayed WC-Co Coatings, J. Therm. Spray Technol., 2001, 10(1), p 118-125.

217. J.A. Picas, M. Punset, M. Teresa Baile, E. Martín and A. Forn, Tribological Evaluation of HVOF Thermal-Spray Coatings as a Hard Chrome Replacement, Surf. Interface Anal., 2011, 43(10), p 1346-1353.

218. A. Milanti, V. Matikainen, G. Bolelli, H. Koivuluoto, L. Lusvarghi and P. Vuoristo, Microstructure and Sliding Wear Behavior of Fe-Based Coatings Manufactured with HVOF and HVAF Thermal Spray Processes, J. Therm. Spray Technol., 2016, 25(5), p 1040-1055.

219. I. Hulka, V.A. Şerban, K. Niemi, P. Vuoristo and J. Wolf, Comparison of Structure and Wear Properties of Fine-Structured WC-CoCr Coatings Deposited by HVOF and HVAF Spraying Processes, Solid State Phenom., 2012, 188, p 422-427.

220. V. Matikainen, S. Rubio Peregrina, N. Ojala, H. Koivuluoto, J. Schubert, S. Houdková and P. Vuoristo, Slurry and Dry Particle Erosion Wear Properties of WC-10Co4Cr and $\mathrm{Cr} 3 \mathrm{C} 2-25 \mathrm{NiCr}$ Hardmetal Coatings Deposited by HVOF and HVAF Spray Processes, Tribologia, 2019, 36(1-2), p 58-61.

221. Q. Wang, Z. Tang and L. Cha, Cavitation and Sand Slurry Erosion Resistances of WC-10Co-4Cr Coatings, J. Mater. Eng. Perform., 2015, 24(6), p 2435-2443. https://doi.org/10.1007/ s11665-015-1496-Z

222. I. Hulka, V.A. Şerban, I. Secoşan, P. Vuoristo and K. Niemi, Wear Properties of CrC-37WC-18M Coatings Deposited by HVOF and HVAF Spraying Processes, Surf. Coat. Technol., 2012, 210, p 15-20.

223. L. Thakur and N. Arora, A Comparative Study on Slurry and Dry Erosion Behaviour of HVOF Sprayed WC-CoCr Coatings, Wear, 2013, 303(1-2), p 405-411. https://doi.org/10.1016/j. wear.2013.03.028

224. A. Hamilton, A. Sharma and U. Pandel, Solid Particle Erosion Resistance of Hvaf-Sprayed Wc-10Co-4Cr Coating On Ca6Nm Steel, Surf. Rev. Lett., 2017, 24(2), p 1850011.

225. T. Peat, A. Galloway, A. Toumpis, D. Harvey and W.H. Yang, Performance Evaluation of HVOF Deposited Cermet Coatings Under Dry and Slurry Erosion, Surf. Coat. Technol., 2016, 300, p 118-127. https://doi.org/10.1016/j.surfcoat.2016.05.039

226. A.S. Praveen, J. Sarangan, S. Suresh and B.H. Channabasappa, Optimization and Erosion Wear Response of NiCrSiB/WC-Co HVOF Coating Using Taguchi Method, Ceram. Int., 2016, 42(1), p 1094-1104. https://doi.org/10.1016/j.ceramint.2015.09. 036 
227. Y. Liu, W. Liu, Y. Ma, S. Meng, C. Liu, L. Long and S. Tang, A Comparative Study on Wear and Corrosion Behaviour of HVOF- and HVAF-Sprayed WC-10Co-4Cr Coatings, Surf. Eng., 2017, 33(1), p 63-71.

228. L.-M. Berger, M. Woydt and S. Saaro, Comparison of SelfMated Hardmetal Coatings Under Dry Sliding Conditions up to 600 C, Wear, 2009, 266(3-4), p 406-416.

229. G. Bolelli, I. Hulka, H. Koivuluoto, L. Lusvarghi, A. Milanti, K. Niemi and P. Vuoristo, Properties of WC-FeCrAl Coatings Manufactured by Different High Velocity Thermal Spray Processes, Surf. Coat. Technol., 2014, 247, p 74-89. https://doi.org/ 10.1016/j.surfcoat.2014.03.021

230. N.P. Suh, The Delamination Theory of Wear, Wear, 1973, 25, p 111-124.

231. M.J. Furey, Tribology-Encyclopedia of Materials Science and Engineering, M.B. Bever. MIT Press, Cambridge, 1985.

232. E. Rabinowicz, Friction and Wear of Materials, 2nd ed. Wiley, Hoboken, 2013.

233. K.G. Budinski, Friction, Wear, and Erosion Atlas, CRC Press, Boca Raton, 2013.

234. V. Rajinikanth and K. Venkateswarlu, An Investigation of Sliding Wear Behaviour of WCCo Coating, Tribol. Int., 2011, 44(12), p 1711-1719. https://doi.org/10.1016/j.triboint.2011.06. 021

235. P. Suresh Babu, B. Basu and G. Sundararajan, Abrasive Wear Behavior of Detonation Sprayed WC-12Co Coatings: Influence of Decarburization and Abrasive Characteristics, Wear, 2010, 268(11-12), p 1387-1399. https://doi.org/10.1016/j.wear.2010. 02.013

236. H. Wang, X. Wang, X. Song, X. Liu and X. Liu, Sliding Wear Behavior of Nanostructured WC-Co-Cr Coatings, Appl. Surf. Sci., 2015, 355, p 453-460. https://doi.org/10.1016/j.apsusc. 2015.07.144

237. J.A.R. Wesmann and N. Espallargas, Effect of Atmosphere, Temperature and Carbide Size on the Sliding Friction of SelfMated HVOF WC-CoCr Contacts, Tribol. Int., 2016, 101, p 301-313. https://doi.org/10.1016/j.triboint.2016.04.032

238. N. Amousoltani, H. Salimijazi and M. Golozar, Study of Alumina Sealing of HVOF Thermally Sprayed WC-Co Coatings by Sol-Gel Method, Mater. Res. Express, 2019, 7(1), p 016410.

239. B. Xu, Z. Zhu, S. Ma, W. Zhang and W. Liu, Sliding Wear Behavior of $\mathrm{Fe}-\mathrm{Al}$ and $\mathrm{Fe}-\mathrm{Al} / \mathrm{WC}$ Coatings Prepared by High Velocity Arc Spraying, Wear, 2004, 257(11), p 1089-1095.

240. K. Torkashvand, V.K. Selpol, M. Gupta and S. Joshi, Influence of Test Conditions on Sliding Wear Performance of High Velocity Air Fuel-Sprayed WC-CoCr Coatings, Materials (Basel), 2021, 14(11), p 3074.

241. A.K. Maiti, N. Mukhopadhyay and R. Raman, Improving the Wear Behavior of WC-CoCr-Based HVOF Coating by Surface Grinding, J. Mater. Eng. Perform., 2009, 18(8), p 1060-1066.

242. D. Kekes, P. Psyllaki and M. Vardavoulias, Wear MicroMechanisms of Composite WC-Co/Cr-NiCrFeBSiC Coatings. Part I: Dry Sliding, Tribol. Ind., 2014, 36(4), p 361.

243. V. Stoica, R. Ahmed and T. Itsukaichi, Influence of HeatTreatment on the Sliding Wear of Thermal Spray Cermet Coatings, Surf. Coat. Technol., 2005, 199(1), p 7-21.

244. T.B. Torgerson, M.D. Harris, S.A. Alidokht, T.W. Scharf, S.M. Aouadi, R.R. Chromik, J.S. Zabinski and A.A. Voevodin, Room and Elevated Temperature Sliding Wear Behavior of Cold Sprayed Ni-WC Composite Coatings, Surf. Coat. Technol., 2018, 350, p 136-145.

245. ASTM Standard B611, B611, Standard Test Method for Determining the High Stress Abrasion Resistance of Hard Materials, vol. 13 (2013), p 1-6. https://doi.org/10.1520/B0611

246. M.R. Thakare, J.A. Wharton, R.J.K. Wood and C. Menger, Effect of Abrasive Particle Size and the Influence of
Microstructure on the Wear Mechanisms in Wear-Resistant Materials, Wear, 2012, 276-277, p 16-28. https://doi.org/10. 1016/j.wear.2011.11.008

247. M.G. Gee, A. Gant, W.P. Byrne, B. Roebuck, Abrasion and Reciprocating Wear of Hardmetals and Ceramics (1999)

248. N. Vashishtha, R.K. Khatirkar and S.G. Sapate, Tribological Behaviour of HVOF Sprayed WC-12Co, WC-10Co-4Cr and Cr3C2-25NiCr Coatings, Tribol. Int., 2017, 105, p 55-68.

249. P.H. Shipway and L. Howell, Microscale Abrasion-Corrosion Behaviour of WC-Co Hardmetals and HVOF Sprayed Coatings, Wear, 2005, 258, p 303-312.

250. M.R. Thakare, J.A. Wharton, R.J. Wood and C. Menger, Investigation of Micro-Scale Abrasion-Corrosion of WC-Based Sintered Hardmetal and Sprayed Coating Using in Situ Electrochemical Current-Noise Measurements, Wear, 2009, 267, p 1967-1977.

251. M.G. Gee, A. Gant and B. Roebuck, Wear Mechanisms in Abrasion and Erosion of WC/Co and Related Hardmetals, Wear, 2007, 263, p 137-148.

252. A. Ghabchi, S. Sampath, K. Holmberg and T. Varis, Damage Mechanisms and Cracking Behavior of Thermal Sprayed WCCoCr Coating under Scratch Testing, Wear, 2014, 313(1-2), p 97-105. https://doi.org/10.1016/j.wear.2014.02.017

253. A.A.A. Younis, Microstructure, Mechanical Properties and Sliding Wear Behaviour of Thermally Sprayed Cermet Coatings, University of Nottingham, Nottingham, 2016.

254. M. Road, I.M. Hutchings, R.E. Winter and J.E. Field, Solid Particle Erosion of Metals: The Removal of Surface Material by Spherical Projectiles, Proc. R. Soc. Lond. A Math. Phys. Sci., 1976, 348(1654), p 379-392.

255. A. Surzhenkov, M. Viljus, T. Simson, R. Tarbe, M. Saarna and F. Casesnoves, Wear Resistance and Mechanisms of Composite Hardfacings at Abrasive Impact Erosion Wear, J. Phys. Conf. Ser., 2017, 843(1), p 012060.

256. M. Pasha and M. Kaleemulla, Erosive Wear Behavior of Sprayed Metal Matrix Composites: An Overview, Proc. Inst. Mech. Eng. Part J J. Eng. Tribol., 2013, 227(10), p 1063-1075.

257. L. Thakur and N. Arora, An Investigation on the Development and Wear Performance of Chromium-MWCNTs Transformed HVOF Sprayed Nano-WC-CoCr Coatings, Surf. Coat. Technol., 2020, 388, p 125610.

258. M.R. Ramesh, S. Prakash, S.K. Nath, P.K. Sapra and B. Venkataraman, Solid Particle Erosion of HVOF Sprayed WC$\mathrm{Co} / \mathrm{NiCrFeSiB}$ Coatings, Wear, 2010, 269(3-4), p 197-205. https://doi.org/10.1016/j.wear.2010.03.019

259. P. Kulu, I. Hussainova and R. Veinthal, Solid Particle Erosion of Thermal Sprayed Coatings, Wear, 2005, 258, p 488-496.

260. L. Thakur, N. Arora, R. Jayaganthan and R. Sood, An Investigation on Erosion Behavior of HVOF Sprayed WC-CoCr Coatings, Appl. Surf. Sci., 2011, 258(3), p 1225-1234.

261. Y. Li, Y. Lian, J. Cao and L. Li, Solid Particle Erosion Behavior of HVOF/HVAF Sprayed WC-Co-Cr Coatings, Proc. Inst. Mech. Eng. Part J J. Eng. Tribol., 2016, 230(6), p 634-643.

262. D.W. Wheeler and R.J.K. Wood, Erosion of Hard Surface Coatings for Use in Offshore Gate Valves, Wear, 2005, 258, p 526-536.

263. A. Kumar, A. Sharma and S.K. Goel, Erosion Behaviour of WC-10Co-4Cr Coating on 23-8-N Nitronic Steel by HVOF Thermal Spraying, Appl. Surf. Sci., 2016, 370, p 418-426. https://doi.org/10.1016/j.apsusc.2016.02.163

264. R.K. Kumar, M. Kamaraj, S. Seetharamu, T. Pramod and P. Sampathkumaran, Effect of Spray Particle Velocity on Cavitation Erosion Resistance Characteristics of HVOF and HVAF Processed 86WC-10Co4Cr Hydro Turbine Coatings, J. Therm. Spray Technol., 2016, 25(6), p 1217-1230. 
265. W. Tillmann, D. Stangier, L. Hagen, P. Schröder and M. Krabiell, Influence of the WC Grain Size on the Properties of PVD/ HVOF Duplex Coatings, Surf. Coat. Technol. Coat. Technol., 2017, 328, p 326-334.

266. J. Heinrichs, S. Norgren, S. Jacobson, K. Yvell and M. Olsson, Influence of Binder Metal on Wear Initiation of Cemented
Carbides in Sliding Contact with Granite, Wear, 2021, 470-471, p 203645. https://doi.org/10.1016/j.wear.2021.203645

Publisher's Note Springer Nature remains neutral with regard to jurisdictional claims in published maps and institutional affiliations. 